\title{
ESTUDIO CLÍNICO DE LA ENFERMEDAD RENAL CRÓNICA EN EL PACIENTE ANCIANO.
}

UNIVERSIDAD DE SALAMANCA.

Facultad de Medicina. Departamento de Medicina.

Tesis doctoral presentada por Manuel Heras Benito.

Salamanca 2012. 
Departamento de Medicina

El que suscribe, Dr. Pedro García Cosmes, profesor asociado del Departamento de Medicina-Nefrología, de la Universidad de Salamanca certifica:

Que el presente trabajo para optar al título de Doctor, ha sido elaborado por D. Manuel Heras Benito, cuyo título es "Estudio Clínico de la Enfermedad Renal Crónica en el Paciente Anciano", y ha sido realizado bajo su dirección y supervisión, y reúne todos los requisitos para su evaluación.

Salamanca a 9 de febrero de 2011.

Fdo. Dr. Pedro García Cosmes. 
DEDICATORIA.

A mis padres por todo lo que me han dado. 


\section{AGRADECIMIENTOS.}

- Al Dr. Pedro García Cosmes, tutor durante mi formación como residente de Nefrología en el Hospital Universitario de Salamanca y director de esta tesis, por asumir este proyecto, su interés, dedicación, consejos, su espíritu crítico y perfeccionista.

- Al D. Fernando Alvarez-Ude, por haber confiado en mí para trabajar en su equipo de Nefrología del Hospital General de Segovia, donde he podido elaborar el presente trabajo.

- A todos los miembros del Servicio de Nefrología del Hospital General de Segovia, por su apoyo, consejos y motivación para seguir adelante.

- Al Servicio de Geriatría del Hospital General de Segovia por su colaboración en la inclusión de personas ancianas de sus consultas.

- A Da María Antonia Pérez González (Secretaria de Nefrología del Hospital General de Segovia) por su ayuda en el seguimiento tan minucioso de los pacientes.

- A todos los miembros del Servicio de Nefrología del Hospital Universitario de Salamanca que contribuyeron a mi formación como nefrólogo durante los anos 1998-2002. 
1. INTRODUCCIÓN. 1.

1.1 Cambios funcionales y estructurales en el riñón del anciano. 4.

1.1.a. Cambios funcionales. 4.

1.1.b. Cambios estructurales. 5.

1.2. Estimación del filtrado glomerular. 6.

1.3. Utilidad clínica de la estimación del filtrado glomerular. 8.

1.4. Prevalencia de la enfermedad renal crónica en el anciano. 9.

1.5. Comorbilidad asociada a la enfermedad renal crónica. 11.

1.6. Enfermedades renales específicas en el anciano. 11.

1.7. Manifestaciones analíticas asociadas a la ERC. 13.

1.7.a. Anemia. 13.

1.7.b. Acidosis metabólica. 14.

1.7.c. Alteraciones del metabolismo óseo-mineral. 15.

1.8. ¿Cómo progresa la ERC en el anciano? 16.

1.9. Implicaciones de la ERC en el anciano. 17.

2. HIPÓTESIS Y OBJETIVOS. 21.

2.1. Hipótesis. 22.

2.2. Objetivos. 23.

2.2.a. Objetivos principales. 23.

2.2.b. Objetivos secundarios. 24. 
3.2.a. FG basal y comorbilidad de los pacientes.

28.

3.2.b. Manifestaciones analíticas asociadas a la enfermedad renal crónica. 28.

3.2.c. Repercusión de los agentes antihipertensivos sobre la función renal. 28.

3.2.d. Control de la presión arterial en el seguimiento a tres y cinco años. 29

3.2.e. Concordancia entre el aclaramiento de creatinina y las fórmulas derivadas de la creatinina sérica

29.

3.3. Análisis estadístico.

30.

\section{RESULTADOS}

31.

\subsection{Resultados del estudio transversal.}

33.

4.1.a. Niveles basales de FGe

33.

4.1.b. Correlaciones basales de la Crs y las fórmulas con otros parámetros de enfermedad renal crónica.

4.1.c. Estudio de la proteinuria basal. 36.

4.1.d. Filtrado glomerular basal y su asociación con la comorbilidad.

36.

4.1.e. Manifestaciones analíticas asociadas a la enfermedad renal crónica. 38.

- Manifestaciones analíticas en pacientes con enfermedad renal oculta.

4.1.f. Análisis de los niveles de ácido úrico en el total de la población estudiada en el periodo basal. 
4.2.b. Resultados del seguimiento a dos años. 46.

4.2.b.1. Datos de función renal a los dos años. 46.

4.2.b.2. Datos de proteinuria a los dos años. 47 .

4.2.b.3. Evolución de parámetros analíticos asociados a la ERC. 48.

4.2.b.4. Análisis de los cambios en el tratamiento establecidos

a los dos años.

49.

4.2.b.5. Morbimortalidad a dos años. 50.

4.2.c. Resultados del seguimiento a tres años. 50.

4.2.c.1. Datos de función renal a tres años. 50.

4.2.c.2. Resultados de la proteinuria a los tres años. 52.

4.2.c.3. Parámetros analíticos asociados a la ERC. 53.

4.2.c.4. Análisis de los cambios en el tratamiento establecidos

a los tres años.

54.

4.2.c.5. Morbimortalidad a tres años. 55.

4.2.d. Resultados del seguimiento a cinco años. 56.

4.2.d.1. Datos de función renal a cinco años. 56.

4.2.d.2. Resultados de la proteinuria a los cinco años. 57.

4.2.d.3. Evolución de parámetros analíticos asociados a la ERC. 57.

4.2.d.4. Análisis de los cambios en el tratamiento establecidos

a los cinco años. 58.

4.2.d.5. Morbimortalidad a los cinco años. 59.

4.2.e. Hipertensión arterial. 59.

4.2.e.1.Repercusión de los agentes antihipertensivos sobre la función renal. 59.

4.2.e.2.Grado de control de la presión arterial en la población a

los tres y cinco años.

61. 


\section{2.f. Análisis global de eventos cardiovasculares}

en los cinco años de seguimiento.

4.2.g. Análisis global de la mortalidad durante los cinco años.

63.

4.3.Concordancia entre el aclaramiento de creatinina y

las fórmulas matemáticas derivadas de la creatinina

en el diagnóstico de daño renal.

65.

\section{DISCUSIÓN}

68.

5.1. Niveles de FGe en el periodo basal.

70.

5.2. Niveles basales de FGe según el género.

71.

5.3. Aportación de la nueva ecuación CKD-EPI en la estimación del filtrado glomerular en el anciano.

72.

5.4. Niveles basales de FG y su asociación con comorbilidad.

73.

5.5. Manifestaciones analíticas asociadas a la ERC:

¿a partir de qué grado de FG se detectan?

5.6. Evolución de la función renal en el tiempo.

78.

5.7. Valor pronóstico de la proteinuria en la evolución de la función renal y en la mortalidad en los ancianos.

80.

5.8. Pronóstico asociado a la enfermedad renal crónica: Desarrollo de nefropatía terminal y mortalidad.

5.9. Análisis de eventos cardiovasculares de novo

en el periodo de seguimiento.

5.10. ¿Se deben aplicar de forma sistemática las fórmulas

de estimación del filtrado glomerular en los ancianos?.

85.

5.11. ¿ Se debe extender la clasificación KDOQI de ERC

a toda la población?.

86.

5.12. El manejo de la enfermedad renal crónica en el anciano.

87. 
5.13.Repercusión de los agentes antihipertensivos

sobre la función renal.

88.

5.14. Concordancia entre el aclaramiento de creatinina (gold standard)

y las fórmulas derivadas de ella en el diagnóstico de daño renal.

90.

6. CONCLUSIONES

92.

7. BIBLIOGRAFÍA

96. 
Tabla 1. Estadios de enfermedad renal crónica atendiendo a las Guías KDOQI/NKF.

Tabla 2. Cambios funcionales y estructurales en el riñón del anciano.

Tabla 3. Diagnósticos histopatológicos descritos en el estudio de biopsias renales en el Hospital General de Segovia considerando la edad.

Tabla 4. Características sociodemográficas, función renal, comorbilidad y tratamiento basal según los grupos estudiados.

Tabla 5. Niveles medios de FGe basales en los grupos de estudio según el género.

Tabla 6. Rangos de FGe basales según los grupos de estudio.

35.

Tabla 7. Filtrado glomerular basal en el total de la población estudiada considerando los antecedentes cardiovasculares estudiados. 37.

Tabla 8. Niveles medios de parámetros analíticos asociados a la enfermedad renal crónica en ancianos con MDRD $<60 \mathrm{ml} / \mathrm{min}$ 40. Tabla 9. Niveles medios de ácido úrico en el periodo basal en toda la población estudiada según antecedentes cardiovasculares, empleo de diuréticos y género. 42. Tabla 10. Evolución de función renal a los tres años de seguimiento. Tabla 11. Comparativa entre tratamientos al inicio del estudio y a los tres años. 55. Tabla 12. Análisis de Cox's hazards para mortalidad. 55. Tabla 13. Análisis multivariante de los factores que influyen en el incremento de creatinina sérica al año. 61. 
Tabla 14. Concordancia en el diagnóstico de daño renal acorde a las medidas del aclaramiento de creatinina y las fórmulas de Cockcroft-Gault y MDRD.

66.

Tabla 15. Concordancia en el diagnóstico de daño renal acorde a las medidas

del aclaramiento de creatinina y las fórmulas de CKD-EPI y MDRD.

67.

FIGURAS.

Página

Figura 1. Excreción renal de hidrógeno.

14.

Figura 2. Niveles basales de FGe según grupo.

33.

Figura 3. Evolución de la función renal al año.

44.

Figura 4. Evolución del hematocrito al año.

45.

Figura 5. Evolución de la función renal a dos años.

47.

Figura 6. Evolución del hematocrito a los dos años.

49

Figura 7. Evolución de función renal a tres años.

52.

Figura 8. Evolución de creatinina sérica según proteinuria.

53.

Figura 9. Evolución del hematocrito a los tres años.

54.

Figura 10. Evolución de la función renal a cinco años.

56.

Figura 11. Evolución del hematocrito a los cinco años.

58.

Figura 12. Evolución de función renal según tratamiento con diuréticos.

60.

Figura 13. Curva de Kaplan Meier de mortalidad según el P50 (A) y P75 (B)

de ácido úrico.

64. 


\section{ABREVIATURAS MAS UTILIZADAS.}

ACV: Accidente Cerebro-Vascular.

AEE: Agentes estimuladores de la eritropoyesis.

AMOM: Alteraciones del metabolismo óseo-mineral.

BR: Biopsia Renal.

Cl: Cardiopatía Isquémica.

Crs: Creatinina sérica.

CCr: Aclaramiento de creatinina.

CG: Cockcroft-Gault

CKD-EPI: Chronic Kidney Disease Epidemiology Collaboration.

DM: Diabetes Mellitus

ERC: Enfermedad Renal Crónica.

FG: Filtrado Glomerular.

FGe: Filtrado Glomerular estimado.

HTA: Hipertensión Arterial.

IC: Insuficiencia Cardiaca.

$\mathrm{ICH}$ : Índice de Charlson.

KDOQI/NKF: Kidney Disease Outcomes Quality Iniciative/National Kidney Foundation MDRD: Modification of Diet in Renal Disease.

NT: Nefropatía Terminal.

PA: Presión Arterial.

SEN: Sociedad Española de Nefrología.

TSR: Tratamiento Sustitutivo Renal. 
1. INTRODUCCIÓN. 


\section{INTRODUCCIÓN.}

La mejoría en los cuidados sanitarios, entre otros factores, ha contribuido a un incremento progresivo en la esperanza de vida de las personas. En la actualidad, en la Unión Europea los adultos de más de 60 años suponen el $21 \%$ de la población y se estima que supondrán el $33 \%$ en el año 2050. Esta situación acarreará como consecuencia un importante impacto social, económico y, desde luego, médico (1).

La enfermedad renal crónica $(E R C)$ ha sido reconocida durante los últimos años como un problema importante de Salud Pública, hasta el punto que se llega a considerar como una "epidemia" (2). Este reconocimiento ha sido posible desde la aplicación del modelo conceptual establecido por las Guías Kidney Disease Outcomes Quality Iniciative/ National Kidney Foundation (KDOQI/NKF) (3). Esta clasificación viene definida por la presencia de dos manifestaciones de daño renal: en primer lugar, se basa en la presencia de hematuria, de micro-macroalbuminuria, y de alteraciones en las pruebas de imagen (estas manifestaciones son necesarias para definir los estadios más leves), y en segundo lugar, en el grado del filtrado glomerular (FG): así, la presencia de un FG inferior a $60 \mathrm{ml} / \mathrm{min}$, mantenido durante 3 ó más meses, es suficiente para considerar a un paciente como portador de una ERC en estadios más graves $(3,4)$. En la tabla 1 se refleja la estratificación de la ERC en estadios, acorde a la definición considerada por las Guías KDOQI. La finalidad de esta clasificación es múltiple: por un lado, identifica a los pacientes con ERC desde sus estadios más precoces; por otro, permite instaurar medidas para frenar su progresión y reducir la morbimortalidad que conlleva, y, finalmente, permite a los profesionales de la Nefrología preparar a los pacientes para la entrada en las distintas modalidades de tratamiento sustitutivo renal (TSR). En principio, se considera que esta clasificación sería aplicable a toda la población.

Con respecto a la evolución de la ERC en la población enferma en su conjunto, viene marcada, en primer lugar, por la pérdida progresiva de la función del riñón hasta el desarrollo ERC terminal que requiera TSR; en segundo lugar, por aparición de 
complicaciones asociadas al descenso del FG, y finalmente, por el incremento del riesgo cardiovascular que la insuficiencia renal conlleva (5).

Sin embargo, el significado pronóstico de la ERC en la población anciana no es tan claro y es menos conocido porque: a) con la edad se producen cambios morfológicos y funcionales en el riñón que hay que tener en cuenta a la hora de interpretar la ERC (1); b) se conoce poco acerca del ritmo de progresión de la ERC en los ancianos; c) no se conoce la frecuencia con la que estos pacientes llegan a nefropatía terminal (NT) que precise TSR; y d) no se conoce el impacto de la ERC sobre la mortalidad en la población anciana (6).

Tabla 1. Estadios de ERC atendiendo a las Guías KDOQI/NKF.

\begin{tabular}{|l|l|l|}
\hline Estadio & Descripción & FG (ml/min/1.73m2) \\
\hline Estadio 1 & "Daño renal" con FG & $>=90$ \\
& normal o aumentado. & \\
\hline Estadio 2 & Daño renal con leve & $60-89$ \\
\hline Estadio 3 & Moderado descenso de FG & $30-59$ \\
\hline Estadio 4 & Severo descenso de FG & $15-29$ \\
\hline Estadio 5 & Insuficiencia renal & $<15$ (o diálisis) \\
\hline
\end{tabular}

Marcadores de "daño renal" incluyen presencia de hematuria, proteinuria, alteración en las pruebas de imagen. FG: filtrado glomerular. 


\subsection{Cambios funcionales y estructurales en el riñón del anciano.}

Con el envejecimiento, en el riñón se producen una serie de cambios funcionales y estructurales cuyo denominador común es la disminución de la reserva funcional renal, que es preciso conocer antes de valorar la ERC en el anciano (1). Estos cambios se sintetizan en la tabla 2 .

\section{1.a. Cambios funcionales.}

El descenso del FG relacionado con la edad se asocia al descenso en el flujo sanguíneo renal, a alteración en la capacidad de concentración urinaria, y a los hallazgos estructurales de esclerosis glomerular global, esclerosis vascular, atrofia tubular y disminución del espesor cortical y del tamaño renal $(7,8)$. El estudio longitudinal de Baltimore demostró un descenso en el FG (estimado por aclaramiento de creatinina) a un ritmo promedio de $0.75 \mathrm{ml} / \mathrm{min} / \mathrm{año}$ entre 254 voluntarios "normales", durante un seguimiento entre los años 1958 y 1981, aunque una tercera parte de los sujetos mantuvieron la estabilidad del aclaramiento de creatinina ( $\mathrm{CCr}$ ) (9). Así, el declive de la función renal con la edad per se puede no ser clínicamente significativo, a no ser que se superpongan otras enfermedades agudas ó crónicas que afecten a la reserva funcional ó a la función renal. En los ancianos es muy común la presencia de enfermedades asociadas con la ERC como hipertensión arterial, diabetes mellitus tipo 2, insuficiencia cardiaca congestiva o deterioro cognitivo (1).

Entre las alteraciones de la función tubular relacionadas con la edad cabe destacar la limitación de la capacidad para retener sodio, lo que hace a los ancianos más susceptibles a la deplección de volumen (10); también se altera la capacidad para la excreción del potasio, que explicaría la predisposición de los ancianos a desarrollar hiperpotasemia relacionada con fármacos (1); así mismo, la capacidad para concentrar o diluir la orina disminuye con la edad, con aparición de nicturia, así como predisposición a la deshidratación y a la hipernatremia o hiponatremia si se administran fluidos en exceso (11). 
Otros cambios funcionales renales asociados a la edad incluyen la reducción en la producción de eritropoyetina renal y de renina, también disminuye la conversión de vitamina $\mathrm{D} 25 \mathrm{OH}$ a $1,25 \mathrm{OH}$, y un descenso en el aclaramiento de insulina paralelo al descenso de la función renal en el anciano (1).

\section{1.b. Cambios estructurales.}

El peso del riñón disminuye de forma progresiva después de la quinta década de vida, con mayor afectación de la corteza que de la médula renal (12). De igual manera, a medida que aumenta la edad, el número de glomérulos viables disminuye, con un incremento del porcentaje de glomérulos con esclerosis global. Se sugiere que se puede considerar glomeruloesclerosis "patológica" cuando el número de glomérulos con esclerosis global excede el número calculado por la fórmula (edad del paciente/2) -10 .

La atrofia tubular y la fibrosis intersticial pueden relacionarse con la edad ó ser consecuencia de procesos de inflamación crónica o enfermedad vascular. Con el envejecimiento, en los tubulos distales y colectores también pueden desarrollarse quistes renales simples que predisponen al desarrollo de infecciones en los ancianos. Además, se describe fibrosis de la íntima en las arterias interlobulares asociada a la edad, que puede agravarse por la presencia de hipertensión arterial y/o diabetes mellitus (1). 
Tabla 2. Cambios funcionales y estructurales en el riñón del anciano.

\begin{tabular}{|l|l|}
\hline Cambios funcionales: & Cambios estructurales: \\
$\begin{array}{l}\text { Disminuye el FG. } \\
\begin{array}{l}\text { Limitación de capacidad para retener } \\
\text { sodio. }\end{array}\end{array}$ & $\begin{array}{l}\text { Disminuye el tamaño y peso renal. } \\
\text { Mayor afectación de la cortical renal que } \\
\text { la médula. }\end{array}$ \\
$\begin{array}{l}\text { Defecto en la concentración urinaria. } \\
\text { Desciende el número de glomérulos. }\end{array}$ \\
$\begin{array}{l}\text { Disminuye la producción de eritropoyetina } \\
\text { y de renina. } \\
\text { Disminuye la conversión de vitamina } \\
25 \text { OH a 1,25 OH. } \\
\text { Disminuye el aclaramiento de insulina. }\end{array}$ & $\begin{array}{l}\text { Atrofia tubular y fibrosis intersticial. } \\
\text { esclentaje global. }\end{array}$ \\
\hline
\end{tabular}

\subsection{Estimación del Filtrado Glomerular.}

La nueva clasificación de ERC establecida por las Guías KDOQI se basa, además de en las manifestaciones de daño renal (hematuria, proteinuria, alteraciones en las pruebas de imagen), en el grado de FG, para lo que es imprescindible su determinación.

Es ampliamente aceptado que el FG es el mejor marcador de la función renal (13). La medición exacta del FG utilizando marcadores exógenos como la inulina ó iothalamate no se hace habitualmente en la práctica clínica por laboriosa y por su alto coste (14). La estimación del FG se realiza de forma rutinaria utilizando marcadores endógenos como la creatinina sérica (Crs) ó, últimamente, la cistatina C (4). La Crs es un componente de $113 \mathrm{Da}$ derivado del metabolismo de la creatina en el músculo esquelético que se libera hacia el plasma en una tasa relativamente constante. Sin embargo, la Crs tiene los inconvenientes de que no es sólo un marcador del FG sino que también es indicador de masa muscular y de ingesta proteica; por otra parte, 
cierta fracción de creatinina en orina procede de excreción tubular proximal. La cistatina $C$ es un inhibidor de proteasa de $13 \mathrm{kDa}$ producido en todas las células, se filtra por el glomérulo y se cataboliza en los túbulos con una pequeña excreción urinaria (4). Numerosos estudios han referido que el nivel de cistatina $C$ es mejor método de estimación del FG y predictor de efectos adversos (eventos cardiovasculares, mortalidad) que la Crs, particularmente en ancianos $(4,15,16)$.

La determinación del aclaramiento de creatinina $(\mathrm{CCr})$ mediante la recogida de orina de 24 horas es el método usado con más frecuencia para evaluar el FG en la práctica clínica. Su estimación se hace de la siguiente manera: la concentración de creatinina plasmática se mide en una muestra de sangre venosa y la concentración de creatinina urinaria y el volumen urinario se miden simultáneamente en la orina de 24 horas, según la siguiente fórmula (17):

$\mathrm{CCr}=$ Creatinina urinaria $(\mathrm{mg} / \mathrm{dl}) \times$ Volumen de orina $(\mathrm{ml} / \mathrm{min}) /$ Creatinina plasma $(\mathrm{mg} / \mathrm{dl})$

Se considera que los valores normales de $\mathrm{CCr}$ son aproximadamente de $95 \pm 20$ $\mathrm{ml} / \mathrm{min}$ en mujeres y de $120 \pm 25 \mathrm{ml} / \mathrm{min}$ en varones (18).

El inconveniente del uso de esta fórmula es que sobreestima ligeramente el FG a causa de la excreción tubular de creatinina; por otra parte, en los ancianos puede ser laboriosa la correcta recogida de orina porque con frecuencia presentan incontinencia urinaria (19).

En los últimos años se han desarrollado fórmulas matemáticas derivadas de la Crs para determinar el filtrado glomerular estimado $(\mathrm{FGe})$ (3). La fórmula de CockcroftGault (CG) utiliza como variables la Crs, la edad, el sexo y el peso; esta fórmula fue validada frente al $\mathrm{CCr}$ como el "gold standard" y ha sido el método tradicional de estimación del FG para el ajuste de dosis de fármacos $(13,19)$. 
La fórmula Modification of Diet in Renal Disease (MDRD) incluye como variables, aparte de la Crs, la edad, el sexo, la raza y se desarrolló en una población con función renal alterada $(19,20)$.

Sin embargo, ninguna de estas fórmulas de estimación del FG se ha validado en ancianos $(1,21)$ : el uso de MDRD en la población sana (sin ERC) puede infraestimar el FG (las personas sanas tienen más masa muscular y más ingesta proteica, y por tanto, más generación de creatinina que las personas con ERC) (22); por tanto, podremos catalogar a ancianos "sanos" como afectados de ERC por el hecho de obtener un FGe disminuido al utilizar la fórmula MDRD de forma sistemática.

En los últimos años, el grupo de investigación establecido por el National Institute of Diabetes and Digestive and Kidney Diseases ha desarrollado una nueva ecuación para estimar el FG a partir de la creatinina sérica: Chronic Kidney Disease Epidemiology Collaboration (CKD-EPI) más exacta que la ecuación MDRD (23). La fórmula CKD-EPI incluye como variables la Crs, la edad, el sexo y la raza; ha sido desarrollada a partir de 10 estudios que incluían a una población de 8254 individuos a los que se les midió el FG mediante el aclaramiento de iotalamato. No se puede obviar que una de las limitaciones del diseño de la ecuación CKD-EPI ha sido la inclusión de un escaso número de individuos de edad avanzada; de hecho en la validación original los pacientes mayores de 66 años representaban un $12 \%$ y menos del $1 \%$ en el caso de pacientes mayores de 80 años (23).

\subsection{Utilidad clínica de la estimación del filtrado glomerular.}

El fin primordial de la estimación del FG es conocer el grado de funcionalismo renal y detectar la existencia de algún grado de disfunción renal que nos permita catalogar la ERC en los diferentes estadios ya citados (3).

Por otra parte, el conocimiento del FG permite el ajuste correcto de la posología de los fármacos que se excretan por el riñón. Así, la administración de una dosis plena de un fármaco en pacientes con función renal alterada puede ocasionar un incremento 
en los niveles plasmáticos del fármaco $\mathrm{y}$, por tanto, desarrollar toxicidad, particularmente con fármacos nefrotóxicos (aminoglucósidos) (24). Ishani et al, demuestran que, en pacientes ancianos, los episodios de fracaso renal agudo, particularmente si ya presentaban daño renal crónico, tienen más riesgo de desarrollar NT que aquellos pacientes que no han sufrido episodios de fracaso renal agudo. Los autores sugieren que estos episodios pueden acelerar la progresión de la enfermedad renal (25).

Por otra parte, aunque en los últimos años se ha incrementado el número de pacientes sometidos a trasplante renal, las listas de espera para recibir un injerto renal también han aumentado. Dado que los órganos disponibles para trasplante son limitados, en los últimos años hemos asistido al creciente interés por el uso de donantes con criterios expandidos (entre los que se encuentran pacientes de más de 60 años). Como consecuencia, el análisis de la viabilidad de los riñones para receptores renales procedentes de donantes añosos precisa, además de criterios histológicos, de una evaluación funcional renal del donante (26).

\subsection{Prevalencia de la ERC en el anciano.}

Con la clasificación actual, la presencia de un FGe disminuido $(<60 \mathrm{ml} / \mathrm{min}$, es decir, estadio 3), es suficiente para diagnosticar a un paciente como afectado de insuficiencia renal (3). Sin embargo, la edad es uno de los principales factores que afectan a la función del riñón, por lo que la prevalencia de ERC varía de manera importante con la edad.

Para conocer la prevalencia de ERC (definida como la presencia de un CCr o filtrado glomerular inferior a $60 \mathrm{ml} / \mathrm{min} / 1.73 \mathrm{~m} 2$ ), Zhang $\mathrm{QL}$ y Rothenbacher $\mathrm{D}$ han realizado una revisión sistemática de 26 estudios que incluyen diferentes grupos poblacionales, con un rango de participantes en los estudios entre 237 a 65.181. En esta revisión, los autores presentan los datos de prevalencia de ERC basándose únicamente en la estimación del FG: en 17 de los estudios revisados se utilizaba la ecuación MDRD, en 
5 estudios se empleaba la fórmula de Cockcroft-Gault y en 4 estudios se utilizaron ambas fórmulas de forma simultánea. Las conclusiones a las que llegaron fueron que la prevalencia media de ERC fue de un $7,2 \%$ en la población de $\geq 30$ años, mientras que en la población de $\geq 64$ años oscilaba entre el $23,4 \%$ y el $35,7 \%$, y que la detección exacta de ERC en grupos especiales, particularmente en ancianos, mujeres y grupos étnicos (asiáticos) era inadecuada (27).

Sin embargo, aunque la prevalencia de ERC en la población anciana oscilaba entre el $23,4 \%$ en el estudio de Manjunath (28) y el $35,7 \%$ en el estudio de Hemmelgarn (29) (en ambos estudios se utilizó la fórmula MDRD), hay que considerar que la mayor proporción de pacientes diagnosticados de ERC presentaban un $\mathrm{FGe} \geq 30$ $\mathrm{ml} / \mathrm{min}$, y eran una minoría los que se encontraban en estadios más avanzados de ERC (estadios 4-5).

En el estudio EPIRCE realizado en España, la prevalencia global de ERC en estadios 3-5 (con la fórmula MDRD) fue de un 6,8\%: un 3,3\% para personas entre 40 y 64 años, con un incremento de este porcentaje hasta el $21,4 \%$ en los mayores de 64 años; en este estudio, la edad junto con la obesidad y la hipertensión arterial previa fueron los predictores independientes para el desarrollo de ERC (30).

En los últimos años se ha generado un debate acerca de la "epidemia" de ERC. Glassock y Winearls cuestionan la validez de la fórmula MDRD, puesto que en base a esta ecuación se describe una alta prevalencia de ERC en personas ancianas, mujeres y personas de raza blanca, en comparación con la baja incidencia de insuficiencia renal que requiere TSR en estos grupos de población (31).

Con la nueva ecuación CKD-EPI, la prevalencia de ERC se reducía en mujeres y en personas de raza blanca mientras que en personas ancianas la prevalencia seguía siendo elevada (23). 


\subsection{Comorbilidad asociada a la ERC.}

Existen numerosas enfermedades asociadas a la ERC en el anciano, fundamentalmente la enfermedad cardiovascular, la diabetes mellitus (DM), y el deterioro cognitivo (32).

El envejecimiento conlleva un aumento de la presión arterial (PA), sobre todo de la sistólica, por lo que la hipertensión arterial (HTA) es una patología con elevada prevalencia en ancianos (33). En el momento actual, la HTA, junto con la DM, son las principales causas de ERC que precisan de TSR (34).

En estudios clínicos randomizados, la reducción de las cifras de PA se asocia con una menor incidencia de enfermedad cerebro y cardiovascular, y con enlentecimiento en la progresión del daño renal (35).

\subsection{Enfermedades renales específicas en el anciano.}

En los ancianos, muchas enfermedades glomerulares pueden pasar desapercibidas, bien porque los síntomas se atribuyen a otras enfermedades sistémicas o porque no se indica la realización de una biopsia renal (BR).

El espectro de las enfermedades renales en las personas de edad avanzada difiere respecto al de la población adulta joven (36). Estas diferencias se confirman en un reciente estudio retrospectivo de BR efectuadas en el Hospital General de Segovia (37): En este estudio se analizan 93 biopsias de riñón nativo efectuadas en la población general en un periodo de cinco años (2004-2008): del total de BR, 54 (58\%) corresponden a personas $<65$ años y $39(42 \%)$ a personas de $\geq 65$ años (tabla 3 ). El síndrome nefrótico constituye la principal indicación de BR; sin embargo, en los pacientes de $\geq 65$ años, el fracaso renal agudo es el síndrome más frecuente, mientras que en la población < 65 años son las alteraciones urinarias persistentes el principal motivo para indicar una BR. Respecto a los hallazgos histológicos descritos en este estudio, en las personas de $\geq 65$ años es la glomerulonefritis extracapilar asociada a vasculitis la histología más común. La nefropatía lúpica sólo aparece en personas más 
jóvenes, y la amiloidosis fue más frecuente en la población más anciana. Estos resultados son superponibles a los comunicados en el registro español de glomerulonefritis de la Sociedad Española de Nefrología (SEN) (38).

Tabla 3. Diagnósticos histopatológicos descritos en el estudio de BR en el Hospital General de Segovia considerando la edad (37).

\begin{tabular}{|l|l|l|}
\hline & $<65$ años $(\mathrm{n}=54)$ & $\geq 65$ años $(\mathrm{n}=39)$ \\
\hline Nefropatía cambios mínimos & $2(3,7 \%)$ & $4(10,3 \%)$ \\
\hline Glomeruloesclerosis focal y segmentaria & $1(1,9 \%)$ & $3(7,7 \%)$ \\
\hline Nefropatía membranosa & $5(9,3 \%)$ & $2(5,1 \%)$ \\
\hline Glomerulonefritis mesangiocapilar & $2(3,7 \%)$ & $2(5,1 \%)$ \\
\hline Glomerulonefritis mesangial IgA & $12(22,3 \%)$ & $2(5,1 \%)$ \\
\hline Glomerulonefritis mesangial no IgA & $2(3,7 \%)$ & 0 \\
\hline Amiloidosis & $1(1,9 \%)$ & $4(10,3 \%)$ \\
\hline Glomerulonefritis extracapilar/vasculitis & $2(3,7 \%)$ & $9(23,1 \%)$ \\
\hline Nefropatía Diabética & $4(7,4 \%)$ & $2(5,1 \%)$ \\
\hline Nefropatía Lupica & $8(14,8 \%)$ & 0 \\
\hline Nefropatía tubulo-intersticial & $2(3,7 \%)$ & $6(15,5 \%)$ \\
\hline Glomerulonefritis post-infecciosa & $2(3,7 \%)$ & $1(2,6 \%)$ \\
\hline Alteraciones histológicas inespecíficas & $8(14,8 \%)$ & $3(7,7 \%)$ \\
\hline No material & $3(5,6 \%)$ & $1(2,6 \%)$ \\
\hline
\end{tabular}




\subsection{Manifestaciones analíticas asociadas a la ERC.}

\section{7.a. Anemia.}

La anemia es una asociación muy frecuente en los pacientes afectos de ERC. Su diagnóstico se establece cuando los niveles de hemoglobina son inferiores a $11 \mathrm{~g} / \mathrm{dl}$ (hematocrito<33\%) en mujeres premenopaúsicas y a $12 \mathrm{~g} / \mathrm{dl}$ (hematocrito $<37 \%$ ) en varones adultos y mujeres postmenospaúsicas (39). Entre las causas de la anemia, la deficiencia de eritropoyetina desempeña un papel crucial. Las células peritubulares del córtex renal, especializadas en producir eritropoyetina, resultan dañadas en los pacientes con insuficiencia renal (40). La inadecuada producción de eritropoyetina por el riñón enfermo conlleva, a su vez, una disminución de la estimulación en la médula ósea para producir glóbulos rojos. Por lo general, la anemia de la ERC se inicia de forma temprana y empeora con la progresión de la insuficiencia renal (41). Además, la anemia se muestra como un factor de riesgo para el desarrollo de la enfermedad cardiovascular y se asocia también con altas tasas de hospitalización y de mortalidad en estos pacientes (41).

Otros factores que pueden contribuir al desarrollo de la anemia en el paciente con ERC serían el déficit de hierro, pérdidas sanguíneas, déficit de vitamina B12 y de ácido fólico, procesos inflamatorios asociados, existencia de neoplasias, el hiperparatiroidismo secundario grave y la, cada vez menos frecuente, toxicidad por aluminio $(40,41)$.

Es muy importante resaltar que el tratamiento de la anemia desde estadios más precoces es esencial para prevenir la aparición de las complicaciones asociadas y mejorar la calidad de vida de los pacientes. La terapia con agentes estimuladores de la eritropoyesis (AEE) para el manejo de la anemia de la ERC se ha convertido en primera línea de tratamiento para estos pacientes. La utilización de AEE ha supuesto grandes ventajas en el control de los pacientes: han disminuido muy significativamente la necesidad de las transfusiones sanguíneas, ha supuesto una mejoría evidente en la 
calidad de vida, ha incrementado su supervivencia y significa un factor de enlentecimiento de la progresión de la insuficiencia renal (42).

La eficacia de los AEE requiere, a su vez, disponer de unos depósitos adecuados de hierro (índice de saturación de transferrina $>20 \%$ y ferritina $>100 \mathrm{mg}$ ) (41).

\section{7.b. Acidosis Metabólica.}

En condiciones normales, la concentración extracelular de hidrogeniones $(\mathrm{H}+)$ se mantiene en unos márgenes muy estrechos (40 nanomol/L) (43). Entre los mecanismos involucrados en la regulación de $\mathrm{H}+$ cabe señalar: 1) los sistemas tampón; 2) la PCO2 variando el grado de ventilación (compensación rápida) y 3) regulación de la concentración de bicarbonato a través de la excreción renal de $\mathrm{H}+$ (compensación lenta). Esta participación del riñón en la regulación del equilibrio ácidobase se hace de dos maneras: 1) mediante la reabsorción del bicarbonato filtrado y 2) mediante la eliminación del excedente de $\mathrm{H}+$ procedentes de la ingesta alimentaria a través de la producción de acidez titulable $\left(\mathrm{HPO}^{2-}{ }_{4}\right)$ o de amonio (NH4+) (44).

En la figura 1 se representa la participación renal en la excreción de H+.

Figura 1. Excreción renal de hidrógeno

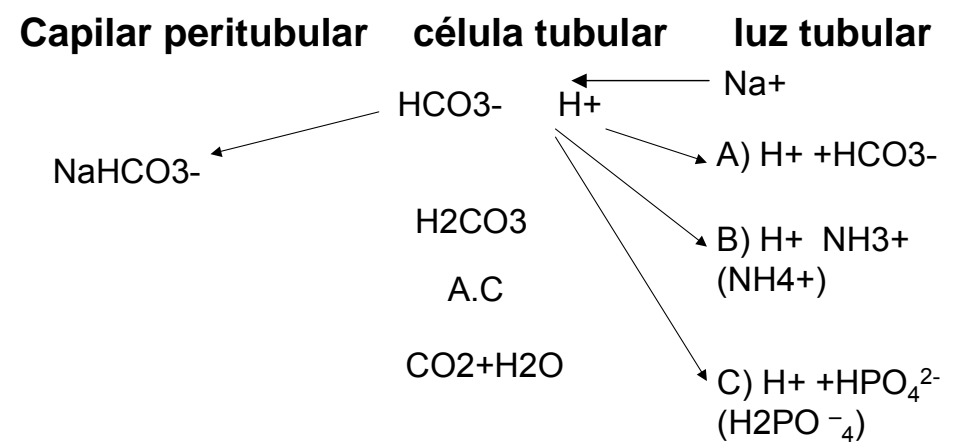

La secreción de $\mathrm{H}+$ desde la célula a la luz tubular conlleva: Recuperación del bicarbonato filtrado $(\mathrm{A})$; Eliminación de la carga diaria de $\mathrm{H}+$ producto del metabolismo (50-100 mEq/día) en forma de amonio (B) y acidez titulable (C). A.C: Anhidrasa carbónica 
Con el metabolismo de la ingesta alimentaria se genera, aproximadamente, $1 \mathrm{mEq} /$ Kg de peso de hidrogeniones por día en adultos. La reabsorción de una gran cantidad de bicarbonato filtrado por el riñón y la generación de una cantidad de bicarbonato equivalente, permite mantener una concentración plasmática de bicarbonato de aproximadamente $25,4 \pm 0,09 \mathrm{mEq} / \mathrm{L}$ en varones y $24,4 \pm 1,3 \mathrm{mEq} / \mathrm{L}$ en mujeres. Con el desarrollo de la ERC, la recuperación del bicarbonato puede alterarse, y por tanto, producir acidosis metabólica (45). La acidosis metabólica suele detectarse generalmente cuando el nivel de FG cae por debajo de $30 \mathrm{ml} / \mathrm{min}$ y suele ser de intensidad leve-moderada, con una media en la concentración plasmática de bicarbonato entre $12-23 \mathrm{mEq} / \mathrm{L}$.

Las consecuencias clínicas de la acidosis metabólica son diversas; entre ellas se pueden mencionar el desarrollo o exacerbación de la enfermedad cardiovascular y de la enfermedad ósea, el estímulo de cierto grado de inflamación, la reducción en la síntesis de albúmina con predisposición a hipoalbuminemia, el incremento del catabolismo proteico, la resistencia a los efectos de la insulina y una aceleración de la progresión de la enfermedad renal (46). Respecto a esta última consecuencia, un estudio prospectivo y randomizado demuestra que la suplementación con bicarbonato oral es beneficiosa tanto para enlentecer la progresión de la enfermedad renal hacia nefropatía terminal, como para mejorar los parámetros nutricionales (47).

\section{7.c. Alteraciones del metabolismo óseo-mineral.}

Las alteraciones del metabolismo óseo-mineral (AMOM) son comunes en la ERC, y causan importante morbilidad, disminuye la calidad de vida de los enfermos, y se asocian con un incremento de mortalidad cardiovascular $(48,49)$. La retención de fósforo juega un papel clave en el desarrollo de las AMOM y es una consecuencia inevitable del descenso gradual del FG y, por lo tanto, de la eliminación renal de fosfatos. En los estadios precoces de la ERC, la retención de fósforo estimula la 
secreción de PTHi y del Factor de Crecimiento Fibroblástico 23 (FGF-23), que a su vez suprimen la reabsorción renal de fosfatos en un intento de aumentar la eliminación renal de los mismos. El FGF-23 también suprime la producción de 1,25 vitamina D (la cual limita la absorción intestinal de fosfato) pero permite el incremento de la PTHi. La progresión de la ERC a estadios más avanzados conlleva una saturación de estos mecanismos de homeostasis del fósforo, como consecuencia, se produce hiperfosforemia con niveles cada vez más elevados de FGF-23 y de PTHi (hiperparatiroidismo secundario) (50).

Las consecuencias a nivel óseo de esas alteraciones en la ERC se concretan en la baja calidad del hueso, con elevada prevalencia de fracturas en pacientes en diálisis comparada con la población general en todos los grupos de edad. Del mismo modo, las AMOM se relacionan con un incremento de calcificaciones vasculares tanto de arterias coronarias como de arterias periféricas (49).

El tratamiento precoz de la retención de fosfatos o de la hiperfosfatemia puede prevenir o enlentecer la aparición de las AMOM. La restricción de fosfatos en la dieta, el empleo de quelantes del fósforo y la suplementación con vitamina $D$ o calcimiméticos son medidas eficaces para el manejo precoz de las AMOM asociadas a la $\operatorname{ERC}(50)$.

\section{8. ¿Cómo progresa la ERC en el anciano?}

Existen numerosos estudios que intentan establecer la prevalencia de ERC en la población general $(27,30)$. En cambio, los trabajos que analizan el ritmo de progresión de la enfermedad renal en el ancianos son escasos. Hallan et al (51) estudian las estrategias para detectar la ERC en la población general con edad superior a los 20 años, sobre una población de 65.604 personas, y con un seguimiento prospectivo de 8 años; del total de personas reclutadas, 3069 (4,7\%) tienen un FGe basal menor a 60 $\mathrm{ml} / \mathrm{min}$. Después de 8 años de seguimiento, $38(1,2 \%)$ personas de las 3069 portadoras de ERC, desarrollan nefropatía terminal. En este estudio se encuentra que 
el riesgo de progresión a ERC terminal es especialmente bajo en pacientes sin diabetes ni HTA, en mujeres y en pacientes con una edad $\geq 70$ años ó con $\mathrm{FGe}$ entre $45-59 \mathrm{ml} / \mathrm{min}$ en el momento del cribado.

Hemmelgarn et al analizan la progresión de la ERC en una población seleccionada de personas de más de 66 años durante un periodo de seguimiento de dos años. Los autores encuentran que en la mayoría de ancianos no existe progresión de la enfermedad renal o ésta es mínima durante el periodo analizado; entre los factores que colaboran con una progresión más rápida de la ERC mencionan la presencia de

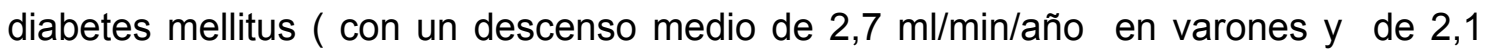
$\mathrm{ml} / \mathrm{min} /$ año en mujeres) y también el hecho de tener un FGe basal reducido, sobre todo inferior a $30 \mathrm{ml} / \mathrm{min}(29)$.

En otro estudio realizado en veteranos americanos, con una edad media de 68,4 años, mayoritariamente varones y con un seguimiento de 5 años, se encuentra que la raza negra, el alto cociente de proteína/creatinina en orina, la elevación de la presión arterial sistólica, el FG basal disminuido y pacientes de menor edad, son factores de riesgo para la progresión de la ERC hacia nefropatía terminal (52).

\subsection{Implicaciones de la ERC en el anciano.}

La introducción sistemática en los laboratorios de la fórmula MDRD para conocer el FGe de la población, según las Guías KDOQI, ha provocado un aumento considerable de derivaciones de enfermos a las consultas de Nefrología, particularmente de pacientes ancianos con un FGe disminuido, pero sin otras manifestaciones de daño renal (por ejemplo, proteinuria). Esto ha generado preocupación y debate entre los profesionales sanitarios acerca de la conveniencia de aplicar sistemáticamente esta clasificación en ancianos y el significado pronóstico de la ERC en este grupo poblacional $(31,53,54)$.

Las Guías recomiendan que se pueden aplicar los mismos criterios de la clasificación KDOQI para detectar la ERC en jóvenes y en la población anciana $(3,55)$. De esta 
forma, todos los pacientes que presenten un FGe inferior a $60 \mathrm{ml} / \mathrm{min} / 1,73 \mathrm{~m} 2$ son considerados portadores de ERC, con independencia de su edad. Sin embargo, en los ancianos hay que tener en cuenta que el descenso del FGe es muy común asociado a la edad- y que las fórmulas utilizadas para estimar el FG en esta población no han sido validadas $(1,13)$.

En décadas pasadas, el interés de los nefrólogos se centraba en los programas de diálisis y trasplante, y se prestaba relativamente poca atención a las medidas de prevención de la pérdida de la función renal (14). En los últimos años, con el conocimiento de medidas terapéuticas renoprotectoras, la comunidad nefrológica ha puesto especial énfasis en la detección precoz de la ERC, a través del desarrollo de las Guías KDOQI.

La identificación precoz de ERC permite establecer estrategias de prevención, y que los pacientes se puedan beneficiar de tratamientos actualmente disponibles, tanto para frenar el ritmo de progresión de la enfermedad renal (por ejemplo, fármacos bloqueadores del sistema renina-angiotensina-aldosterona) como para tratar las complicaciones asociadas a la ERC (anemia, AMOM...). Medidas que permiten mejorar la calidad de vida y la supervivencia de los pacientes (5).

El pronóstico de la ERC lo marca, además de la aparición de complicaciones asociadas al descenso del FG, la pérdida de la función renal que requiera TSR, el incremento del riesgo cardiovascular y la mortalidad (3).

Con respecto a la pérdida de la función renal, hay que considerar que la tasa de descenso de la función renal es variable entre los pacientes. Una progresión rápida se definiría por el descenso de FGe superior a $4 \mathrm{ml} / \mathrm{min} / \mathrm{año} \mathrm{(5).}$

En lo que se refiere a la aceptación y la prevalencia de TSR, éstas han aumentado en la mayoría de los países desarrollados, y uno de los principales factores ha sido la aceptación del TSR en ancianos (18). Sin embargo, según los datos del NANHES III, se considera que de 20 millones de pacientes afectados de ERC, sólo cerca de un $2 \%$ reciben TSR con diálisis ó trasplante (56). 
El uso de las Guías KDOQI, por otra parte, permite instaurar medidas preparatorias para la diálisis (por ejemplo, creación de acceso vascular) cuando se demuestra que la ERC progresa hacia estadio 4 (3). Sin embargo, en los ancianos con estadios avanzados (estadios 4-5) los esfuerzos preparatorios para TSR pueden resultar inútiles y de coste elevado si los pacientes fallecen antes de que la ERC progrese hacia estadio terminal (57).

La ERC es un factor de riesgo independiente para el desarrollo de enfermedad cardiovascular. Por eso, se recomienda que los pacientes con ERC sean considerados un grupo de alto riesgo para desarrollar eventos cardiovasculares y que la mayoría de las intervenciones efectivas en la población general deberían también aplicarse en pacientes con ERC (5). De igual manera, la enfermedad cardiovascular es la principal causa de mortalidad entre los pacientes en diálisis y trasplante (58).

Sin embargo, aunque la clasificación KDOQI de ERC se considera aplicable a toda la población, el pronóstico de la ERC es heterogéneo: pacientes jóvenes en estadios más leves de ERC, pero con síndrome nefrótico asociados a nefropatía glomerular pueden acabar desarrollando nefropatía terminal antes que pacientes ancianos con reducciones moderadas del FG (estadio 3) asociadas a nefroangioesclerosis. Este hecho ha cuestionado la validez de esta clasificación aplicada de forma uniforme a toda la población $(5,22)$. Así, el estudio de O’Hare et al donde se estudian 209,622 veteranos americanos en estadios 3-5, encuentra que entre los pacientes con un mismo grado de FGe basal, en los pacientes más jóvenes existe más probabilidad de desarrollar nefropatía terminal que de fallecer; en los pacientes entre 65-84 años, sólo los que tienen niveles basales de FGe menor a $15 \mathrm{ml} / \mathrm{min}$ el riesgo de desarrollar nefropatía terminal supera al riesgo de fallecimiento; y entre los mayores de 85 años, el riesgo de fallecer supera a la enfermedad renal terminal, incluso con FGe menor a $15 \mathrm{ml} / \mathrm{min}$. Los autores describen así el "efecto modificador de la edad" en la ERC: en los pacientes ancianos, quizás el FGe disminuido pudiera ser un marcador de una variedad de enfermedades asociadas a la edad y por tanto, podría ser un mejor 
predictor de pronóstico "global" más que de un pronóstico "específico" renal, mientras que en la población más joven, quizás el bajo FGe es el resultado de una enfermedad que afecta de forma selectiva al riñón y así ser un mejor predictor de pronóstico renal (6).

En resumen, desde la introducción de las Guías KDOQI la ERC se ha convertido en un problema de Salud Pública. En la población general, la prevalencia de ERC se sitúa en torno a un 7\%. En los ancianos, la prevalencia de ERC es aún mayor, pero con una incidencia variable que depende tanto del estudio como del método que se utilice para estimar el FG; la mayoría de las fórmulas utilizadas para estimar el FG en la población general no se han validado en ancianos, por lo que existen grandes dificultades a la hora de definir la ERC en este grupo de pacientes. Finalmente, no hay evidencias suficientes para establecer el verdadero significado pronóstico de la ERC en los ancianos.

De los datos expuestos surgirían diversas cuestiones:

- ¿se deben instaurar medidas específicas de prevención de la progresión de la ERC en todos los ancianos?

- ¿los nefrólogos deberían valorar y realizar un seguimiento a todos los ancianos con reducciones moderadas en el FGe y que no presentan otras manifestaciones de daño renal?. 
2. HIPÓTESIS Y OBJETIVOS. 


\section{HIPÓTESIS Y OBJETIVOS.}

\subsection{Hipótesis.}

Se ha demostrado, en experimentación animal y humana, que el filtrado glomerular y el flujo plasmático renal efectivo experimentan un descenso con la edad en ausencia de enfermedad renal $(59,60,61,62,63)$. El estudio de Baltimore demostró un descenso en el FG (estimado por aclaramiento de creatinina) por término medio de 0,75 $\mathrm{ml} / \mathrm{min} / a n ̃ o$, aunque una tercera parte de los participantes mantuvieron estable el aclaramiento de creatinina (9). Fliser et al, valoró la reserva funcional renal comparando 15 personas sanas normotensas, con una mediana de edad de 26 años (rango 23 a 32), frente a 10 personas de edad avanzada, con una mediana de edad de 70 años (rango de 61 a 82), y encontró que el FG, estimado por aclaramiento de inulina (Cin), era significativamente más bajo en personas de más edad respecto al grupo más joven (Cin: 102 frente a $122 \mathrm{ml} / \mathrm{min}$ ), si bien los niveles de FGe por Cin, en las personas de más edad se mantenían en rango normal (62). Posteriormente, otro trabajo que incluía a 68 ancianos, comprobó también que el FG en pacientes ancianos estaba sólo discretamente reducido respecto a un grupo control de jóvenes y, además, esta reducción del FG estaba estrechamente vinculada a la existencia de enfermedades asociadas como hipertensión arterial ó insuficiencia cardíaca (63).

Los hallazgos de estos estudios demuestran que ancianos sanos no experimentan un serio deterioro de la función renal $(9,62,63)$, y cuestionan el dogma del descenso inexorable de la función renal en el anciano (64).

Por otra parte, las Guías KDOQI establecen una definición/ clasificación de ERC, con cinco estadios basados en el grado de FG y/o en la presencia de manifestaciones de daño renal (hematuria, proteinuria, alteración en pruebas de imagen). Y consideran también que los diferentes estadios de la ERC son válidos para las personas de todas las edades. Sin embargo, existe un amplio debate acerca de cuál es el rango de función renal normal en el anciano, si el FG disminuido en el anciano obedece a un 
proceso fisiológico de envejecimiento o, por el contrario, sería debido a enfermedad renal intrínseca.

En este trabajo planteamos la siguiente hipótesis:

En los ancianos sin proteinuria ni otras alteraciones en el sistemático urinario, el filtrado glomerular estará disminuido (<90 ml/min). El seguimiento de la función renal en el tiempo nos permitirá demostrar un lento descenso del filtrado glomerular (< $1 \mathrm{ml} / \mathrm{min} / \mathrm{año}$ ), lo cual podrá considerarse como una consecuencia del proceso de envejecimiento humano en lugar de una verdadera enfermedad renal.

\subsection{Objetivos.}

\section{2. a. Objetivos principales:}

- En el periodo trasversal:

- Conocer el nivel de FGe basal en los grupos de estudio utilizando fórmulas matemáticas derivadas de la creatinina sérica (MDRD, CKD-EPI y CockcroftGault).

- Demostrar la posible asociación entre el nivel basal de FG con la comorbilidad.

- Valorar a partir de qué grado de FGe detectamos la presencia de manifestaciones típicas de ERC (anemia, acidosis metabólica, alteraciones del calcio-fósforo e iones).

- En el periodo de seguimiento:

- Valorar cómo evoluciona la función renal en el tiempo.

- Analizar los pronósticos asociados a la ERC (progresión a nefropatía terminal que requiera TSR y mortalidad). 
2.2.b Objetivos secundarios:

- En el periodo transversal:

- Valorar el grado de concordancia entre el aclaramiento de creatinina (gold standard) con las formulas matemáticas derivadas de la Crs (Cockcroft-Gault, MDRD, CKD-EPI).

- En el periodo de seguimiento:

- Estudiar la repercusión de los agentes antihipertensivos sobre la función renal.

- Conocer los tratamientos establecidos en los diferentes periodos de estudio.

- Analizar los eventos cardiovasculares de novo (insuficiencia cardíaca, cardiopatía isquémica, accidente cerebro-vascular) acaecidos en el periodo de estudio. 
3. PACIENTES Y MÉTODOS. 


\section{PACIENTES Y MÉTODOS.}

\subsection{Pacientes.}

Se estudiaron ochenta pacientes ancianos clínicamente estables, con una mediana de edad de 83 años (rango: 69-97 años), reclutados aleatoriamente cuando los pacientes acudían a las consultas externas programadas de Geriatría y de Nefrología General en el Hospital General de Segovia, en el periodo Enero-Abril de 2006.

Según los niveles de Crs basal se establecieron dos grupos de estudio: Grupo 1, $\mathrm{n}=38$, Crs $\leq 1,1 \mathrm{mg} / \mathrm{dl}$ (rango 0,7-1,1) y Grupo 2, n= 42, Crs $>1,1 \mathrm{mg} / \mathrm{dl}$ (rango 1,2-3).

\subsection{Métodos.}

Se realizó un primer corte transversal, en el periodo entre enero-abril de 2006, para conocer el nivel de FG basal de los pacientes incluidos en el estudio. Posteriormente, los ancianos fueron seguidos de forma prospectiva, analizando la evolución clínica, la función renal y los pronósticos asociados a la ERC. Se realizaron nuevos cortes al año (reevaluación entre enero-abril de 2007), dos años (reevaluación entre enero-abril de 2008), tres años (reevaluación entre enero-abril de 2009) y cinco años (reevaluación entre enero-abril 2011).

Las determinaciones analíticas fueron realizadas una semana antes de que los pacientes acudieran a sus consultas programadas de Geriatría y de Nefrología General, de forma basal, al año, dos años, tres años y cinco años.

Se determinó en sangre venosa, con la metodología rutinaria del Hospital General de Segovia: creatinina, urea, ácido úrico, hemograma, metabolismo del hierro, calciofósforo, ionograma y perfil lipídico. En el periodo basal además fue incluido el equilibrio ácido-base (pH, pCO2 y bicarbonato).

En orina, se hizo a todos los pacientes un sistemático urinario para despistaje de proteinuria; además en el grupo 1 se calculó el cociente proteínas (mg/dl)/creatinina 
$(\mathrm{mg} / \mathrm{dl})$ en una micción matutina y en el grupo 2 se realizó una cuantificación de proteínas en orina de 24 horas.

El filtrado glomerular se estimó con la formula Modification of Diet in Renal Disease Study Equation (MDRD abreviada) (65):

$\mathrm{FGe}(\mathrm{ml} / \mathrm{min} / 1.73 \mathrm{~m} 2)=$ $186 \times(\mathrm{Cr} \mathrm{s})^{-1.154} \times(\text { edad })^{-0.203} \times(0.742$ mujer $) \times(1.21$ afro-americano $)$

Se utilizó la fórmula MDRD abreviada en el momento del estudio transversal y en el seguimiento de la función renal en el tiempo por su simplicidad (no precisa disponer del peso del paciente ni tener que recoger una orina de 24 horas) y por ser la fórmula que recomendaba la SEN para conocer el filtrado glomerular (66).

Para comparar los niveles basales de filtrado glomerular con otros métodos de estimación derivados de la Crs, también se determinó el FG con la fórmula de Cockcroft-Gault (67):

$F G=(140-e d a d) \times$ Peso $/ 72 \times$ Crs $(X 0.85)$ si mujer.

Igualmente, en el periodo basal el filtrado glomerular fue determinado con la fórmula Chronic Kidney Disease Epidemiology Collaboration (CKD-EPI) (23):

$\mathrm{FG}=141 \mathrm{X} \min (\mathrm{Crs} / \mathrm{K}, 1)^{\alpha} \times \max (\mathrm{Crs} / \mathrm{K}, 1)^{-1.209} \times 0.993^{\text {edad }} \times 1.018$ [si mujer] $X 1.159$ [si raza negra]

Donde Crs es creatinina sérica $(\mathrm{mg} / \mathrm{dL})$, $\mathrm{k}$ es 0.7 para mujeres y 0.9 para varones, $\alpha$ es -0.329 para mujeres y -0.411 para varones, min indica el mínimo de $\mathrm{Crs} / \mathrm{K}$ o 1 , y max indica el máximo de Crs/K o 1. 
Se registró la comorbilidad basal con el índice de Charlson (ICH) sin incluir la edad (68). También se analizó la aparición de eventos cardiovasculares de novo: insuficiencia cardíaca (IC), cardiopatía isquémica (CI), accidente cerebro-vascular (ACV) y los fármacos que utilizaban los pacientes en los diferentes periodos de estudio.

\section{2.a FG basal y comorbilidad de los pacientes.}

En el corte trasversal, se estudió si existía alguna asociación entre los niveles basales de FG (usando las fórmulas derivadas de la Crs: Cockcroft-Gault, MDRD y CKD-EPI) con la presencia o ausencia de antecedentes cardiovasculares.

\section{2.b Manifestaciones analíticas asociadas a la enfermedad renal crónica.}

La clasificación KDOQI considera ERC los estadios 3-5 con presencia de un FGe $<60$ $\mathrm{ml} / \mathrm{min}$. Para estudiar a partir de qué grado de filtrado glomerular se detectan las manifestaciones analíticas asociadas a la ERC (anemia, acidosis metabólica, alteraciones del metabolismo calcio-fósforo) seleccionamos del total de la población estudiada a aquellos pacientes que tenían un FGe inferior a $60 \mathrm{ml} / \mathrm{min}$ (estimado por MDRD abreviado) en el periodo basal. Estos pacientes fueron subdivididos a su vez en dos grupos de análisis según el nivel de FGe (MDRD) basal: grupo A, aquellos pacientes con $F G \geq 30 \mathrm{ml} / \mathrm{min}$ (estadio 3 de $E R C$ ) y grupo $B$, pacientes con $F G<30$ $\mathrm{ml} / \mathrm{min}$ (estadios 4 y 5 de ERC).

\section{2.c Repercusión de los agentes antihipertensivos sobre la función renal.}

Los sesenta y seis ancianos con antecedentes de hipertensión arterial en el periodo basal (enero-abril de 2006), $(\mathrm{N}=30$ con $\mathrm{Cr} \mathrm{s} \leq 1,1 \mathrm{mg} / \mathrm{dl}$ y N=36 con $\mathrm{Cr} \mathrm{s}>1,1 \mathrm{mg} / \mathrm{dl})$, fueron seleccionados para estudiar cómo repercuten los agentes antihipertensivos sobre la función renal. Estos pacientes fueron seguidos clínica y analíticamente de forma prospectiva y reevaluados al cabo de un año (reevaluación en el periodo enero- 
abril de 2007). En la población hipertensa seleccionada se estimó en el momento basal y al cabo de un año el filtrado glomerular $(F G)$ con fórmula de Modification of Diet in Renal Disease (MDRD), así como la existencia de proteinuria. Los pacientes mantuvieron el mismo tratamiento hipotensor instaurado de forma basal. Se valoraron aquellos agentes antihipertensivos que producían un deterioro de la función renal al cabo de un año. Se definió la variable "Incremento de Cr s" como aquellos pacientes con $($ Cr s al año- $\mathrm{Cr}$ s basal $) \geq 0.1 \mathrm{mg} / \mathrm{dl}$.

\section{2.d. Control de la presión arterial en el seguimiento a tres y cinco años.}

Se recogieron las cifras de presión arterial sistólica y diastólica de la última medición ambulatoria previa a que los pacientes acudieran a sus consultas correspondientes.

3.2.e. Concordancia entre el aclaramiento de creatinina y las fórmulas derivadas de la creatinina sérica en el diagnóstico de daño renal.

En treinta y dos pacientes, procedentes de la consulta de Nefrología General, en el periodo entre enero-abril de 2006, se pudo hacer un aclaramiento de creatinina. En los treinta y dos pacientes que disponían del $\mathrm{CCr}$ se hizo un estudio de concordancia entre el CCr y las fórmulas derivadas de la Crs.

El aclaramiento de creatinina se determinó en orina recogida de 24 horas (17).

CCr: Creatinina en orina $(\mathrm{mg} / \mathrm{dl}) \times$ Volumen de orina de 24 horas $(\mathrm{ml} / \mathrm{min}) /$ Creatinina sérica $(\mathrm{mg} / \mathrm{dl})$

El aclaramiento de creatinina se consideró el gold standard. En los mismos treinta y dos pacientes a los que se había determinado el $\mathrm{CCr}$, se consideró también el filtrado glomerular con las fórmulas Cockcroft-Gault; MDRD abreviada y CKD-EPI.

Para conocer el grado de concordancia entre el CCr (gold standard) con las fórmulas Cockcroft-Gault, MDRD y CKD-EPI, en el diagnóstico de daño renal, se establecieron 
tres categorías de daño renal: ausencia de daño renal ( $F G e \geq 60 \mathrm{ml} / \mathrm{min})$; daño renal moderado (FGe: 30-59,9 ml/min) y daño renal severo ( $F G e<30 \mathrm{ml} / \mathrm{min})$.

\subsection{Análisis Estadístico.}

El análisis estadístico se realizó con el programa SPSS 11.0 (versión 15.0 en el estudio del seguimiento a los cinco años). Los datos se expresan como porcentajes, medias y desviaciones estándar. También se incluyen percentiles en la valoración de los niveles de ácido úrico en el periodo basal.

La comparación de medias se hace con $t$ de student ( $U$ de Mann Withney en el análisis de la presencia de manifestaciones analíticas asociadas a la ERC). La comparación de proporciones se realizó con chi $^{2}$ (Fisher).

En el seguimiento prospectivo, para valorar la evolución de la función renal con el paso del tiempo, fue utilizado un modelo lineal para medidas repetidas.

Para analizar el efecto simultáneo de varias variables sobre la mortalidad se utilizó un análisis de Cox.

Para el estudio de la repercusión de los agentes antihipertensivos sobre la función renal y valorar qué factores influían en el incremento de la creatinina sérica al cabo de un año, se realizó un análisis de regresión uni y multivariante.

La concordancia entre los métodos de estimación del FG estudiados según categorías de daño renal se estableció con el coeficiente Kappa.

El nivel de significación fue del 95\% $(\mathrm{P}<0.05)$. 


\section{RESULTADOS.}




\section{RESULTADOS.}

De los ochenta pacientes estudiados, cincuenta y cinco pacientes (69)\% eran mujeres; veintiocho (35\%) tenían DM y sesenta y seis (83 \%) tenían HTA. Las características sociodemográficas, la función renal, la comorbilidad basal y el tratamiento basal de ambos grupos se muestran en la Tabla 4.

Tabla 4. Características sociodemográficas, función renal, comorbilidad y tratamiento basal según los grupos estudiados.

\begin{tabular}{|l|l|l|l|}
\hline & Grupo 1 (N=38) & Grupo 2 (N=42) & P \\
\hline Edad (años) & $80,31 \pm 6,35$ & $84,45 \pm 6,06$ & 0.004 \\
\hline Sexo (varón/mujer) & $6 / 32$ & $19 / 23$ & 0.005 \\
\hline Cr s basal (mg/dl) & $0,95 \pm 0,09$ & $1,63 \pm 0,51$ & 0.000 \\
\hline MDRD basal (ml/min) & $63,56 \pm 10$ & $40,15 \pm 12$ & 0.000 \\
\hline Cockcroft-Gault basal (ml/min) & $47,95 \pm 11$ & $30,59 \pm 11$ & 0.000 \\
\hline Proteinuria (g/24h) & $0,01 \pm 0,02$ & $0,31 \pm 0,51$ & 0,019 \\
\hline Hipertensión arterial (\%) & $78,9 \%$ & $85,7 \%$ & NS \\
\hline Diabetes mellitus (\%) & $36,8 \%$ & $33,3 \%$ & NS \\
\hline Antecedentes de Cl (\%) & $7,9 \%$ & $21,4 \%$ & NS \\
\hline Antecedentes de IC (\%) & $13,9 \%$ & $25 \%$ & NS \\
\hline Antecedentes de EVP (\%) & $0 \%$ & $9,5 \%$ & NS \\
\hline Antecedentes de EVC (\%) & $28,9 \%$ & $21,4 \%$ & NS \\
\hline Antecedentes de FA (\%) & $28,9 \%$ & $16,7 \%$ & NS \\
\hline Índice de Charlson & $1,68 \pm 1$ & $1,90 \pm 1$ & NS \\
\hline Diuréticos (\%) & $63,2 \%$ & $73,2 \%$ & 0,002 \\
\hline IECAs & $42,1 \%$ & $34,1 \%$ & NS \\
\hline ARAll & $18,4 \%$ & $7,9 \%$ & \\
\hline Betabloqueantes & $0 \%$ & & \\
\hline AEE & & & \\
\hline & & & \\
\hline
\end{tabular}


Cr s: creatinina sérica; Grupo 1: Crs $\leq 1.1 \mathrm{mg} / \mathrm{dL}$; Grupo 2: Crs $>1.1 \mathrm{mg} / \mathrm{dL}$; $\mathrm{Cl}$ : Cardiopatía isquémica; IC: Insuficiencia cardíaca; ICH: Indice de Charlson; EVP: Enfermedad vascular periférica; EVC: Enfermedad vascular cerebral; FA: Fibrilación auricular. AEE: Agentes estimuladores de la eritropoyesis. P: nivel de significación. NS: no significativo.

\subsection{Resultados del Estudio Transversal.}

\section{1.a. Niveles basales de FGe.}

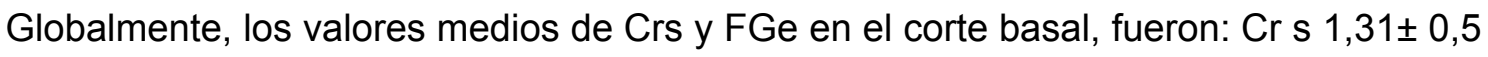

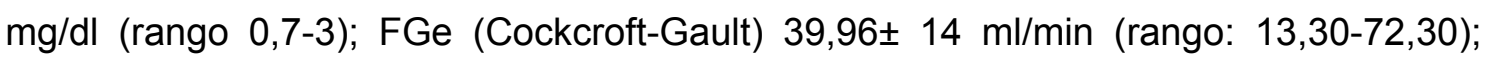

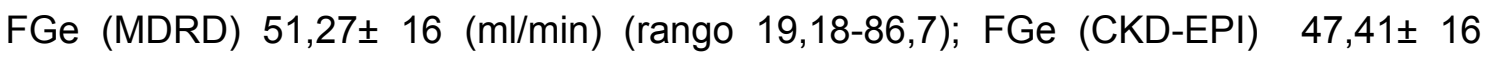
$\mathrm{ml} / \mathrm{min}$ (rango 16,30-85). Los niveles medios basales de $\mathrm{FGe}$, según los grupos de

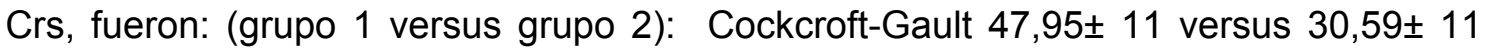
$\mathrm{ml} / \mathrm{min}(p=0,000) ;$ MDRD $63,56 \pm 10$ versus $40,15 \pm 12 \mathrm{ml} / \mathrm{min}(p=0,000)$ y CKD-EPI $59,87 \pm 10$ versus $36,13 \pm 11 \mathrm{ml} / \mathrm{min}(p=0,000)$ (figura 2 ).

Figura 2. Niveles basales de FGe según grupo

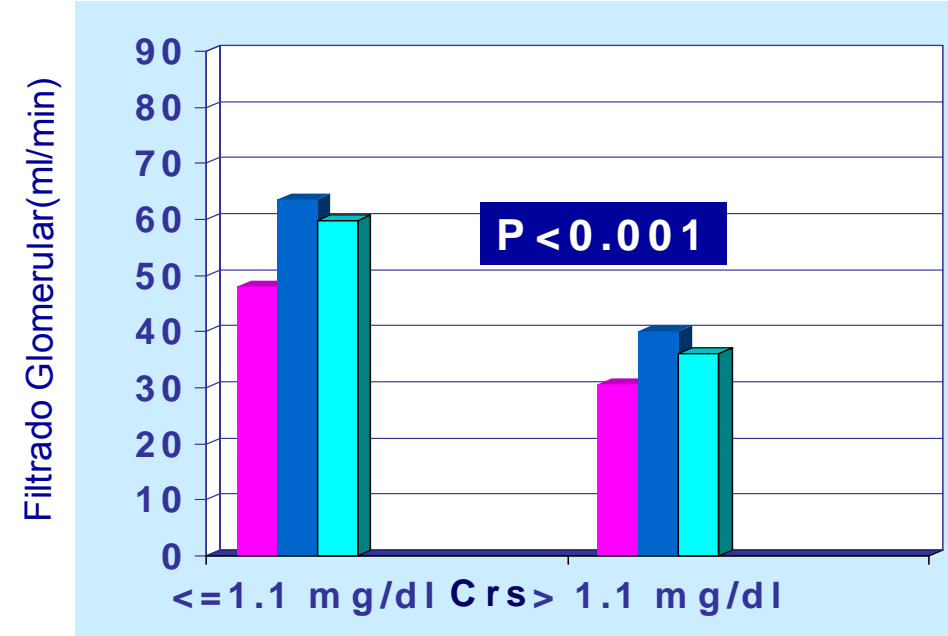

DCOCKROFT

- M DRD

$\square C K D-E P I$ 
En el total de la población estudiada, las medias de las diferencias en el FGe al comparar los métodos de estimación usados fueron: MDRD frente a CKD-EPI 3,85 $\pm 1,52 \mathrm{ml} / \mathrm{min}(\mathrm{IC} 95 \%: 3,51 ; 4,19),(p=0,000)$; MDRD frente a Cockcroft-Gault 13,76 \pm 8,61 ml/min (IC95\%:11,59;15,93) ( $p=0,000)$; CKD-EPI frente a Cockcroft-Gault $9,95 \pm 8,20 \mathrm{ml} / \mathrm{min}(\mathrm{IC} 95 \%: 7,88 ; 12,01)(p=0,000)$.

En el análisis por grupos, las medias de las diferencias al comparar los niveles de FGe según las fórmulas estudiadas han sido: Grupo 1: MDRD frente a CKD-EPI 3,68 $\pm 1,86$

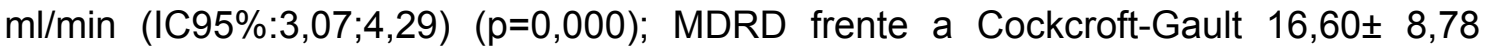
$\mathrm{ml} / \mathrm{min}($ IC95\%:13,54;19,67) $(\mathrm{p}=0,000)$; CKD-EPI frente a Cockcroft-Gault 12,91 $\pm 8,15$ $\mathrm{ml} / \min ($ IC95\%:10,00;15,82) $(p=0,000)$. En el grupo 2: MDRD frente a CKD-EPI

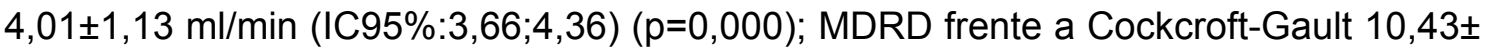
$7,20 \mathrm{ml} / \mathrm{min} \quad(I C 95 \%: 7,69 ; 13,17) \quad(p=0,000) ; \quad$ CKD-EPI frente a Cockcroft-Gault $6,48 \pm 6,60 \mathrm{ml} / \mathrm{min}(\mathrm{IC} 95 \%: 3,96 ; 8,99)(p=0,000)$.

En la tabla 5 se presentan los niveles medios de FGe según los grupos de estudio considerando el género.

En la tabla 6 se exponen los rangos de FGe basales teniendo en cuenta los grupos de Crs.

Tabla 5. Niveles medios de FGe basales en los grupos de estudio según el género.

\begin{tabular}{|l|l|l|l|}
\hline & varón & mujer & $p$ \\
\hline Grupo 1 (MDRD) (ml/min) & $78,01 \pm 7$ & $60,85 \pm 8$ & 0,000 \\
\hline Grupo 1 (CKD-EPI) (ml/min) & $71,83 \pm 7$ & $57,62 \pm 9$ & 0,001 \\
\hline Grupo 1 (Cockcroft-Gault) (ml/min) & $58,78 \pm 11$ & $45,63 \pm 9$ & 0,007 \\
\hline Grupo 2 (MDRD) (ml/min) & $43,60 \pm 15$ & $37,30 \pm 8$ & NS \\
\hline Grupo 2 (CKD-EPI) (ml/min) & $39,01 \pm 14$ & $33,76 \pm 8$ & NS \\
\hline Grupo 2 (Cockcroft-Gault) (ml/min) & $31,86 \pm 16$ & $29,69 \pm 6$ & NS \\
\hline
\end{tabular}

Grupo 1: Crs <=1,1 mg/dl; Grupo 2: Crs $>1,1 \mathrm{mg} / \mathrm{dl}$. NS: No significativo. 
Tabla 6. Rangos de FGe basales según los grupos de estudio.

\begin{tabular}{|l|l|l|}
\hline & Grupo 1 & Grupo 2 \\
\hline Mínimo-Máximo MDRD (ml/min) & $49,00-86,70$ & $19,18-62,90$ \\
\hline Mínimo- Máximo CKD-EPI (ml/min) & $44,00-85,00$ & $16,30-59,20$ \\
\hline Mínimo-Máximo Cockcroft-Gault (ml/min) & $25,00-72,30$ & $13,30-63,40$ \\
\hline
\end{tabular}

La distribución de los pacientes, según los estadios de ERC establecidos por las Guías KDOQI, según las fórmulas matemáticas derivadas de la Crs fue: Con la fórmula de Cockcroft-Gault (67): estadio 1: 0\%; estadio 2: 7,9\%; estadio 3: $66,6 \%$; estadio 4: 20,6\%; estadio 5: 4,7\%. Con la fórmula MDRD abreviada (65), la distribución seria: estadio 1: 0\%; estadio 2: $30 \%$; estadio 3: $60 \%$; estadio 4:10\%; estadio 5 : $0 \%$. Según la fórmula de CKD-EPI (23): estadio 1: 0\%; estadio 2: 16,25\%; estadio 3: 66,25\%; estadio 4: $17,5 \%$; estadio 5: 0\%.

4.1.b. Correlaciones basales de la Crs y las fórmulas con otros parámetros de ERC (urea, ácido úrico, potasio, calcio-fósforo y hematocrito).

La Crs se correlaciona con urea ( $r: 0,73 ; p<0,001)$, ácido úrico $(r: 0,49 ; p<0,001)$, calcio $(r:-0,24 ; p=0,032)$ y potasio $(r: 0,26 ; p=0,021)$.

Cockcroft-Gault se correlaciona con Crs (r:-0,67, p<0,001), urea (r:-0,61; p <0,001) . La fórmula MDRD se correlaciona con Crs ( $r:-0,84 ; p<0,001)$, urea (r:-0,68; $p<$ 0,001), ácido úrico $(r:-0,48 ; p<0,001)$ y la fórmula CKD-EPI se correlaciona con Crs ( $r:-0,84 ; p<0,001)$; urea $(r:-0,68, p<0,001)$, ácido úrico $(r:-0,514, p<0,001)$; pero ninguna de estas fórmulas se correlaciona con otras alteraciones típicas de ERC (potasio, calcio, fósforo, ni hematocrito). 


\section{1.c. Estudio de la proteinuria basal.}

En el grupo 1, no se detectó presencia de proteinuria en el sistemático y el cociente proteínas/creatinina en una micción matutina fue menor a $0.05 \mathrm{~g}$. En el grupo 2, la proteinuria basal fue de $0,31 \pm 0,51 \mathrm{~g} / 24$ horas, rango de $0-3 \mathrm{~g} / 24$ horas: el $87 \%$ de este grupo 2 tenía una proteinuria inferior a $0,5 \mathrm{~g} / 24$ horas, el 5,2\% tenía proteinuria entre 0,5-1g/24horas y el 7,8\% tenía una proteinuria entre $2-3 \mathrm{~g} / 24 \mathrm{~h}$.

4.1.d Filtrado glomerular basal y su asociación con la comorbilidad.

Los niveles basales de filtrado glomerular según la presencia o no de antecedentes cardiovasculares se recogen en la tabla 7. 
Tabla 7. Filtrado glomerular basal en el total de la población estudiada considerando los antecedentes cardiovasculares estudiados.

\begin{tabular}{|c|c|c|c|c|c|c|}
\hline & $\begin{array}{l}\text { FG (Cockroft) } \\
(\mathrm{ml} / \mathrm{min})\end{array}$ & $P$ & $\begin{array}{l}\mathrm{FG} \quad(\mathrm{MDRD}) \\
(\mathrm{ml} / \mathrm{min})\end{array}$ & $P$ & $\begin{array}{l}\mathrm{FG} \quad(\mathrm{CKD}-\mathrm{EPI}) \\
(\mathrm{ml} / \mathrm{min})\end{array}$ & $P$ \\
\hline HTA (no) (18.7\%) & $44 \pm 19$ & NS & $57 \pm 18$ & NS & $52 \pm 17$ & NS \\
\hline HTA (sí) (87.3\%) & $39 \pm 13$ & & $50 \pm 15$ & & $46 \pm 15$ & \\
\hline $\mathrm{Cl}$ (no) (83.3\%) & $41 \pm 13$ & $(0.014)$ & $53 \pm 16$ & $(0.022)$ & $49 \pm 16$ & $(0.023)$ \\
\hline $\mathrm{Cl}$ (sí) (16.7\%) & $29 \pm 11$ & & $41 \pm 13$ & & $37 \pm 13$ & \\
\hline IC (no) $(80.3 \%)$ & $41 \pm 14$ & NS & $53 \pm 16$ & $(0.028)$ & $49 \pm 16$ & $(0.019)$ \\
\hline IC (sí) $(19.7 \%)$ & $33 \pm 12$ & & $42 \pm 12$ & & $38 \pm 11$ & \\
\hline FA (no) $(76.4 \%)$ & $39 \pm 14$ & NS & $50 \pm 15$ & NS & $46 \pm 15$ & NS \\
\hline FA (sí) $(23.6 \%)$ & $39 \pm 13$ & & $54 \pm 17$ & & $50 \pm 17$ & \\
\hline EVC (no) $(72.6 \%)$ & $38 \pm 13$ & NS & $51 \pm 15$ & NS & $47 \pm 15$ & NS \\
\hline EVC (sí) (27.4\%) & $44 \pm 13$ & & $51 \pm 19$ & & $48 \pm 19$ & \\
\hline EVP (no) $(94.5 \%)$ & $40 \pm 13$ & NS & $51 \pm 16$ & NS & $47 \pm 16$ & NS \\
\hline EVP (sí) (5.5\%) & $35 \pm 21$ & & $44 \pm 17$ & & $40 \pm 17$ & \\
\hline $\mathrm{DM}(\mathrm{no}) 62.7 \%$ & $39 \pm 15$ & NS & $50 \pm 16$ & NS & $47 \pm 16$ & NS \\
\hline DM (sí) $37.7 \%$ & $40 \pm 12$ & & $52 \pm 15$ & & $48 \pm 15$ & \\
\hline
\end{tabular}

HTA: hipertensión arterial. Cl: Cardiopatía isquémica; IC: Insuficiencia cardíaca; FA: Fibrilación auricular; EVC: Enfermedad vascular cerebral; EVP: Enfermedad vascular periférica. DM: Diabetes mellitus. NS: no significativo. Datos expresados en media \pm SD. 


\section{1.e. Manifestaciones analíticas asociadas a la ERC.}

Cincuenta y seis pacientes (70\%) tenían un FGe (MDRD abreviado) $<60 \mathrm{ml} / \mathrm{min}$ (estadio 3: $60 \%$ y estadio 4: $10 \%$, estadio 5: $0 \%$ ). De ellos, quince pacientes $(26,8 \%)$ eran varones y cuarenta y una $(73,2 \%)$ eran mujeres.

Los varones tenían un FGe (MDRD) de $38,7 \pm 13 \mathrm{ml} / \mathrm{min}$ y las mujeres de $45 \pm 10$ $\mathrm{ml} / \mathrm{min}$ (no significativo). La media de edad \pm SD de los cincuenta y seis pacientes era de $83,7 \pm 6$ años. Los pacientes con $\mathrm{FG}<30 \mathrm{ml} / \mathrm{min}$ eran más ancianos respecto a los que tenían un $F G \geq 30 \mathrm{ml} / \mathrm{min}(87,6 \pm 6$ versus $83 \pm 6$ años $)(p=0,05)$.

Estos pacientes en estadio 3-4 de ERC presentaban los siguientes valores analíticos (media $\pm \mathrm{SD}$ ) : Cr s 1,46 \pm 0,5 mg/dl, urea $71,26 \pm 41 \mathrm{mg} / \mathrm{dl}$, ácido úrico 6,54 $\pm 1 \mathrm{mg} / \mathrm{dl}$, potasio $4,5 \pm 0,4 \mathrm{mEq} / \mathrm{L}, \mathrm{pH} 7,37 \pm 0,05$, bicarbonato $29 \pm 3 \mathrm{mEq} / \mathrm{L}, \mathrm{pCO} 251 \pm 8$ $\mathrm{mmHg}$, calcio $9,39 \pm 0,5 \mathrm{mg} / \mathrm{dl}$, fósforo $3,47 \pm 0,6 \mathrm{mg} / \mathrm{dl}$, fosfatasa alcalina $109 \pm 91$ $\mathrm{U} / \mathrm{L}$, colesterol $186 \pm 31 \mathrm{mg} / \mathrm{dl}$, triglicéridos $116 \pm 62 \mathrm{mg} / \mathrm{dl}$, hemoglobina 13,56 \pm 1 $\mathrm{g} / \mathrm{dl}$, hematocrito $41,2 \pm 5 \%$.

De ellos, el $16,1 \%$ recibían AEE, el $26,3 \%$ tratamiento con hierro, el $22,2 \%$ sales cálcicas y el $85,8 \%$ agentes antihipertensivos.

Los pacientes en tratamiento con AEE $(16,1 \%)$ tenían mayores niveles de Crs respecto a aquellos que no los tenían $(2,27 \pm 0,5$ versus $1,31 \pm 0,3 \mathrm{mg} / \mathrm{dl})(p=0,001)$; tenían menor FGe (MDRD: $28,2 \pm 8$ versus $46,2 \pm 10 \mathrm{ml} / \mathrm{min})(p=0,000)$ y mayor edad $(89,6 \pm 5$ versus $82,65 \pm 6$ años $),(p=0,002)$

Los pacientes en tratamiento con hierro presentaban menor FGe (MDRD) 33,2 \pm 9 versus $41,2 \pm 12 \mathrm{ml} / \mathrm{min}$ (no significativo) y mayores niveles de Crs $(1,92 \pm 0,4$ versus $1,55 \pm 0,5 \mathrm{mg} / \mathrm{dl})$ (no significativo).

Los pacientes con sales cálcicas tenían un FGe (MDRD) menor $(28,25 \pm 6$ versus $40,4 \pm 12 \mathrm{ml} / \mathrm{min})(p=0,07)$, mayores niveles de $\operatorname{Crs}(2,15 \pm 0,5$ versus $1,57 \pm 0,5 \mathrm{mg} / \mathrm{dl})$ 
( $p=0,099)$ y mayores niveles de fósforo sérico $(4,36 \pm 0,4$ versus $3,06 \pm 0,2 \mathrm{mg} / \mathrm{dl})(p=$ 0,000). No se encontraron diferencias significativas en niveles de calcio ni en la edad entre los pacientes que recibían ó no sales cálcicas.

En la tabla 8 se adjuntan los valores medios analíticos de los ancianos que tenían un FG (estimado por MDRD) $<60 \mathrm{ml} / \mathrm{min}$ en el periodo basal $(\mathrm{N}=56)$. 
Tabla 8. Niveles medios de parámetros analíticos asociados a la ERC en ancianos con MDRD $<60 \mathrm{ml} / \mathrm{min}(\mathrm{N}=56)$.

\begin{tabular}{|c|c|c|c|}
\hline & $\begin{array}{l}\mathrm{FG} \geq 30 \mathrm{ml} / \mathrm{min} \\
(\mathrm{N}=48)\end{array}$ & $\begin{array}{l}\mathrm{FG}<30 \mathrm{ml} / \mathrm{min} \\
(\mathrm{N}=8)\end{array}$ & $P$ \\
\hline Cr s (mg/dl) & $1,3 \pm 0,3$ & $2,47 \pm 0,4$ & $<0,001$ \\
\hline Urea $(\mathrm{mg} / \mathrm{dl})$ & $58,5 \pm 19$ & $140 \pm 59$ & $<0,001$ \\
\hline Ácido úrico (mg/dl) & $6,26 \pm 1$ & $8,22 \pm 2$ & 0,022 \\
\hline Sodio (mEq/L) & $139 \pm 2$ & $138 \pm 2$ & N.S \\
\hline Potasio (mEq/L) & $4,43 \pm 0,4$ & $4,91 \pm 0,38$ & 0,009 \\
\hline $\mathrm{pH}$ & $7,37 \pm 0,05$ & $7,36 \pm 0,06$ & N.S \\
\hline $\mathrm{pCO} 2(\mathrm{mmHg})$ & $51 \pm 9$ & $51 \pm 3$ & N.S \\
\hline Bicarbonato (mEq/L) & $29,1 \pm 3$ & $28,8 \pm 1$ & N.S \\
\hline Calcio (mg/dl) & $9,44 \pm 0,5$ & $9,12 \pm 0,51$ & N.S \\
\hline Fósforo (mg/dl) & $3,4 \pm 0,5$ & $3,86 \pm 0,64$ & N.S \\
\hline $\begin{array}{l}\text { Fosfatasa Alcalina } \\
(\mathrm{U} / \mathrm{L})\end{array}$ & $111 \pm 98$ & $92 \pm 16$ & N.S \\
\hline Colesterol (mg/dl) & $187 \pm 32$ & $181 \pm 23$ & N.S \\
\hline Triglicéridos (mg/dl) & $119 \pm 66$ & $97 \pm 21$ & N.S \\
\hline Hemoglobina (g/dl) & $13,45 \pm 1$ & $14,28 \pm 2$ & N.S \\
\hline Hematocrito (\%) & $40,89 \pm 5$ & $43 \pm 6$ & N.S \\
\hline $\begin{array}{l}\text { Hierro sérico } \\
(\mathrm{mcg} / \mathrm{dl})\end{array}$ & $68 \pm 30$ & $64 \pm 18$ & N.S \\
\hline Ferritina (ng/ml) & $161 \pm 200$ & $111 \pm 85$ & N.S \\
\hline I.Saturación (\%) & $23,24 \pm 10.18$ & $23,82 \pm 6.22$ & N.S \\
\hline
\end{tabular}

Comparación de medias ( $U$ de Mann-Withney). P: nivel de significación. NS: no significativo. 
Se comprueba que los pacientes con FGe (MDRD) $<30 \mathrm{ml} / \mathrm{min}$ (estadio 4 de ERC) tenían niveles plasmáticos de creatinina, urea, ácido úrico y potasio más altos de forma significativa, pero no existían diferencias significativas para el resto de manifestaciones asociadas a la ERC al comparar los grupos de FG (MDRD), si bien un porcentaje de pacientes de este grupo recibían tratamiento con AEE y sales cálcicas.

- Manifestaciones analíticas en pacientes con Enfermedad Renal Oculta:

Entre los pacientes con MDRD $<60 \mathrm{ml} / \mathrm{min}$, dieciocho tenían Crs en rango normal (100\% mujeres) mientras que treinta y ocho tenían la Crs basal $>1,1 \mathrm{mg} / \mathrm{dl}$ (quince varones [39,5\%], y veintitrés mujeres [60,5\%], $p=0,001)$.

Las dieciocho pacientes con Crs normal y MDRD <60ml/min ("enfermedad renal oculta") tenían una edad media de $81,33 \pm 6$ años. La media de sus niveles analíticos en sangre fueron: urea $42,92 \pm 7,6 \mathrm{mg} / \mathrm{dl}$; ácido úrico $5,33 \pm 1 \mathrm{mg} / \mathrm{dl}$; calcio $9,40 \pm 0,35$ $\mathrm{mg} / \mathrm{dl}$; fósforo $3,60 \pm 0,77 \mathrm{mg} / \mathrm{dl}$; potasio $4,44 \pm 0,41 \mathrm{mEq} / \mathrm{L} ; \mathrm{pH} 7,39 \pm 0,05 ; \mathrm{pCO} 2$ $50,78 \pm 10 \mathrm{mmHg}$; bicarbonato $30,07 \pm 3 \mathrm{mEq} / \mathrm{L}$; hematocrito $40,31 \pm 4,7 \%$. En orina no

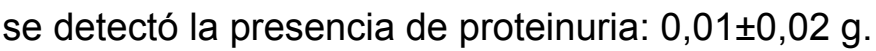

Respecto al tratamiento de las dieciocho pacientes con enfermedad renal oculta, los diuréticos eran los fármacos más empleados $(66,7 \%)$, seguidos por los inhibidores del sistema renina-angiotensina-aldosterona $(38,9 \%)$, los betabloqueantes eran los menos empleados $(5,6 \%)$. Sólo un $11,1 \%$ empleaban terapia con hierro y ninguna de ellas recibía terapia con AEE. 
4.1. f. Análisis de los niveles de ácido úrico en el total de la población estudiada en el periodo basal.

El ácido úrico presentó una distribución normal. Los niveles medios de ácido úrico en el periodo basal fueron de $6,11 \pm 1,7 \mathrm{mg} / \mathrm{dl}$ (rango $2,8-11$ ) y su mediana fue de 5,85 $\mathrm{mg} / \mathrm{dl}(\mathrm{P} 25=4,90 \mathrm{mg} / \mathrm{dl}, \mathrm{P} 75=7,07 \mathrm{mg} / \mathrm{dl})$. En la tabla 9 se muestra la asociación entre los niveles de ácido úrico y el género, los antecedentes cardiovasculares y el empleo de diuréticos. Se comprueba en la tabla 9 que los pacientes con antecedentes de insuficiencia cardíaca tenían niveles de ácido úrico más elevados de forma significativa.

TABLA 9. Niveles medios de ácido úrico $(\mathrm{mg} / \mathrm{dl})$ en el periodo basal en toda la población estudiada según antecedentes cardiovasculares, empleo de diuréticos y género.

\begin{tabular}{|l|l|l|l|}
\hline & Sin antecedentes & Con antecedentes & P \\
\hline Hipertensión Arterial & $5,87 \pm 1,81$ & $6,16 \pm 1,72$ & 0,56 \\
\hline Diabetes Mellitus & $6,25 \pm 1,85$ & $5,84 \pm 1,53$ & 0,314 \\
\hline Insuficiencia Cardiaca & $5,90 \pm 1,71$ & $7,00 \pm 1,74$ & 0,031 \\
\hline Cardiopatía Isquémica & $5,96 \pm 1,66$ & $6,93 \pm 1,94$ & 0,075 \\
\hline Diuréticos & $6,00 \pm 1,84$ & $6,17 \pm 1,70$ & 0,70 \\
\hline Género & Varón: $6,51 \pm 1,55$ & Mujer: $5,93 \pm 1,78$ & 0,167 \\
\hline
\end{tabular}




\subsection{Resultados del Seguimiento Prospectivo.}

4.2.a. Resultados del seguimiento a un año.

4.2.a.1. Datos de función renal al año.

Setenta y dos pacientes (90\%) completaron el estudio al año: treinta y seis pacientes pertenecientes a cada uno de los grupos. Globalmente estos ancianos presentaban los siguientes valores de función renal (basal versus un año): Creatinina (mg/dl) 1,29 $\pm 0,5$ versus $1,31 \pm 0,5$ (no significativo); MDRD ( $\mathrm{ml} / \mathrm{min}$ ) $52,13 \pm 16$ versus $50,95 \pm 16$ (no significativo). La evolución de la función renal (basal versus un año) según los grupos de estudio fue la siguiente: Creatinina (mg/dl): grupo 1, 0,95 $\pm 0,09$ versus $1,01 \pm 0,15$;

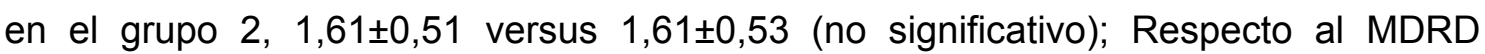
( $\mathrm{ml} / \mathrm{min}$ ) los valores fueron los siguientes: Grupo $1,63,75 \pm 10$ versus $60,52 \pm 11$; en el grupo $2,40,82 \pm 12$ versus $41,64 \pm 15$ (no significativo). En la figura 3 se muestra la evolución de la función renal en los setenta y dos pacientes que llegaron al año de estudio. Puede comprobarse que los niveles de Crs y de FG (MDRD) no variaron significativamente respecto a los basales en cada uno de los grupos. Ningún paciente inició terapia sustitutiva renal en este periodo de análisis. 
Figura 3. Evolución de la función renal al año
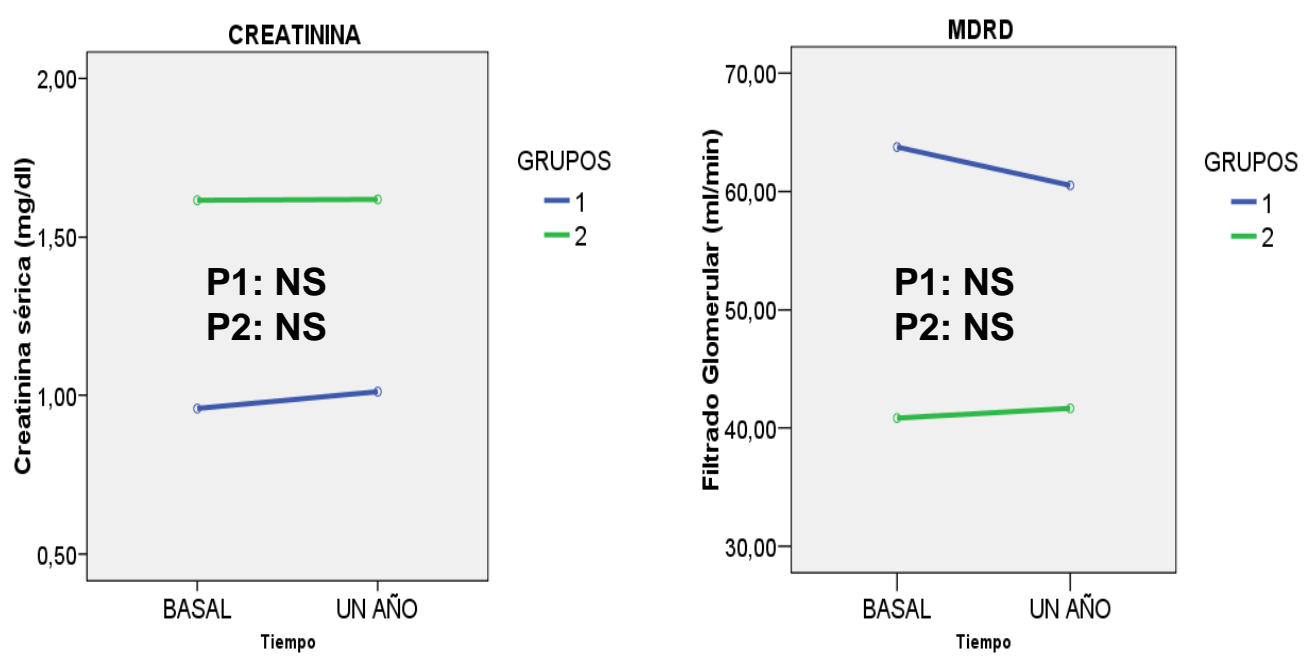

Grupo 1: Creatinina sérica <=1,1 mg/dl; Grupo 2: Creatinina sérica > 1,1 mg/dl.

P1: Cambios de la variable estudiada en el tiempo de seguimiento en el global de la población.

P2: Diferencias en el cambio en ambos grupos.

\section{2.a.2. Datos de proteinuria al año.}

Globalmente no se encontraron cambios significativos en el seguimiento de la proteinuria (basal versus un año): $0,12 \pm 0,33$ versus $0,14 \pm 0,35 \mathrm{~g} / 24 \mathrm{~h}$. Los pacientes del grupo 1 seguían sin tener proteinuria al cabo de un año.

La evolución de la proteinuria en el grupo 2 tampoco mostró variaciones significativas al cabo de un año: basal: $0,14 \pm 0,23 \mathrm{~g} / 24$ horas (rango $0-3 \mathrm{~g} / 24 \mathrm{~h}$ ) versus un año: 0,23 $\pm 0,46 \mathrm{~g} / 24 \mathrm{~h}$ (rango $0-1,96 \mathrm{~g} / 24 \mathrm{~h}$ ).

4.2.a.3. Evolución de parámetros analíticos asociados a la enfermedad renal crónica. Globalmente no se detectaron variaciones significativas en el seguimiento del hematocrito (basal versus un año): $41,85 \pm 4$ versus $41,65 \pm 4 \%$. 
En la figura 4 se muestra la evolución del hematocrito al año: puede comprobarse que los pacientes del grupo 1 incrementaron sus niveles mientras que en pacientes del grupo 2 los niveles de hematocrito disminuyeron en el tiempo $(p=0,010)$. Sin embargo, los niveles medios de hematocrito fueron superiores al $35 \%$ tanto en el periodo basal como al año de seguimiento.

No se detectaron variaciones significativas en la evolución global del calcio (basal versus un año): 9,39 $\pm 0,44$ versus $9,41 \pm 0,49 \mathrm{mg} / \mathrm{dl}$ ni tampoco en la evolución de niveles de fósforo sérico: $3,38 \pm 0,62$ versus $3,37 \pm 0,42 \mathrm{mg} / \mathrm{dl}$.

\section{Figura 4 . Evolución del hematocrito al año}

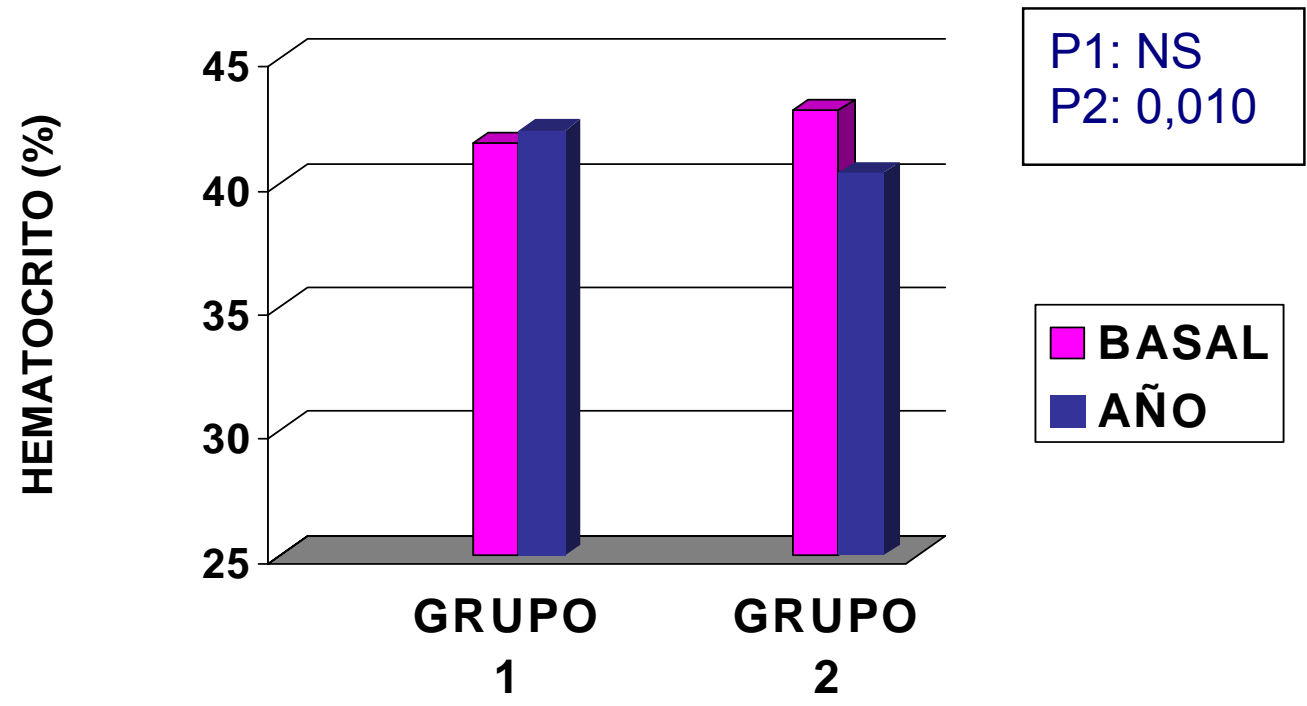

Grupo 1: Creatinina sérica $<=1,1 \mathrm{mg} / \mathrm{dl}$; Grupo 2: Creatinina sérica $>1,1 \mathrm{mg} / \mathrm{dl}$.

$\mathrm{P} 1$ : Cambios de la variable en el tiempo de seguimiento en el global de la población.

P2: Diferencias en el cambio en ambos grupos.

\section{2.a.4. Análisis de los tratamientos establecidos al año.}

El $82,8 \%$ de los pacientes recibían agentes antihipertensivos, el $27,7 \%$ estatinas, el $10,3 \%$ sales cálcicas y el $14,5 \%$ hierro. No hubo diferencias significativas en la utilización de estos fármacos al comparar ambos grupos. Sólo algunos pacientes del grupo 2 recibían AEE $(p<0,003)$; eran el $23 \%$ del total de ese grupo: se trataba de 
pacientes de más edad ( $89 \pm 5$ versus $81 \pm 6$ años, $p<0,001$ ), con niveles más altos de Crs $(2,0 \pm 0,5$ versus $1,2 \pm 0,2 \mathrm{mg} / \mathrm{dl} ; \mathrm{p}<0,001)$ y menor nivel de MDRD $(32 \pm 10$ versus $54 \pm 15 \mathrm{ml} / \mathrm{min} ; \mathrm{p}<0,001)$.

\section{2.a.5 Morbimortalidad al año.}

Antes de completar el año de estudio, ocho pacientes (10\%) habían fallecido: dos correspondían al grupo 1 y seis al grupo 2. Las causas del fallecimiento fueron: cuatro por deterioro estado general, dos por complicaciones de fracturas, uno por tumor y otro por ictus cerebral. No hubo diferencias significativas en mortalidad, número de ingresos ni eventos cardiovasculares al comparar ambos grupos.

\section{2.b. Resultados del seguimiento a dos años.}

4.2.b.1. Datos de función renal a los dos años.

Al cabo de dos años, sesenta y dos pacientes $(77,5 \%)$ continuaban en el estudio: treinta y dos pertenecientes al grupo 1 y treinta correspondían al grupo 2. Los datos globales de evolución de pacientes que siguen en el estudio a los dos años fueron (basal versus dos años): Creatinina $1,27 \pm 0,49$ versus $1,26 \pm 0,44 \mathrm{mg} / \mathrm{dl}$ (no significativo). Respecto a MDRD: $52,16 \pm 15$ versus $51,92 \pm 15 \mathrm{ml} / \mathrm{min}$ (no significativo). La evolución de la función renal (basal versus dos años) según los grupos de estudio fue la siguiente: Creatinina (mg/dl): grupo 1, 0,95 $\pm 0,10$ versus $0,97 \pm 0,14$; en el grupo 2, $1,59 \pm 0,53$ versus $1,55 \pm 0,45$ (no significativo); Respecto al MDRD (ml/min) los valores fueron los siguientes: grupo $1,62,75 \pm 10$ versus $61,75 \pm 11$; en el grupo 2 , $41,22 \pm 12$ versus $41,77 \pm 12$ (no significativo).

En la figura 5 se muestra la evolución de la función renal al cabo de dos años de los sesenta y dos ancianos que completaron este periodo. En esta figura se comprueba que, a los dos años, los niveles de Crs y de FGe (MDRD) no variaban 
significativamente respecto a sus valores basales; tampoco existían diferencias significativas en el cambio de la pendiente en cada uno de los grupos.

Ningún paciente precisó iniciar terapia sustitutiva renal en este periodo de análisis.

Figura 5. Evolución de la función renal a dos años
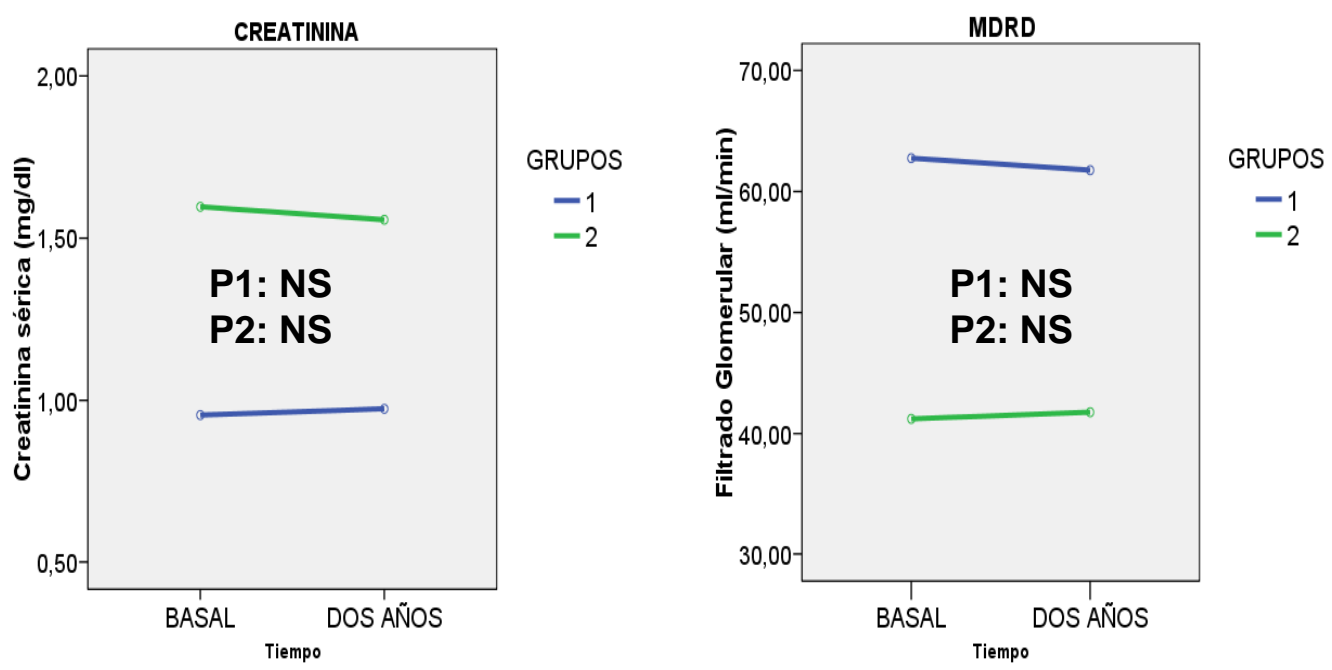

Grupo 1: Creatinina sérica <=1,1 mg/dl; Grupo 2: Creatinina sérica $>1,1 \mathrm{mg} / \mathrm{dl}$.

$\mathrm{P} 1$ : Cambios de la variable estudiada en el tiempo de seguimiento en el global de la población.

P2: Diferencias en el cambio en ambos grupos.

4.2.b.2. Datos de proteinuria a los dos años.

No se detectaron variaciones significativas en la evolución de la proteinuria en el conjunto de los sesenta y dos pacientes que llegaron a los dos años (basal: 0,16 \pm 0,39 versus dos años: $0,23 \pm 0,61 \mathrm{~g} / 24 \mathrm{~h}$ ).

Los pacientes del grupo 1 seguían a los dos años sin presentar proteinuria. La evolución de la proteinuria en el grupo 2 tampoco mostró variaciones significativas al 
cabo de dos años: basal, $0,31 \pm 0,51 \mathrm{~g} / 24$ horas versus dos años, $0,41 \pm 0,81$ g/24horas.

4.2.b.3. Evolución de parámetros analíticos asociados a la enfermedad renal crónica. De forma global, no se detectaron cambios significativos a los dos años de seguimiento en lo referente a hematocrito, calcio-fósforo, potasio, ácido úrico. Sólo se detectó un incremento significativo en los valores de urea (basal, $57,40 \pm 29$ versus dos años, $61,95 \pm 31 \mathrm{mg} / \mathrm{dl}, \mathrm{p}=0,041)$.

En el análisis por grupos no encontramos variaciones significativas en la evolución de los parámetros analíticos estudiados (calcio-fósforo, potasio, ácido úrico y urea).

En la figura 6 se puede comprobar que el grupo 2 presentó un descenso significativo de hematocrito a los dos años $(p=0,014)$, mientras que en el grupo 1 no hubo cambios significativos.

Sólo el 23,3\% de pacientes con AEE (grupo 2) lo estaban desde el inicio del estudio con un hematocrito basal de $42,24 \pm 5 \%$ y a los dos años $39,8 \pm 4 \%(p=0,014)$, manteniéndose los mismos pacientes con los AEE a los dos años. Los pacientes del grupo 1 que no precisaban AEE de forma basal, al cabo de los dos años seguían sin necesitarlos, con niveles de hematocrito basal, $41,6 \pm 3 \%$ y a los dos años, $42 \pm 3 \%$. 


\section{Figura 6 . Evolución del hematocrito a los dos años}

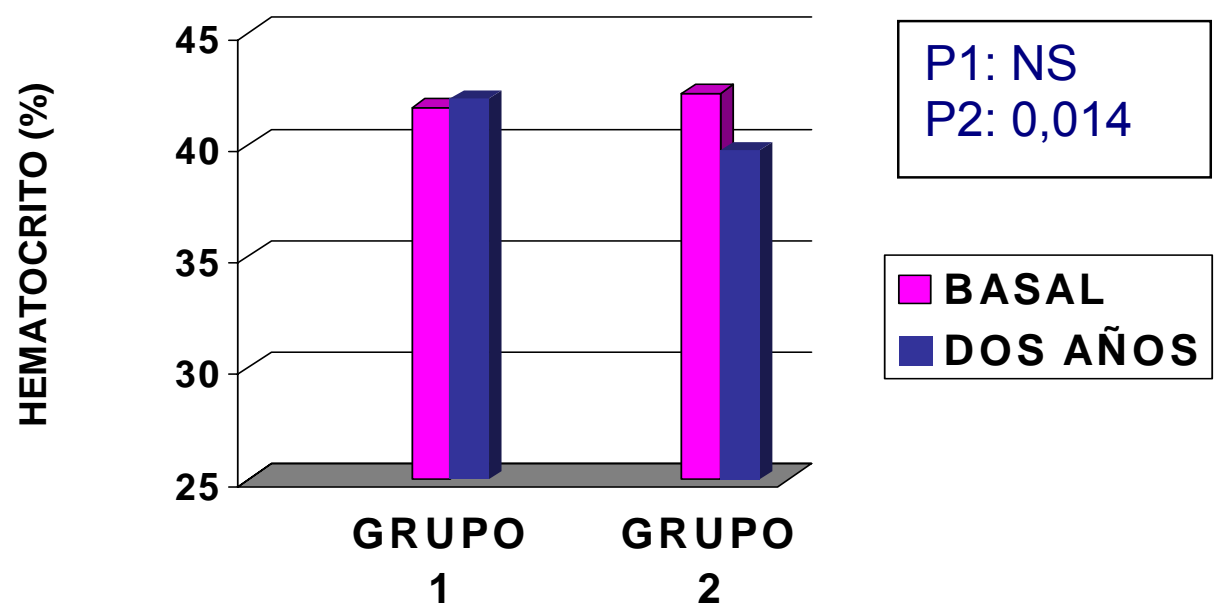

Grupo 1: Creatinina sérica $<=1,1 \mathrm{mg} / \mathrm{dl}$; Grupo 2: Creatinina sérica $>1,1 \mathrm{mg} / \mathrm{dl}$. P1: Cambios de la variable en el tiempo de seguimiento en global de población.

P2: Diferencias en el cambio en ambos grupos.

4.2.b.4. Análisis de los cambios en el tratamiento establecidos a los dos años.

A los dos años de seguimiento, el $89,1 \%$ de los pacientes recibían antihipertensivos (diuréticos el $71 \%$ de ellos), el $21,7 \%$ estatinas; el $21,7 \%$ sales cálcicas y el $18,6 \%$ hierro oral. No hubo diferencias significativas en la frecuencia al comparar ambos grupos. Sólo hubo diferencias significativas en el uso de AEE: el 23,3\% de los pacientes del grupo 2 que los recibían al inicio del estudio los siguieron recibiendo durante los dos años, frente a ninguno del grupo $1(p=0,014)$; se trataba de pacientes con niveles más altos de Crs $(2,10 \pm 0,29$ versus $1,14 \pm 0,33 \mathrm{mg} / \mathrm{dl} ; \mathrm{p}<0,001)$ y menor FGe MDRD (30 \pm 7 versus $55 \pm 14 \mathrm{ml} / \mathrm{min} ; \mathrm{p}<0,001)$. 


\section{2.b.5. Morbimortalidad a dos años.}

No se encontraron diferencias significativas en los eventos cardiovasculares ocurridos en este periodo de tiempo al comparar los grupos de estudio.

En total, antes de completar los dos años de estudio, la mortalidad se había incrementado hasta dieciocho pacientes $(22,5 \%)$ : seis por deterioro del estado general, tres por infecciones, dos por complicaciones de fracturas, dos por ictus cerebral, uno por tumor, uno de causa cardiaca y tres de causa desconocida. Entre los pacientes que fallecieron, seis de ellos pertenecían al grupo 1 y doce correspondían al grupo 2 (no significativo). No se encontraron diferencias significativas en la mortalidad al comparar sexos (diez de los pacientes fallecidos eran mujeres).

4.2.c. Resultados del seguimiento a tres años.

4.2.c.1. Datos de función renal a tres años.

Cincuenta y seis pacientes $(70 \%)$ continuaron en el estudio a los tres años: treinta del grupo 1 y veintiséis del grupo 2. Los datos globales de evolución de la función renal de estos pacientes que siguen en estudio a los tres años fueron (basal versus tres años):

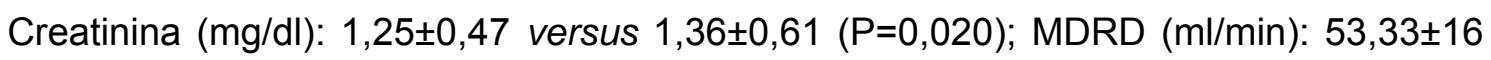
versus $50,23 \pm 17(P=0,032)$. En la tabla 10 se reflejan los resultados de la función renal considerando los grupos. 
Tabla 10. Evolución de función renal a los tres años de seguimiento.

\begin{tabular}{|l|l|l|l|l|}
\hline & $\begin{array}{l}\text { GRUPO1 } \\
\mathrm{N}=30\end{array}$ & $\begin{array}{l}\text { GRUPO2 } \\
\mathrm{N}=26\end{array}$ & $\mathrm{P}(1)$ & $\mathrm{P}(2)$ \\
\hline $\begin{array}{l}\text { Crs basal } \\
\text { Crs tres años } \\
\text { (mg/dl) }\end{array}$ & $0.94 \pm 0.1$ & $1.55 \pm 0.5$ & 0,022 & $\mathrm{NS}$ \\
$1.0 \pm 0.1$ & $1.71 \pm 0.6$ & & \\
\hline $\begin{array}{l}\text { FGe(MDRD) basal } \\
\text { FGe (MDRD) tres años } \\
\text { (ml/min) }\end{array}$ & $60.75 \pm 13$ & $40.11 \pm 14$ & 0,033 & $\mathrm{NS}$ \\
\hline
\end{tabular}

$\left(^{*}\right)$ : Los grupos son diferentes en el periodo basal $(p=0,000)$.

$P(1)$ : cambios de la variable estudiada en el tiempo de seguimiento. $P(2)$ : diferencias en el cambio en ambos grupos. NS: no significativo.

Aunque en nuestro estudio se detectó un lento deterioro de la función renal con el paso del tiempo $(p=0,022)$, este deterioro ocurrió de la misma manera en cada uno de los grupos de estudio (no significativo) (figura 7).

Ningún paciente del estudio había iniciado programa de TSR a los tres años. 
Figura 7. Evolución de la función renal a tres años
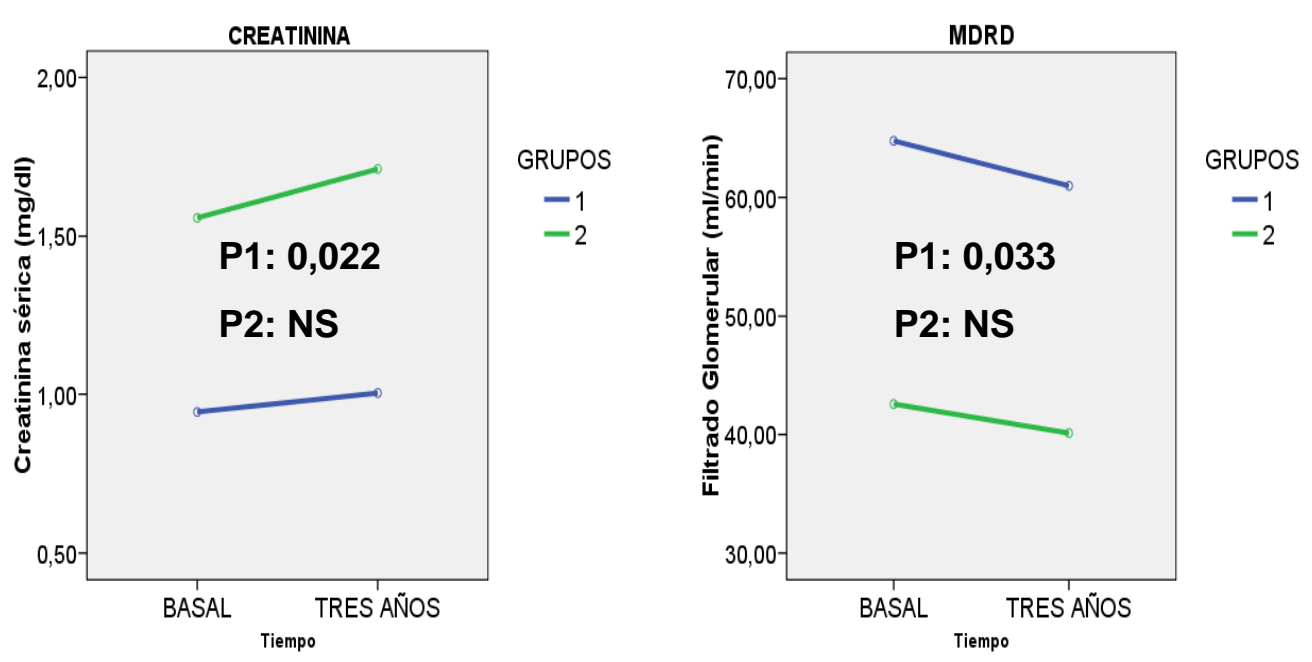

Grupo 1: Creatinina sérica <=1,1 mg/dl; Grupo 2: Creatinina sérica > 1,1 mg/dl.

P1: Cambios de la variable estudiada en el tiempo de seguimiento en el global de la población.

P2: Diferencias en el cambio en ambos grupos.

4.2.c.2. Resultados de la proteinuria a los tres años.

No se encontraron variaciones significativas en la evolución de la proteinuria (basal:0,15 $\pm 0,38$ versus tres años: 0,26 $\pm 0,60 \mathrm{~g} / 24 \mathrm{~h}$ ). Los pacientes del grupo 1 seguían sin presentar proteinuria.

Al considerar el impacto de la presencia de proteinuria en el periodo basal sobre los valores de creatinina a los tres años, encontramos que los pacientes con proteinuria en periodo basal presentaron un incremento significativo de la creatinina a los tres años (figura 8). 


\section{Figura 8. Evolución de Creatinina sérica según proteinuria}

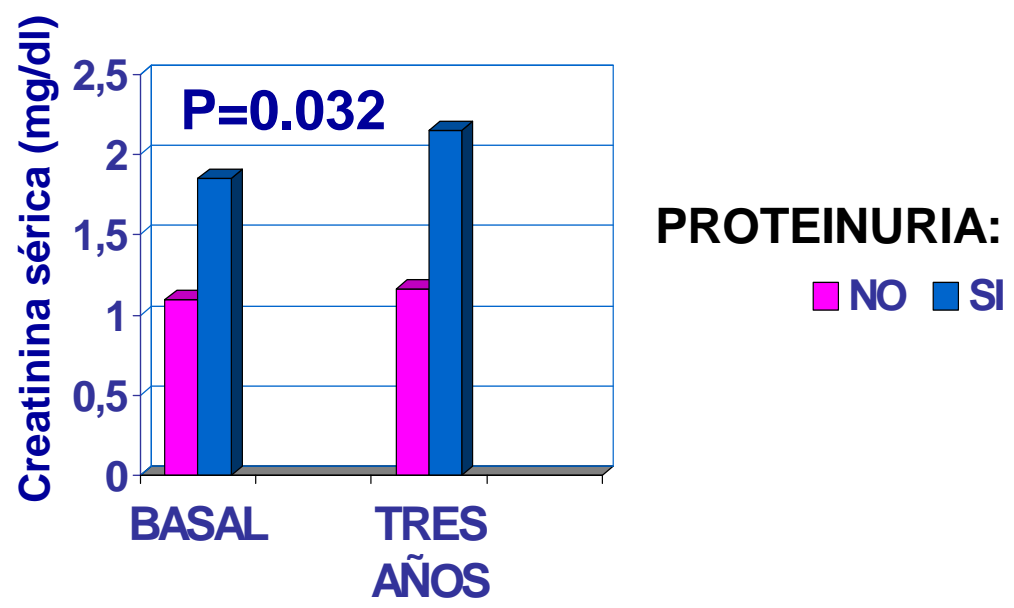

4.2.c.3. Parámetros analíticos asociados a la enfermedad renal crónica.

En toda la población, los parámetros analíticos que cambiaron a los tres años de forma significativa fueron (basal versus tres años): Urea (mg/dl): $57,92 \pm 30$ versus $66,75 \pm 40$, $p=0,006$; Calcio (mg/dl): $9,37 \pm 0,40$ versus $9,20 \pm 0,50, p=0,016$ y hematocrito $(\%)$ : $41,82 \pm 4$ versus $39,93 \pm 3, p=0,001$. No se encontraron cambios para otros parámetros analizados (ácido úrico, potasio, fósforo).

En el análisis por grupos sólo se detectaron cambios significativos en lo referente a la evolución del hematocrito (figura 9). 


\section{Figura 9 . Evolución del hematocrito a los tres años}

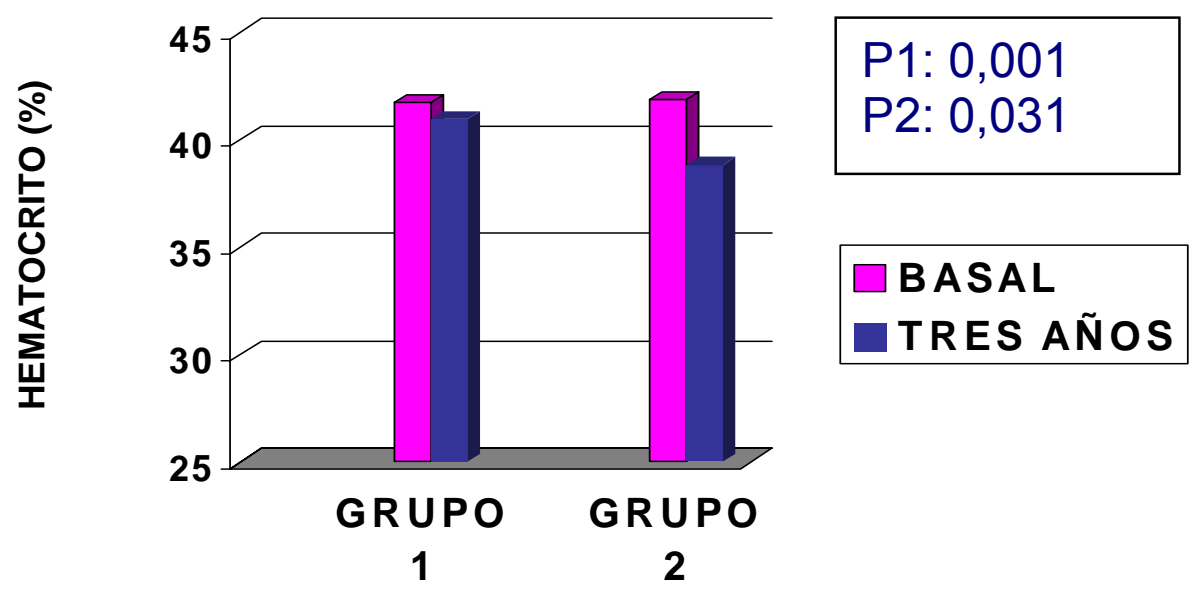

Grupo 1: Creatinina sérica <=1,1 mg/dl; Grupo 2: Creatinina sérica $>1,1 \mathrm{mg} / \mathrm{dl}$. $\mathrm{P} 1$ : Cambios de la variable en el tiempo de seguimiento en el global de población. P2: Diferencias en el cambio en ambos grupos.

4.2.c.4. Análisis de los cambios en el tratamiento establecidos a los tres años.

En este corte, los diuréticos $(66 \%)$ y los betabloqueantes $(7,14 \%)$ seguían siendo los agentes antihipertensivos más y menos utilizados respectivamente.

Sólo cuatro pacientes empleaban AEE a los tres años (todos del grupo 2, $p=0,044$ ). No se encontraron variaciones significativas en el uso de sales de hierro, cálcicas ni estatinas entre los grupos.

En la tabla 11 se incluye información relacionada con los tratamientos antihipertensivos en el periodo basal y a los tres años. 
Tabla 11. Comparativa entre tratamientos al inicio del estudio y a los tres años.

\begin{tabular}{|l|l|l|l|}
\hline & Grupo 1 & Grupo 2 & P \\
\hline IECA: & & & \\
Basal & $42.1 \%$ & $34.1 \%$ & NS \\
Tres años & $36.0 \%$ & $34.6 \%$ & NS \\
& & & \\
\hline ARAll: & & & NS \\
Basal & $18.4 \%$ & $19,5 \%$ & NS \\
Tres años & $20.0 \%$ & $19.2 \%$ & NS \\
\hline Diuréticos: & & & NS \\
Basal & $63.2 \%$ & $73.2 \%$ & \\
Tres años & $80.0 \%$ & $65.2 \%$ & NS \\
\hline BB: & & & NS \\
Basal & $7.9 \%$ & $7.3 \%$ & NS \\
Tres años & $7.7 \%$ & $7.7 \%$ & NS \\
\hline Calcioantagonistas: & & $15,4 \%$ & NS \\
Basal & $18,4 \%$ & $26,9 \%$ & 0,038 \\
Tres años & $15,4 \%$ & & \\
\hline Alfabloqueantes: & & $22 \%$ & \\
Basal & $7,9 \%$ & $30,8 \%$ & \\
Tres años & $7,7 \%$ & &
\end{tabular}

IECA: Inhibidores del sistema renina-angiotensina-aldosterona; ARAll: Antagonistas de los receptores de angiotensina II. BB: Betabloqueantes.

\section{2.c.5. Morbimortalidad a tres años.}

Veinticuatro pacientes (30\%) habían fallecido antes de los tres años de seguimiento: ocho $(21,1 \%)$ del grupo 1 y dieciséis $(38,1 \%)$ del grupo $2(P=0,097)$. Las causas del exitus fueron: siete por deterioro estado general; cuatro por ictus; tres por tumores y tres por infecciones, dos por complicaciones de fracturas, dos de causas cardíacas y tres de causa desconocida.

Únicamente la edad y la proteinuria fueron los factores predictores de mortalidad a los tres años como se muestra en el análisis de Cox (tabla 12).

Tabla 12. Análisis de Cox's hazards para mortalidad.

\begin{tabular}{|c|c|c|c|c|}
\hline & Exp B & inferior IC95 & Superior IC95 & $\mathrm{P}$ \\
\hline Edad (años) & 1,080 & 1,001 & 1,165 & 0,048 \\
\hline Proteinuria (g/24h) & 2,127 & 1,077 & 4,201 & 0,03 \\
\hline
\end{tabular}


4.2.d. Resultados del seguimiento a cinco años.

4.2.d.1. Datos de función renal a cinco años.

Tras cinco años de seguimiento, treinta y nueve pacientes (48,8\%), (diez varones), con una media de edad de $84,94 \pm 6$ años $(74-101)$ concluyeron el estudio.

Los datos globales de evolución de la función renal (basal versus cinco años) de los pacientes que llegaron a los cinco años fueron : Crs (mg/dl):1,15 $\pm 0,41$ versus $1,21 \pm$ 0,49 (no significativo); MDRD ( $\mathrm{ml} / \mathrm{min}$ ): $57,47 \pm 15$ versus 54,86 \pm 17 (no significativo). La evolución de la función renal por grupos se muestra en la figura 10.

Figura 10. Evolución de la función renal a cinco años
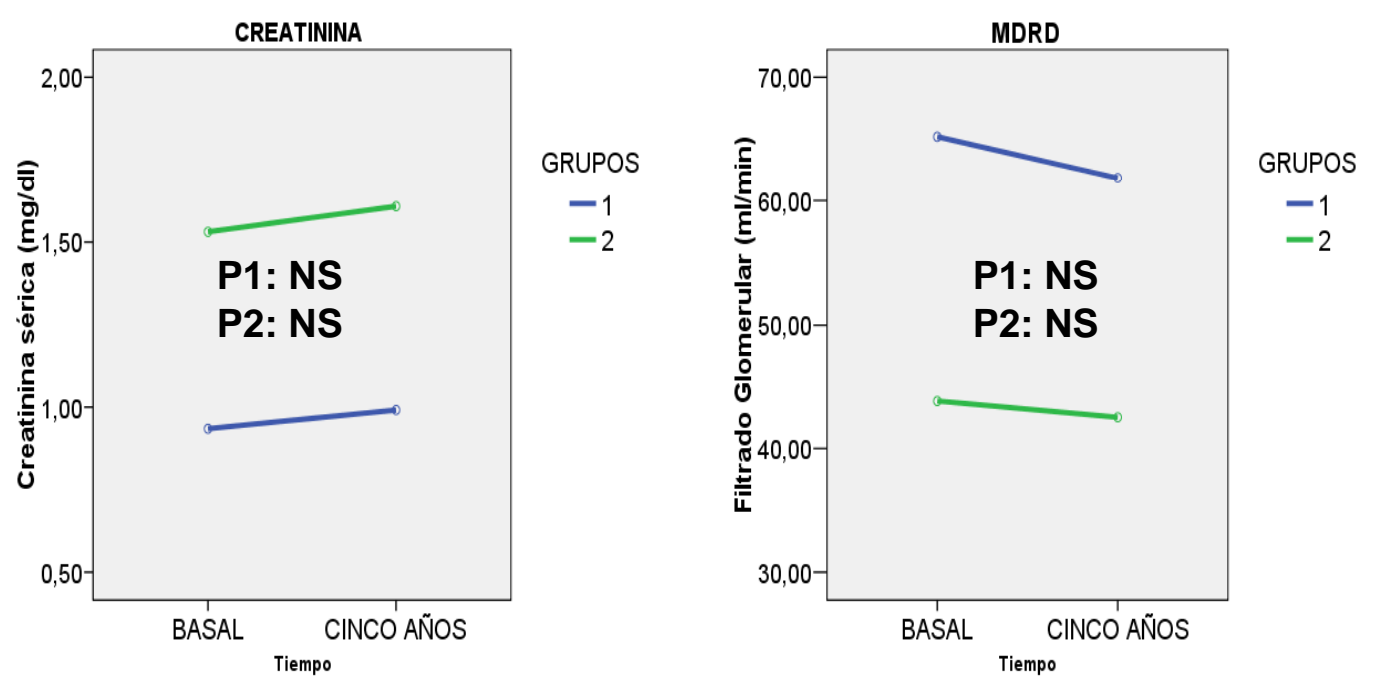

Grupo 1: Creatinina sérica <=1,1 mg/dl; Grupo 2: Creatinina sérica > 1,1 mg/dl.

$\mathrm{P} 1$ : Cambios de la variable estudiada en el tiempo de seguimiento en el global de la población.

P2: Diferencias en el cambio en ambos grupos. 
En el conjunto de los supervivientes, el FG (MDRD) descendió a un ritmo promedio de 0,52 ml/min/año; cuando se analizó por separado el descenso en ambos grupos, en el

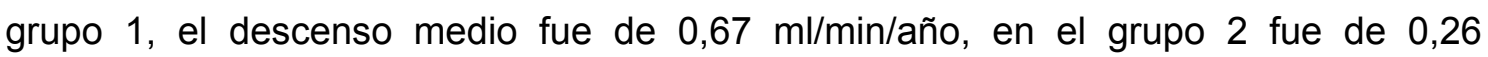
$\mathrm{ml} / \mathrm{min} / \mathrm{año.}$

Sólo dos pacientes, ambos del grupo 2, progresaron a estadio 5 , aunque ninguno de ellos inició terapia sustitutiva renal: en un caso, por decisión del paciente, se realizó tratamiento conservador, y en el otro, se decidió su no inclusión debido a su edad avanzada (89 años) y su elevada comorbilidad (intervenido de meningioma, se encontraba en silla de ruedas y presentó un tumor vesical de novo); ambos fallecieron antes de completar el estudio.

\section{2.d.2. Resultados de la proteinuria a los cinco años.}

No se evidenciaron cambios significativos en la evolución global de la proteinuria

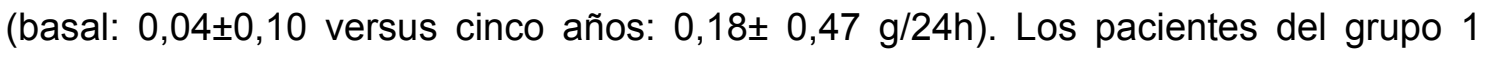
seguían sin tener proteinuria al cabo de los cinco años.

4.2.d.3. Evolución de parámetros analíticos asociados a la enfermedad renal crónica.

En los pacientes que sobrevivían a los cinco años, sólo encontramos un incremento significativo en los niveles de urea (mg/dl): basal $52,21 \pm 13$ versus cinco años $61,21 \pm$ 27, $p=0,047$ y de ácido úrico (mg/dl): basal 5,30 $\pm 1,32$ versus cinco años $6,07 \pm 1,96$, $p=0,040$.

En el análisis por grupos no se encontraron diferencias estadísticamente significativas en la evolución de los niveles de urea, ácido úrico, calcio-fósforo, potasio. Sólo en los niveles de hematocrito se detectaron cambios significativos con el paso del tiempo (figura 11). 


\section{Figura 11 . Evolución del hematocrito a los cinco años}

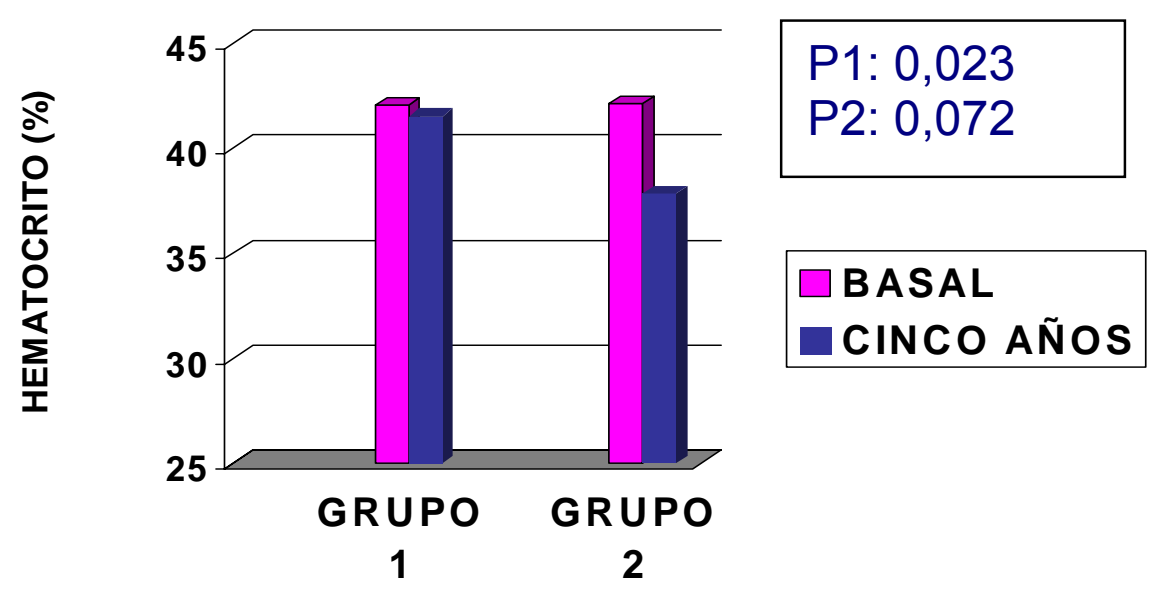

Grupo 1: Creatinina sérica <=1,1 mg/dl; Grupo 2: Creatinina sérica $>1,1 \mathrm{mg} / \mathrm{dl}$.

$\mathrm{P} 1$ : Cambios de la variable en el tiempo de seguimiento en el global de población.

$\mathrm{P} 2$ : Diferencias en el cambio en ambos grupos.

4.2.d.4. Análisis de los cambios en tratamiento establecidos a los cinco años.

Los diuréticos seguían siendo los fármacos más utilizados (76,9\%), fundamentalmente diuréticos de asa (48,7\%); el 35,9\% recibían inhibidores del enzima de conversión de angiotensina (IECAs), el 20,5\% antagonistas de los receptores de angiotensina II (ARAII) y antagonistas del calcio respectivamente, el 17,9\% recibían alfabloqueantes; por último, los betabloqueantes eran los hipotensores menos empleados $(10,3 \%)$.

Sólo dos pacientes $(5,1 \%)$, ambos del grupo 2 empleaban AEE; cinco $(12,8 \%)$ recibían tratamiento con sales de hierro; diez $(25,6 \%)$ utilizaban sales cálcicas y doce $(30,8 \%)$ estatinas.

No se encontraron diferencias significativas entre ambos grupos en lo referente a prescripción de AEE, hierro, sales cálcicas, estatinas, diuréticos, IECAs, ARAll, antagonistas del calcio o betabloqueantes. Los pacientes del grupo 2 tenían pautado más alfabloqueante que los del grupo $1(35,7 \%$ versus $8 \%, p=0,044)$. 


\section{2.d.5. Morbimortalidad a los cinco años.}

El fallecimiento fue la única causa de pérdida de pacientes en todo el seguimiento.

Este aspecto se abordará de forma global más adelante (apartado 4.2.g).

\section{2.e. Hipertensión Arterial.}

4.2.e.1.Repercusión de los agentes antihipertensivos sobre la función renal.

Sesenta y seis pacientes (83\%) estaban diagnosticados de hipertensión arterial: el $78,9 \%$ en el grupo 1 y el $85,7 \%$ en el grupo 2 (no significativo).

El $68,1 \%$ de los ancianos tenían pautado dos ó mas antihipertensivos. El $80 \%$ utilizaban diuréticos, el $46,2 \%$ y el $23,1 \%$ recibían IECAs o ARA Ils respectivamente, $31,8 \%$ calcioantagonistas, $18,5 \%$ alfabloqueantes y $9,2 \%$ betabloqueantes. No se encontraron diferencias significativas en el número de hipotensores al comparar los grupos de función renal basal.

Todos los ancianos con antecedentes previos de insuficiencia cardiaca tenían prescrito un diurético y el $73,5 \%$ de los que no tenían insuficiencia cardiaca recibían también tratamiento diurético $(p=0,032)$.

El tratamiento con betabloqueantes era usado en el $33,3 \%$ de aquellos ancianos con cardiopatía isquémica mientras que sólo el $3,8 \%$ de los que no tenían cardiopatía isquémica recibían estos fármacos $(p=0,009)$.

No se encontraron asociaciones del resto de agentes antihipertensivos con los antecedentes personales previos analizados.

La función renal global basal de los pacientes hipertensos fue: $\operatorname{Cr} s$ 1,29 $\pm 0,5 \mathrm{mg} / \mathrm{dl}$, FG (MDRD) $50,9 \pm 15 \mathrm{ml} / \mathrm{min}$ y proteinuria $0,08 \pm 0,1 \mathrm{~g} /$ día.

Las variaciones significativas en la función renal asociadas al empleo de diurético pueden verse en la figura 12. Puede comprobarse que los ancianos en tratamiento diurético presentaban, de forma significativa, un aumento de Crs al cabo del año y, 
por ende, un descenso del FG (MDRD) con respecto a aquellos que no tomaban diuréticos.

\section{Figura 12. Evolución de función renal según tratamiento con diurético}
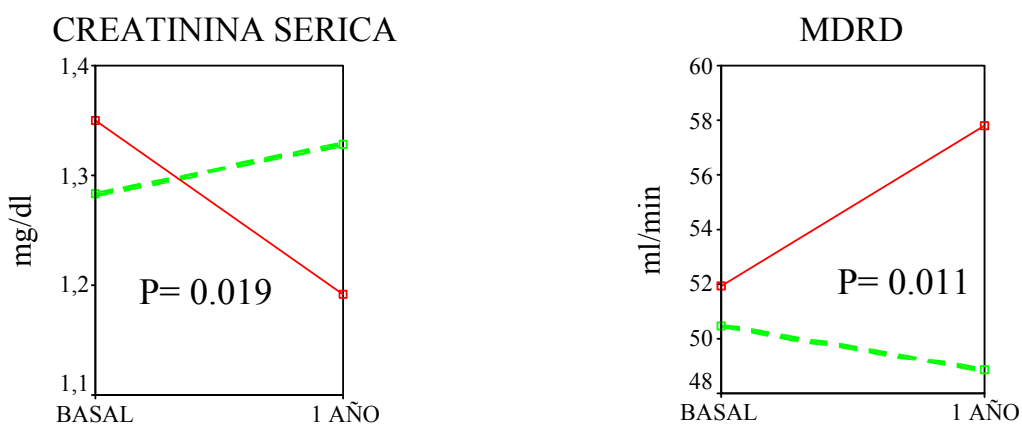

Línea continua : no diurético; Línea discontinua: si diurético.

El análisis de medidas repetidas muestra variaciones significativas en la evolución de la Cr s y FG (MDRD) según el uso de diurético.

El tratamiento con diuréticos no evidenció diferencias significativas en la proteinuria basal $(0,08 \pm 0,2 \mathrm{~g} /$ día con diurético versus $0,07 \pm 0,1 \mathrm{~g} /$ día sin diurético $) \mathrm{ni}$ al año de evaluación.

Un 39\% de los pacientes incrementaron la Crs a lo largo del año (Cr1año-Cr Basal $\geq 0,1$ $\mathrm{mg} / \mathrm{dl})$ y en un $61 \%$ permaneció estable ó disminuyó $(<0,1 \mathrm{mg} / \mathrm{dl})$. En el análisis de regresión univariante y multivariante para ver qué factores influían en el incremento de creatinina sérica con el paso del tiempo, el uso de diuréticos se mostró como factor de riesgo independiente para este incremento de Crs (Tabla 13). 
Tabla 13. Análisis multivariante de los factores que influyen en el incremento de creatinina sérica al año.

\begin{tabular}{|l|l|l|l|}
\hline & Exp $(\mathrm{B})$ & $\mathrm{IC}(95 \% \mathrm{E}[\mathrm{B}])$ & $\mathrm{p}$ \\
\hline Diurético sólo & 0,099 & $(0,012-0,83)$ & 0,033 \\
\hline Ajustado por : & & & \\
\hline Edad & 0,103 & $(0,012-0,88)$ & 0,039 \\
\hline Sexo & 0,100 & $(0,012-0,84)$ & 0,034 \\
\hline Uso de hipotensores & 0,107 & $(0,012-0,92)$ & 0,042 \\
\hline IECA & 0,099 & $(0,012-0,83)$ & 0,033 \\
\hline ARAll & 0,103 & $(0,012-0,87)$ & 0,037 \\
\hline Betabloqueante & 0,095 & $(0,011-0,81)$ & 0,031 \\
\hline Calcioantagonistas & 0,093 & $(0,011-0,79)$ & 0,03 \\
\hline Alfabloqueantes & 0,105 & $(0,012-0,89)$ & 0,039 \\
\hline $\begin{array}{l}\text { Creatinina sérica } \\
\text { basal }\end{array}$ & 0,100 & $(0,012-0,84)$ & 0,034 \\
\hline
\end{tabular}

IECA: Inhibidores del enzima de conversión de angiotensina II; ARAll: antagonistas de los receptores de angiotensina II.

Al comparar los ancianos que utilizaban IECAs, ARAlls, Calcioantagonistas, alfa y betabloqueantes respecto a los que no los empleaban, no se encontraron diferencias significativas en la Crs, el FG ( MDRD) ni en proteinuria al cabo de un año.

4.2.e.2. Grado de control de la presión arterial en la población a los tres y cinco años:

- Control de la presión arterial (PA) en la población que continúa a los tres años:

En los cincuenta y seis pacientes que llegan a los tres años, el grado medio de control de PA logrado fue: PA sistólica $131,44 \pm 16 \mathrm{mmHg}$ (rango 90-170) y PA diastólica 70,84 $\pm 10 \mathrm{mmHg}(50-90)$. En el análisis por grupos tampoco se detectaron variaciones significativas en los niveles medios de PA (mmHg): Sistólica grupo 1, $129,62 \pm 16$ y grupo $2,133,40 \pm 15$; Diastólica grupo $1,71,9 \pm 10$ y grupo $2,69,68 \pm 9$. 
El $34,6 \%$ de los pacientes tenía una PA sistólica $\geq 140 \mathrm{mmHg}$ y el $5,8 \%$ de ellos tenía una PA diastólica $\geq 90 \mathrm{mmHg}$.

- Control de la presión arterial en la población que concluye el estudio:

Los niveles medios de PA de los treinta y nueve pacientes que concluyeron el estudio fueron: PA sistólica $(\mathrm{mmHg})$ 128,83 13 (rango 100-160) y PA diastólica (mmHg) $70,56 \pm 10$ (rango 50-95). No se encontraron diferencias significativas en los niveles medios de PA al considerar los grupos de estudio.

El $27 \%$ y el $8,1 \%$ de los ancianos tenían una PA sistólica $\geq 140 \mathrm{mmHg}$ y PA diastólica $\geq 90 \mathrm{mmHg}$ respectivamente.

4.2.f. Análisis global de eventos cardiovasculares en los cinco años de seguimiento.

El $60 \%$ del total de pacientes estudiados han tenido al menos un ingreso por causa cardiovascular en todo el periodo de estudio. Acerca de la aparición de eventos cardiovasculares de novo: el $20,3 \%$ ha presentado algún episodio de IC; el $7,5 \%$ ha tenido un ACV y el $6,3 \%$ ha presentado cardiopatía isquémica. Comparando los dos grupos de estudio respecto a eventos cardiovasculares de novo: en el grupo 1 el $13,5 \%$ de los pacientes ha tenido un episodio de IC y en el grupo 2 el $26,8 \%$ ha desarrollado uno ó más episodios; la cardiopatía isquémica ha estado presente en el $5,3 \%$ del grupo 1, y en el 7,3\% del grupo 2; un episodio de ACV ocurrió en el 11,5\% del grupo 1 frente a ningún evento en el grupo 2; ninguna de estas diferencias alcanzó significación estadística. 
4.2.g. Análisis global de la mortalidad durante los cinco años.

Respecto a la mortalidad global, cuarenta y un pacientes $(51,2 \%)$ fallecieron a lo largo de los cinco años de seguimiento: quince por deterioro del estado general; ocho por infecciones; cuatro por ictus; cuatro por tumores; tres de causa cardiovascular; dos por complicaciones de fracturas y cinco por causa desconocida.

La mortalidad fue superior en el grupo $2(66,7 \%$ versus $34,2 \% ; p=0,004)$. Los pacientes fallecidos tenían más edad $(84,73 \pm 5,69$ versus $80,12 \pm 6,5$ años; $p=0,001)$. No hubo diferencias estadísticamente significativas en la mortalidad al comparar por género, presencia de DM o HTA, e ICH basal. En el análisis de regresión logística para mortalidad global (variables independientes: edad, género, $\mathrm{ICH}$, antecedentes cardiovasculares, Crs basal y grupo) sólo la edad (RR: 1,12; 1,03 - 1,23; $p=0,009$ ) y el grupo (RR: 3,$06 ; 1,10-8,40 ; p=0,031$ ) se asociaban independientemente con la mortalidad.

Al considerar la influencia de los niveles de ácido úrico en el periodo basal sobre la mortalidad global a los cinco años, en el análisis multivariante de Cox, la única variable predictora de mortalidad global tras corregir para edad, género, Charlson, antecedentes de insuficiencia cardiaca, uso de diurético, creatinina, presencia de proteinuria y FG-MDRD, fue el nivel de ácido úrico (mg/dl) $(R R$ 1,35;1,17-1,56; $p=$ 0,000). En la figura 13 A y B se muestran las curvas de Kaplan-Meier de mortalidad según la mediana de ácido úrico y el P75. En ambas se comprueba una mortalidad significativamente superior en pacientes con niveles de ácido úrico mayor a la mediana y al P75. 
Figura 13. Curva de Kaplan Meier de mortalidad según el P50 (A) y el P75 (B) de ácido úrico.

A

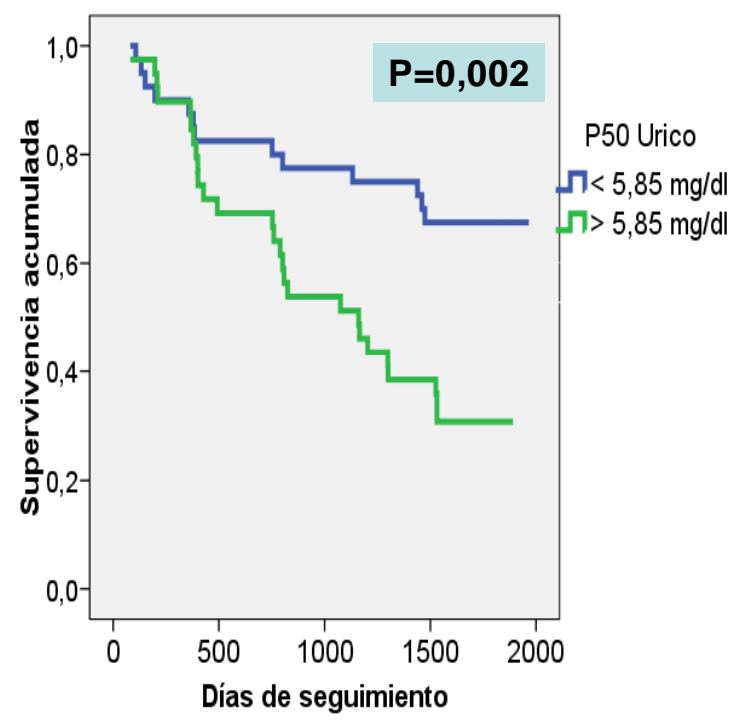

B

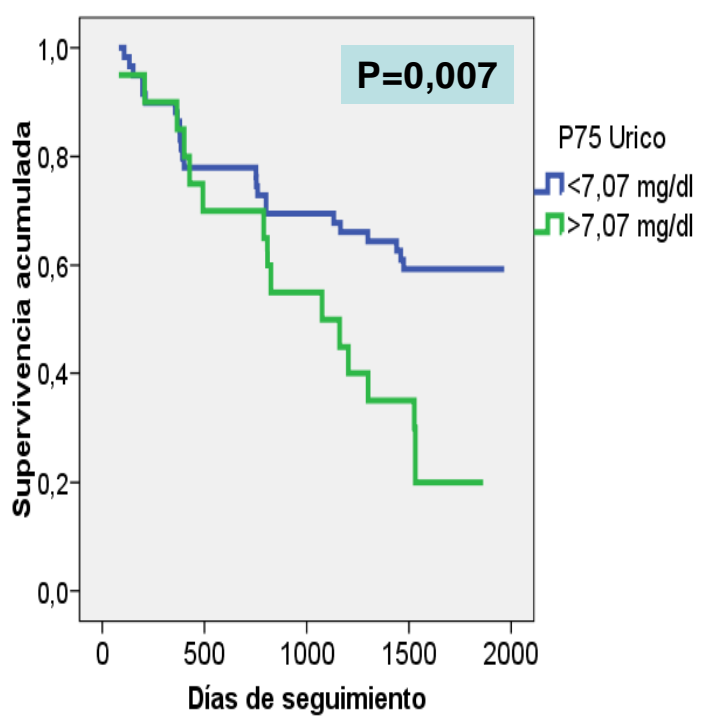




\subsection{Concordancia entre el aclaramiento de creatinina y las fórmulas matemáticas}

derivadas de la creatinina en el diagnóstico de daño renal.

En treinta y dos pacientes que disponían de $\mathrm{CCr}$ (considerado gold standard) se realizó un estudio de concordancia entre éste y las fórmulas matemáticas derivadas de la Crs en el diagnóstico de daño renal.

Los niveles medios de Crs en los treinta y dos pacientes que tenían $\mathrm{CCr}$ fueron: $1,53 \pm 0,6 \mathrm{mg} / \mathrm{dl}$ (rango 0,8-3). Las mujeres tenían menor cifra de Crs que los varones: $1,27 \pm 0,47$ versus $1,90 \pm 0,67 \mathrm{mg} / \mathrm{dl}(p=0,004)$. Las medias $\pm \mathrm{SD}$ globales de $\mathrm{FGe}$

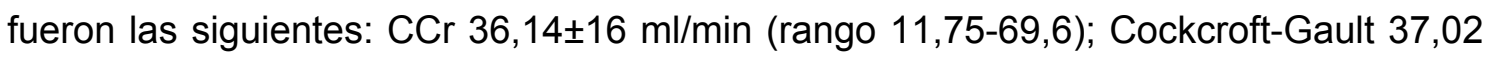
$\pm 16 \mathrm{ml} / \mathrm{min}$ (rango 13,3-72,3); MDRD 45,52 $\pm 16 \mathrm{ml} / \mathrm{min}$ (rango 19,2-75,36) y CKD-EPI $42,05 \pm 17 \mathrm{ml} / \mathrm{min}$ (rango 16,30-74,90).

La concordancia en el diagnóstico de daño renal entre el $\mathrm{CCr}$ y las fórmulas se presenta en las tablas 14y 15. 
Tabla 14. Concordancia en el diagnóstico de daño renal (ausente: $F G e \geq 60 \mathrm{ml} / \mathrm{min}$, moderado: $\mathrm{FGe}=30-59,9 \mathrm{ml} / \mathrm{min}$, severo: $\mathrm{FGe}<30 \mathrm{ml} / \mathrm{min}$ ) determinado acorde a las medidas del aclaramiento de creatinina (gold estándar) y las fórmulas de Cockcroft-Gault y MDRD.

\begin{tabular}{|c|c|c|c|c|}
\hline & $\begin{array}{l}\text { Daño renal } \\
\text { aclaramiento }\end{array}$ & $\begin{array}{l}\text { acorde a las } \\
\text { e creatinina: }\end{array}$ & didas del & \\
\hline & Ausente $(\mathrm{N}=2)$ & Moderado(N=16) & Severo(N=14) & Valor Kappa \\
\hline $\begin{array}{l}\text { Daño renal acord } \\
\text { las fórmulas: }\end{array}$ & & & & \\
\hline Cockcroft-Gault & & & & 0.44 \\
\hline Ausente $(\mathrm{N}=3)$ & $\mathrm{N}=1$ & $\mathrm{~N}=2$ & $\mathrm{~N}=0$ & \\
\hline Moderado(N=16) & $\mathrm{N}=1$ & $N=11$ & $\mathrm{~N}=4$ & \\
\hline Severo $(N=13)$ & $\mathrm{N}=0$ & $\mathrm{~N}=3$ & $\mathrm{~N}=10$ & \\
\hline MDRD & & & & 0.35 \\
\hline Ausente $(\mathrm{N}=5)$ & $\mathrm{N}=1$ & $\mathrm{~N}=3$ & $N=1$ & \\
\hline Moderado $(\mathrm{N}=21)$ & $\mathrm{N}=1$ & $\mathrm{~N}=13$ & $N=7$ & \\
\hline Severo $(N=6)$ & $\mathrm{N}=0$ & $\mathrm{~N}=0$ & $N=6$ & \\
\hline
\end{tabular}

MDRD: Modification of Diet in Renal Disease; N: número de pacientes. 
Tabla 15. Concordancia en el diagnóstico de daño renal (ausente o leve: $F G e ~ \geq 60 \mathrm{ml} / \mathrm{min}$, moderado: $\mathrm{FGe}=30-59,9 \mathrm{ml} / \mathrm{min}$, severo: $\mathrm{FGe}<30 \mathrm{ml} / \mathrm{min}$ ) determinado acorde a las medidas del aclaramiento de creatinina (gold estándar) y las fórmulas de CKD-EPI y MDRD.

\begin{tabular}{|c|c|c|c|c|}
\hline & $\begin{array}{l}\text { Daño renal } \\
\text { aclaramiento }\end{array}$ & $\begin{array}{l}\text { acorde a las } \\
\text { e creatinina: }\end{array}$ & edidas del & \\
\hline & Ausente $(\mathrm{N}=2)$ & Moderado(N=16) & Severo $(\mathrm{N}=14)$ & $\begin{array}{l}\text { Valor } \\
\text { Kappa }\end{array}$ \\
\hline $\begin{array}{l}\text { Daño renal acorde a } \\
\text { las fórmulas: }\end{array}$ & & & & \\
\hline CKD-EPI & & & & 0.45 \\
\hline Ausente $(\mathrm{N}=4)$ & $\mathrm{N}=1$ & $\mathrm{~N}=2$ & $\mathrm{~N}=1$ & \\
\hline Moderado $(\mathrm{N}=19)$ & $\mathrm{N}=1$ & $\mathrm{~N}=13$ & $\mathrm{~N}=5$ & \\
\hline Severo $(N=9)$ & $\mathrm{N}=0$ & $\mathrm{~N}=1$ & $\mathrm{~N}=8$ & \\
\hline MDRD & & & & 0.35 \\
\hline Ausente $(\mathrm{N}=5)$ & $\mathrm{N}=1$ & $N=3$ & $\mathrm{~N}=1$ & \\
\hline Moderado $(\mathrm{N}=21)$ & $\mathrm{N}=1$ & $N=13$ & $N=7$ & \\
\hline Severo $(N=6)$ & $\mathrm{N}=0$ & $\mathrm{~N}=0$ & $\mathrm{~N}=6$ & \\
\hline
\end{tabular}

CKD-EPI: Chronic Kidney Disease Epidemiology Collaboration; MDRD: Modification of Diet in Renal Disease; N: número de pacientes. 
5. DISCUSIÓN 


\section{DISCUSIÓN.}

En los últimos años se ha generado una gran controversia acerca de cuál sería el rango normal de función renal en el anciano $(22,31,69,70,71)$. Inicialmente se pensaba que con el envejecimiento se producían una serie de cambios "normales" en el riñón, entre los que se describía el descenso del filtrado glomerular $(1,61)$. Posteriormente, algunos estudios pusieron en evidencia el hecho de que el FG en el anciano sano se mantenía en un rango normal, aunque inferior al de personas más jóvenes $(62,63)$. Por tanto, un FG por debajo del rango normal en ancianos debería atribuirse a patología asociada más que al proceso mismo de envejecimiento (72).

Con la clasificación de ERC, recogida en las Guías KDOQI, se establece una estratificación de esta enfermedad en estadios según el FG, y se consideran aplicables a toda la población (3).

En nuestro estudio se ha incluido a un grupo de personas ancianas con Crs en rango normal $(\leq 1,1 \mathrm{mg} / \mathrm{dl})$, en los que pretendemos conocer su FG, determinado por tres métodos diferentes de estimación del FG, con ecuaciones derivadas de la Crs. También se estudió un grupo de ancianos con Crs alterada (> 1,1 mg/dl).

Una vez conocido el FGe de ambos grupos, valoramos si los niveles de corte de FG, que definen a los distintos estadios de ERC de las Guías KDOQI, serían válidos para este tipo de población. Además, según el grado de función renal en el periodo basal que presentaban los ancianos, analizamos el comportamiento de la función renal con el paso del tiempo, así como el pronóstico asociado a la progresión de la ERC: necesidad de terapias de reemplazo renal y la mortalidad.

Los hallazgos obtenidos en nuestro estudio han mostrado que los ancianos con Crs en rango normal tenían un FGe inferior al rango considerado normal, de $90 \mathrm{ml} / \mathrm{min}$. Estos resultados se confirman por los tres métodos de estimación del FG empleados en el periodo basal (MDRD, CKD-EPI y Cockcroft-Gault). En el seguimiento de la función renal en el tiempo de los pacientes que sobrevivieron a los cinco años, se comprobó en ellos un descenso medio de $\mathrm{FGe}$ inferior a $1 \mathrm{ml} / \mathrm{min} / \mathrm{año}$. 
La interpretación de los resultados se hará siguiendo el orden cronológico. Se destaca, en primer lugar, los hallazgos obtenidos en el periodo transversal, después se discutirán los resultados del estudio prospectivo y, por último, se interpretará la concordancia entre el CCr y las fórmulas matemáticas derivadas de la creatinina.

\subsection{Niveles de FGe en el periodo basal.}

El dogma de un descenso inexorable de la función renal asociada al envejecimiento ha sido cuestionado puesto que se considera que los ancianos sanos deberían de presentar una función renal en rango normal (>90 $\mathrm{ml} / \mathrm{min}$ ) (64). De hecho, en las Guías KDOKI se establece que la ERC debe ser definida y clasificada en estadios según el FG, con validez y aplicabilidad generalizada para toda la población. Así, un anciano con un FGe inferior a $60 \mathrm{ml} / \mathrm{min}$ mantenido durante al menos 3 meses, debe ser considerado portador de ERC al menos en estadio 3.

En nuestro estudio, hemos valorado a pacientes con Crs en rango normal (grupo 1) y pacientes con Crs alterada (grupo 2). Hemos encontrado, en primer lugar, que los pacientes con Crs en rango normal tenían un FGe inferior a lo que se considera el grado de FG normal, 90 ml/min; el rango máximo del FGe en pacientes del grupo 1 no llegó a los $90 \mathrm{ml} / \mathrm{min}$. En segundo lugar, el descenso del FGe en esos pacientes se confirmó por los tres métodos de estimación de FG con fórmulas matemáticas derivadas de la creatinina. Según estos resultados, los ancianos que nosotros consideramos sanos tienen un FGe disminuido (<90 ml/min), pero con la clasificación de ERC de las Guías KDOQI tendrían que considerarse portadores de una ERC, al menos, en estadio 2.

Por otra parte, a la hora de determinar el nivel de FGe que presentan los ancianos, encontramos discordancias según el método de valoración: los niveles medios de FGe con la fórmula MDRD son superiores a los conseguidos con la formula de CockcroftGault. Este fenómeno tiene implicaciones tanto en el estadiaje de la ERC, y por lo 
tanto en la prevalencia de la enfermedad, como a la hora de realizar ajustes de dosis de medicamentos.

En lo que se refiere a la prevalencia de ERC, en un metaanálisis realizado por Zhang y Rothenbacher se concluía que, en los ancianos, esta enfermedad era muy común y además variaba fuertemente con la edad (27). En nuestro estudio, si tenemos en cuenta los pacientes con un FGe (por MDRD abreviado) inferior a $60 \mathrm{ml} / \mathrm{min}$, podríamos concluir que la prevalencia de ERC es aún mayor que la reflejada en otros estudios en ancianos $(28,29)$. Este fenómeno podría atribuirse a las características de nuestra población, fundamentalmente una población muy longeva (la mediana de edad fue de 83 años). En cualquier caso, aunque la prevalencia de ERC es elevada, $70 \%$ con $\mathrm{FGe}$ (MDRD) inferior a $60 \mathrm{ml} / \mathrm{min}$, la mayoría de nuestros ancianos se encuentran en un estadio 3 de ERC, y sólo un $10 \%$ en estadios más avanzados (estadios 4-5). Estos resultados son acordes con estudios como el de Manjunath (28) y Hemmalgarn (29), donde se refiere que la mayoría de pacientes con FGe (MDRD) inferior a $60 \mathrm{ml} / \mathrm{min}$ estaría en un estadio 3 de ERC.

\subsection{Niveles basales de FGe según el género.}

En general, en los estudios epidemiológicos se encuentra que la prevalencia de ERC es mayor en las mujeres que en los varones, con independencia de la edad $(27,73)$. En el estudio de Labrador et al, se valora la prevalencia de insuficiencia renal oculta (definida por $\mathrm{FGe}$ inferior a $60 \mathrm{ml} / \mathrm{min}$ y Crs en rango normal); los autores encuentran que un $43,5 \%$ de las mujeres estudiadas la presentaba, con una media de edad de 77 años (74). En nuestro estudio, encontramos también que el FGe de las mujeres con Crs en rango normal es inferior de forma significativa al de los varones; esta diferencia no es tan acusada cuando consideramos a los pacientes con Crs alteradas (grupo 2). Por lo tanto, nuestros datos confirman una mayor prevalencia de ERC en mujeres si la evaluación se realiza únicamente mediante la medición del FGe; esta afirmación es válida fundamentalmente para los sujetos del grupo 1. 
Las diferencias en el FG entre sexos y grupos de estudio quizás radican en las propias fórmulas matemáticas de estimación del FG. Las ecuaciones matemáticas empleadas en nuestro estudio derivan de la Crs, y ésta es un reflejo de la masa muscular y del estado nutricional del paciente. En ese sentido, es probable que las diferencias de FG entre sexos, en pacientes con Crs en rango normal, expresen menor masa muscular en mujeres más que el FG real. Tampoco hay que olvidar, que la fórmula MDRD fue diseñada en pacientes con función renal alterada, pero no validada en población sana: la aplicación de esta fórmula en personas con Crs en rango normal puede infraestimar el grado de FG real hasta un $50 \%$ (75). Sin embargo, cuando aplicamos la fórmula MDRD en personas con función renal alterada, las diferencias entre sexos son menos acusadas, lo que podría traducir que el FGe expresa más la presencia de verdadera enfermedad renal y menos el estado nutricional y/o la masa muscular del paciente.

\subsection{Aportación de la nueva ecuación CKD-EPI en la estimación del FG en el anciano.}

En los últimos años se ha recomendado la fórmula MDRD para la estimación del FG en la población general $(65,66)$. Recientemente un grupo de investigación establecido por el National Institute of Diabetes and Digestive and Kidney Disease ha desarrollado una nueva ecuación más exacta, conocida como CKD-EPI (23). Cuando se utiliza esta nueva ecuación, la prevalencia de ERC se reduce en mujeres y en personas de raza blanca, pero se mantiene elevada en personas ancianas $(23,76)$. En un estudio reciente, donde se comparan las ecuaciones CKD-EPI y MDRD, la nueva ecuación se manifiesta más exacta que la MDRD, aunque con la limitación del reducido número de personas ancianas o de grupos étnicos incluidos (77).

En nuestro estudio, comprobamos que el FGe (CKD-EPI) medio del conjunto de la población estudiada era de $47,41 \pm 16 \mathrm{ml} / \mathrm{min}$. Igualmente, los pacientes del grupo con Crs dentro de los rangos normales tenían un nivel medio de FGe por CKD-EPI de 
$59,87 \pm 10 \mathrm{ml} / \mathrm{min}$. También observamos que los valores de FG, estimados por CKD$\mathrm{EPI}$, eran menores en las mujeres en ambos grupos (niveles de $\mathrm{FGe}$ aún más bajos que los obtenidos con la fórmula MDRD). Además, cuando analizamos el empleo de una y otra ecuación para el estadiaje de la ERC en los ancianos, con la ecuación CKDEPI aumentaban los pacientes catalogados en estadios 3 y 4 de ERC en detrimento del estadio 2 ( $F G e ~>=60 \mathrm{ml} / \mathrm{min}$ ). Como consecuencia, creemos que, aunque en la población general la fórmula CKD-EPI es más exacta que la MDRD para la estimación del FG, si aquella fórmula se utilizara de forma sistemática en ancianos con Crs normal, la prevalencia de ERC se elevaría de forma inapropiada con el consiguiente incremento de derivaciones innecesarias a los servicios de Nefrología.

\subsection{Niveles basales de FG y su asociación con comorbilidad.}

Algunos estudios han tratado de relacionar el descenso del FG con patologías concomitantes como hipertensión arterial y patología cardiovascular asociada $(78,79)$.

En el presente trabajo se ha valorado el grado de FGe basal de los pacientes según su comorbilidad.

Varios estudios han demostrado que los cambios en el funcionalismo renal no sólo dependen de la edad, sino que también de la patología cardiovascular concomitante $(63,78)$. Fliser et al, relacionan la reducción del FG con la existencia de hipertensión arterial, insuficiencia cardiaca o cardiopatía isquémica (63).

En nuestro estudio, de forma global, demostramos que la presencia de comorbilidad se asocia con tasas menores de FGe, inferior a $60 \mathrm{ml} / \mathrm{min}$ por cualquiera de los tres métodos utilizados.

Es indiscutible que la HTA es un factor de riesgo cardiovascular y que contribuye a la progresión del daño renal (80). Nuestros pacientes hipertensos también tenían unos niveles medios de FGe inferiores a aquellos sin HTA si bien esta diferencia no alcanzó 
la significación estadística (MDRD: $50 \pm 15$ versus $57 \pm 18 \mathrm{ml} / \mathrm{min}$; CKD-EPI: $46 \pm 15$ versus $52 \pm 17 \mathrm{ml} / \mathrm{min}$; CG: $39 \pm 13$ versus $44 \pm 19 \mathrm{ml} / \mathrm{min}$ ).

Con respecto a la presencia de antecedentes cardiacos, insuficiencia cardiaca o cardiopatía isquémica, comprobamos que la existencia previa de estas enfermedades se asocia de forma significativa con tasas inferiores de FG (MDRD: con insuficiencia cardiaca $42 \pm 12$ versus sin insuficiencia cardiaca $53 \pm 16 \mathrm{ml} / \mathrm{min}$; Con cardiopatía isquémica $41 \pm 13$ versus sin cardiopatía isquémica $53 \pm 16 \mathrm{ml} / \mathrm{min}$ ). Estos hallazgos ya han sido descritos por otros autores (63).

Dada la elevada incidencia de eventos cardiovasculares en ancianos y su asociación con la ERC, posiblemente el control de la enfermedad cardiovascular constituya el principal factor modificable para preservar la función renal en este grupo de pacientes.

\subsection{Manifestaciones analíticas asociadas a la ERC: ¿a partir de qué grado de FG} se detectan? .

El riñón juega un papel primordial en el mantenimiento de la homeostasis del medio interno mediante sus funciones de filtración, reabsorción, excreción de agua, electrólitos, productos nitrogenados y la regulación del equilibrio ácido-base; además desarrolla una función endocrina (81). La ERC se caracteriza por una pérdida progresiva e irreversible de la función renal y, por lo tanto, de las funciones en las que el riñón interviene, de la que se derivan múltiples alteraciones entre las que destacan el síndrome anémico, alteraciones del metabolismo calcio-fósforo y acidosis metabólica. El manejo de estas alteraciones incluye, entre otras, normas dietéticas, control del volumen y de la presión arterial, empleo de captores del fósforo, suplementos de vitamina D y agentes eritropoyéticos (82).

La insuficiencia renal crónica tradicionalmente se clasificaba como leve, moderada y severa (83). Con la aparición de las Guías KDOQI, la clasificación de ERC se fundamenta en el grado de FG y en la existencia de manifestaciones de daño renal 
(hematuria, proteinuria), y permite clasificar la ERC en estadios: así, una ERC moderada incluiría a pacientes con FGe entre $30-59 \mathrm{ml} / \mathrm{min}$ y una ERC severa a pacientes con FG inferior a $30 \mathrm{ml} / \mathrm{min}$ (3). El estadio 5, representaría aquel en el que los riñones son incapaces de mantener la homeostasis y por tanto, sería necesario efectuar técnicas de reemplazo renal para lograr la supervivencia del paciente (83). Sin embargo, el punto débil de la clasificación-definición de ERC de las Guías KDOQI es que considera portadores de ERC a todos los pacientes con un FG inferior a 60 $\mathrm{ml} / \mathrm{min}$ ó más de $60 \mathrm{ml} / \mathrm{min}$ pero con manifestaciones de daño renal, sin tener en cuenta ni la influencia de la edad (es válida para toda la población) ni tampoco la existencia de otras alteraciones analíticas asociadas a la presencia de verdadera enfermedad renal.

En nuestro estudio, hemos valorado la presencia de alteraciones analíticas asociadas a la ERC (anemia, AMOM, acidosis metabólica) y a partir de qué nivel de FGe se detectan; para ello se establecieron dos grupos de pacientes: aquellos con FGe entre 30-59 $\mathrm{ml} / \mathrm{min}$ y otro grupo con un FGe inferior a $30 \mathrm{ml} / \mathrm{min}$, medidos por la fórmula MDRD.

El descenso en la excreción urinaria de sustancias procedentes del metabolismo, asociado a la ERC, juega un papel crucial en la retención de esas sustancias en el organismo (azoemia: creatinina, urea, ácido úrico, potasio y agua) (83). Con nuestros datos, comprobamos que los pacientes del grupo con $\mathrm{FGe}$ inferior a $30 \mathrm{ml} / \mathrm{min}$ eran los que presentaban un incremento significativo en los niveles plasmáticos de urea, creatinina, ácido úrico y potasio con respecto a los pacientes con $\mathrm{FGe}>=30 \mathrm{ml} / \mathrm{min}$. También comprobamos que personas con FGe $>30 \mathrm{ml} / \mathrm{min} \mathrm{y}<60 \mathrm{ml} / \mathrm{min}$ tenían una Crs en rango normal (18 personas, todas del género femenino); estas ancianas según la clasificación KDOQI de ERC, deberían etiquetarse como portadoras de ERC al menos en estadio 3 o como pacientes con "enfermedad renal oculta".

En nuestro estudio analizamos también la anemia asociada a la enfermedad renal. La anemia generalmente se observa cuando el FG cae por debajo de $60 \mathrm{ml} / \mathrm{min}$ y 
empeora según la enfermedad renal progresa y disminuye la producción de eritropoyetina (84). Nosotros encontramos que, de forma global en el periodo basal, los niveles medios de hemoglobina y de hematocrito eran superiores a $12 \mathrm{~g} / \mathrm{dl}$ y $37 \%$ respectivamente. Incluso se da la paradoja de que los pacientes con peor grado de función renal ( $F G e$ por MDRD menor a $30 \mathrm{ml} / \mathrm{min}$ ), eran los que tenían niveles medios de hemoglobina y hematocrito más elevados que los ancianos con $\mathrm{FGe}>=30$ $\mathrm{ml} / \mathrm{min}$ (si bien no significativo): probablemente porque aquel grupo era el que recibía tratamiento con AEE. En cualquier caso, observamos que los pacientes con FGe $(M D R D)>=30 \mathrm{ml} / \mathrm{min}$, presentaban niveles medios de hematocrito de $40,8 \%$; quiere decir que, a pesar de tener un FGe reducido, estas personas no tenían anemia asociada. Estas observaciones hay que tomarlas con cautela por la diferencia del número de muestra entre ambos grupos.

El empleo de AEE requiere disponer de depósitos adecuados de hierro, necesarios para incrementar la síntesis de hemoglobina (41). En nuestro estudio, no hubo diferencias significativas en los parámetros del metabolismo del hierro, aunque los pacientes que recibían suplementos con sales de hierro, eran los que presentaban un FGe (MDRD) inferior a $30 \mathrm{ml} / \mathrm{min}$.

Cuando analizamos la evolución en el tiempo de los parámetros hematimétricos según los grupos de estudio de creatinina sérica basal, comprobamos que en el grupo 1, a pesar de tener un FG disminuido, el hematocrito basal era superior a $37 \%$, y se mantenía en niveles similares en los siguientes años, sin necesidad de emplear AEE. Igualmente observamos que los pacientes del grupo 2 presentaban un hematocrito superior al $37 \%$ y se mantenía un año después, siendo escaso el porcentaje de pacientes que precisaban tratamiento con AEE (menor al 25\%). Cuando analizamos los parámetros que se asociaban al uso de AEE, encontramos que la Crs $>2 \mathrm{mg} / \mathrm{dl}$ y la edad avanzada eran los dos factores que parecían contribuir más a la necesidad de dichos agentes. El seguimiento en el tiempo del hematocrito confirma un descenso significativo de éste fundamentalmente en el grupo 2 . 
En relación a las alteraciones del metabolismo del calcio y del fósforo, la retención de fósforo es una consecuencia inevitable del descenso gradual del aclaramiento renal de fosfatos y se inicia en estadios precoces de la ERC (85). La hipocalcemia es el resultado de una inadecuada reabsorción intestinal de calcio por el déficit de vitamina D asociado a la insuficiencia renal (83). En nuestro estudio, globalmente en el periodo basal, los niveles medios tanto de calcio como de fósforo se encontraban en rango normal; aunque, en el análisis según el FG, los pacientes con FGe (MDRD) $<30$ $\mathrm{ml} / \mathrm{min}$ tenían los niveles de calcio más bajos y los de fósforo más elevados que en los pacientes con $\mathrm{FGe} \geq 30 \mathrm{ml} / \mathrm{min}$, aunque estas diferencias no fueron significativas. La ausencia de significación pueda relacionarse con el tratamiento establecido para tratar las AMOM: los pacientes que recibían terapia con captores del fósforo con contenido cálcico eran los que tenían el FGe más reducido ( $28 \pm 6$ versus $40 \pm 12 \mathrm{ml} / \mathrm{min}, \mathrm{p}=0,07)$ y los que presentaban unas concentraciones séricas de fósforo más elevadas $(4,36 \pm 0,4$ versus $3,06 \pm 0,2 \mathrm{mg} / \mathrm{dl}, \mathrm{p}=0,000)$.

Por último, en relación a las alteraciones del equilibrio ácido-base, la acidosis metabólica generalmente se detecta cuando el FG se reduce por debajo de $30 \mathrm{ml} / \mathrm{min}$ $(45,83)$. En este estudio de pacientes ancianos, comprobamos que, globalmente, el $\mathrm{pH}$ se mantiene en valores normales, a expensas de concentraciones medias de bicarbonato elevadas $\mathrm{y}$, paralelamente, unos valores medios de pCO2 también incrementados (compensación respiratoria). Cuando analizamos los pacientes con FGe (MDRD) inferior a $30 \mathrm{ml} / \mathrm{min}$ tampoco detectamos la presencia de acidosis metabólica; estos pacientes presentaban niveles medios de bicarbonato de 28,8 mEq/L. La ausencia de acidosis metabólica en ancianos con un FG por debajo de 30 $\mathrm{ml} / \mathrm{min}$ quizás pueda explicarse, en primer lugar, por la edad tan avanzada de los ancianos estudiados, en los que el reflejo de la sed suele estar disminuido, con la subsiguiente menor ingesta hídrica; por otra parte, en estos pacientes la ingesta alimentaria es menor que en personas adultas y, por tanto, la generación de ácidos es menor; finalmente, por ser elevado el porcentaje de estos ancianos en tratamiento 
con diuréticos, lo que conlleva asociado una tendencia a la alcalosis metabólica por contracción de volumen (86).

\subsection{Evolución de la función renal en el tiempo.}

Pocos trabajos describen la progresión de la ERC en la población anciana.

Una rápida progresión de la $\mathrm{ERC}$ se define por el descenso del $\mathrm{FG}$ a un ritmo $\geq 4$ $\mathrm{ml} / \mathrm{min} / \mathrm{año}(5)$.

En este estudio se expone la evolución de la función renal a lo largo de cinco años en una cohorte de población muy envejecida, con una mediana de edad de 83 años en el periodo de reclutamiento, y con diferentes niveles de Crs: ancianos con Crs en rango normal (grupo 1) y ancianos con Crs alterada (grupo 2). Nuestros resultados demuestran que los ancianos que sobreviven los cinco años presentan un descenso

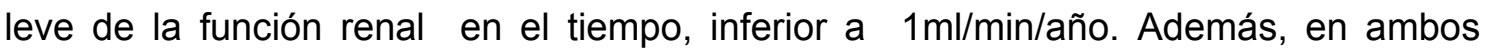
grupos de estudio el FGe disminuyó del mismo modo: descenso lento de la función renal que podría explicarse por el efecto edad (grupo 1: $-0,67$ y grupo 2:-0,26 $\mathrm{ml} / \mathrm{min} / \mathrm{año})$.

Durante los dos primeros años, la función renal permaneció estable contemplados los resultados de forma global y por grupos.

Fue a partir del tercer año cuando se observó un descenso leve pero significativo de la función renal $(-1,03 \mathrm{ml} / \mathrm{min} / \mathrm{año})(p=0,032)$. El deterioro se dio en los dos grupos de estudio (grupo 1: $-1,26 \mathrm{ml} / \mathrm{min} /$ año y grupo $2:-0,81 \mathrm{ml} / \mathrm{min} / \mathrm{año}$ ).

A los tres años también analizamos el impacto de la existencia de proteinuria en el momento de reclutamiento sobre la función renal. Los pacientes que tenían proteinuria en el periodo basal presentaron un incremento significativo de la Crs a los tres años (Crs basal $1,85 \mathrm{mg} / \mathrm{dl}$ y Crs a los tres años $2,15 \mathrm{mg} / \mathrm{dl}, \mathrm{p}=0,032$ ). La presencia de proteinuria en esos pacientes indicaría la existencia de verdadera patología renal y, por tanto, serían los que podrían beneficiarse de una atención nefrológica específica. En los pacientes sin proteinuria, la función renal también disminuye aunque más 
lentamente, posiblemente debido al factor edad, factor de riesgo no modificable (Crs basal $1,1 \mathrm{mg} / \mathrm{dl}$ y Crs a los tres años $1,16 \mathrm{mg} / \mathrm{dl})$.

El seguimiento a los cinco años refuerza los datos previos: de forma global, la función renal se deteriora lentamente en los ancianos; un número importante de ellos fallece antes de que la ERC progrese a un estadio terminal que precisara tratamiento sustitutivo renal.

De forma global, los pacientes que completaron el seguimiento de cinco años, treinta y nueve pacientes (48,8\%), presentaron un descenso medio de FG de 2,61 $\mathrm{ml} / \mathrm{min}$. En el análisis pormenorizado por grupos, los pacientes del grupo 1 presentaron

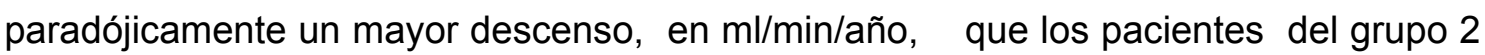
$(-0,67$ versus $-0,26$, no significativo). Este hallazgo se explicaría porque en el grupo 1 , el descenso del FG traduciría el fenómeno fisiológico de reducción del FG asociado a la edad; en tanto que en el grupo 2, la escasa variación podría explicarse porque los pacientes con mayor deterioro del FG fallecían, mientras que sobrevivían los más estables.

Nuestros resultados, son superponibles a otro estudio específico de ancianos de Hemmelgarm (29), donde se describe, en una población de más de 66 años, que la progresión de la ERC, a lo largo de dos años de seguimiento, es lenta (en mujeres 0,8 $\mathrm{ml} / \mathrm{min} /$ año y en varones $1,4 \mathrm{ml} / \mathrm{min} / \mathrm{año}$ ) excepto en los pacientes diabéticos y en aquellos que tenían un $\mathrm{FG}<30 \mathrm{ml} / \mathrm{min}$ en el periodo de reclutamiento.

En nuestra opinión, el hecho de que personas sanas tengan un FG disminuido asociado al proceso de envejecimiento, unido al lento deterioro que experimenta la función renal con el paso del tiempo, justificarían la inconveniencia de utilizar de forma sistemática la clasificación KDOQI en los ancianos. 


\subsection{Valor pronóstico de la proteinuria en la evolución de la función renal y en la}

mortalidad en los ancianos.

La presencia de proteinuria es un signo primordial de daño renal (87). Así mismo, numerosos estudios previos han demostrado que la proteinuria es un factor de riesgo muy importante de la disfunción renal y de mortalidad cardiovascular $(88,89)$. En un reciente metaanálisis, que analiza nueve cohortes de población general y ocho cohortes con pacientes de alto riesgo, con inclusión de más de un millón de personas, se encuentra que un bajo grado de FG unido a la presencia de albuminuria se asocia con alto riesgo de desarrollar nefropatía terminal, con independencia de otros factores de riesgo tradicionales de enfermedad cardiovascular (90).

En nuestro estudio, en el corte basal los pacientes del grupo 1 no presentaban proteinuria y, en los del grupo 2 , sólo el $13 \%$ tenían proteinuria mayor de $0,5 \mathrm{~g} /$ día. Si consideramos que sólo catorce pacientes del grupo 2 seguían en el estudio a los cinco años, este número resulta insuficiente como para extraer conclusiones acerca del valor pronóstico de la proteinuria: de hecho, creemos más fiable la valoración que se hizo a los tres años del seguimiento.

Como comentamos en el párrafo anterior, comprobamos que aquellos pacientes con proteinuria fueron los que incrementaron de forma significativa las cifras de $\mathrm{Crs}$ a los tres años respecto a los pacientes sin proteinuria. En resumen, los ancianos con proteinuria son aquellos en los que la ERC puede progresar de forma más rápida y los que se beneficiarían más de cuidados específicos nefrológicos.

Una de las limitaciones de la clasificación KDOQI radica precisamente en que la proteinuria se tiene en cuenta para definir los estadios más leves (estadio 1 y 2) y, sin embargo, en los estadios más avanzados (3-5), es suficiente tener un FGe inferior a $60 \mathrm{ml} / \mathrm{min}$ para definirlos con independencia de que presenten o no proteinuria. Así, es posible que la función renal de pacientes con ERC en estadio 1 pero con proteinuria progrese antes a nefropatía terminal que requiera diálisis, que otros pacientes en estadio 3 pero sin proteinuria. En nuestro estudio, encontramos pacientes con Crs en 
rango normal sin proteinuria con un FG disminuido, que podrían ser etiquetados de ERC en estadio 3 simplemente por tener FG inferior a $60 \mathrm{ml} / \mathrm{min}$, $\mathrm{y}$, sin embargo, ninguno de estos pacientes progresó a nefropatía terminal en el tiempo de seguimiento.

En nuestro estudio, la proteinuria también mostró ser un factor de riesgo independiente de mortalidad, como se recoge en el análisis de Cox efectuado en el seguimiento a los tres años (RR 2,12, $p=0,03)$.

Nuestros resultados son superponibles a los comunicados en el estudio de Hemmelgarn et al, en el cual se analizó una cohorte de 920.985 adultos, con una mortalidad de un $3 \%$ a los 35 meses de media de seguimiento; los autores concluyeron de que tanto el riesgo de mortalidad, de infarto de miocardio y de progresión a insuficiencia renal asociada con un determinado nivel de FGe se incrementaba de forma independiente en los pacientes con mayores niveles de proteinuria (91).

\subsection{Pronóstico asociado a la ERC: Desarrollo de nefropatía terminal y mortalidad.}

En los últimos años existe gran interés en la detección precoz de la ERC para instaurar de forma anticipada terapias que frenen la progresión de la ERC a un estadio 5 y, en su caso, se pueda preparar con suficiente antelación a los pacientes para el TSR (hemodiálisis/ diálisis peritoneal/ transplante renal) (92). Sin embargo, en la población anciana, estos objetivos no parecen tan claros si se tiene en cuenta que una parte importante de estos pacientes no se va a beneficiar de una preparación específica para el TSR: en unos casos por decisión propia de los pacientes, en otros, por comorbilidad asociada a la ERC que pueden contraindicar su inclusión en estos programas (neoplasias, deterioro cognitivo, etc...), y en otros casos por el fallecimiento de los pacientes. En algunos estudios previos se constata que el riesgo de fallecer es mayor que el de progresar a la nefropatía terminal (56). En el estudio de Eriksen e Ingebretsen, el 31\% de pacientes fallecieron frente al 2\% que inició TSR (93). 
Los hallazgos de nuestro estudio van en consonancia con los datos publicados en la mayoría de trabajos. Nuestros resultados reflejan una elevada mortalidad (superior al $50 \%$ en cinco años) y, además, que el fallecimiento ocurrió antes de que la ERC progresara a un estadio de nefropatía terminal como para necesitar de TSR; sólo dos pacientes progresaron a estadio 5 pero ninguno fue incluido en programa de TSR: en un caso por decisión propia y en el otro caso por criterios médicos que desaconsejaron la inclusión.

Uno de los pocos estudios donde se encuentra una proporción similar de pacientes con estos pronósticos, nefropatía terminal y mortalidad, es el de Agarwal et al. En su estudio, la incidencia acumulada para nefropatía terminal fue del $17,6 \%$ y para la mortalidad del $18 \%$. Cuando se analizó este hallazgo se encontró que se trataba de pacientes mayoritariamente varones (un 96\%), el 49\% eran diabéticos, presentaban enfermedad coronaria un $43 \%$ y enfermedad vascular periférica un $22 \%$. En este estudio, un $8 \%$ de los pacientes rechazaron las técnicas de reemplazo renal con diálisis (52).

Conway et al analizan, en una cohorte de pacientes diagnosticados de ERC en estadio 4, los factores predictores de mortalidad y de necesidad de TSR, y encuentran que la supervivencia como para precisar diálisis disminuye a medida que se incrementa la edad, en parte debido a la baja tasa de descenso de la función renal en los ancianos. También encuentran como factores de riesgo predictores de TSR la presencia de proteinuria, una alta tasa de disminución del FG (> $4 \mathrm{ml} / \mathrm{min} / a n ̃ o)$, bajos niveles basales de FG y niveles de hemoglobina inferiores a $10 \mathrm{~g} / \mathrm{dl}$. Así, los pacientes fallecen por otras causas antes de desarrollar fallo renal que requiera TSR (94). Como hemos expuesto más arriba, los pacientes de nuestro estudio que tenían proteinuria mostraban incremento de Crs a los tres años frente a los que no la tenían, y sólo dos pacientes del grupo con peor función renal basal progresaron a nefropatía terminal (ningún paciente del grupo 1 progresó a ese estadio). 
También hemos referido que la mortalidad en nuestro estudio fue muy elevada (un $50 \%$ ), lo cual se puede explicar por tratarse de una población muy envejecida, con una mediana de 83 años. Los pacientes con peor función renal basal (grupo 2) presentaron una mortalidad significativamente mayor $(66,7 \%$ frente a $34,2 \% ; p=0,004)$. Una de las explicaciones posibles sería que estos pacientes no sólo tenían peor función renal previa, sino que, además, también eran significativamente más añosos; de hecho, en el análisis de regresión logística, la edad se asociaba a la mortalidad independientemente del grupo.

La enfermedad cardiovascular es la causa más frecuente de muerte en los pacientes con ERC $(95,96)$. En un reciente estudio, Roderick et al demuestran que la edad $>75$ años es un factor de riesgo per se de muerte, con independencia de todas las causas de muerte incluyendo la cardiovascular (97).

En el estudio de Keith et al, los pacientes que fallecieron presentaban una mayor prevalencia de enfermedad coronaria, de insuficiencia cardiaca congestiva, de diabetes mellitus y de anemia respecto a los pacientes vivos (56). En nuestro estudio, las principales causas de fallecimiento de nuestros pacientes fueron el deterioro progresivo del estado general, seguidas por las infecciones, en lugar de la enfermedad cardiovascular. La elevada mortalidad detectada en ancianos con peor grado de función renal justificaría la necesidad de tratar a estos pacientes de forma integral, aunque la enfermedad renal no sea el elemento condicionante fundamental de su muerte.

Con las premisas de la alta mortalidad en ancianos, el bajo riesgo de progresión de la ERC a nefropatía terminal y el rechazo por parte del anciano a iniciar TSR, es posible que las recomendaciones de las Guías KDOQI para el cuidado de la ERC en el anciano pierdan su validez a favor del tratamiento individualizado en este grupo de población. En estos pacientes se debe considerar no sólo su FGe, sino factores como su estado general, enfermedades asociadas, su situación mental y funcional, etc, para definir qué ancianos se pueden beneficiar de una preparación específica para el TSR. 
Por otra parte, en los últimos años existe una evidencia creciente de la relación entre los níveles de ácido úrico en sangre y la patología renal y cardiovascular, siendo la lesión endotelial el mecanismo patogénico propuesto $(98,99)$. También se ha demostrado que los niveles de ácido úrico se comportan como un factor de riesgo de mortalidad, tanto cardiovascular como global (100). En nuestro estudio también hemos encontrado que el ácido úrico ha mostrado ser un factor de riesgo independiente de mortalidad global $(R R: 1,35, p=0,000)$.

\subsection{Análisis de eventos cardiovasculares de novo en el periodo de seguimiento.}

Durante el seguimiento a los cinco años, el $60 \%$ de los pacientes ingresaron al menos en una ocasión.

En la literatura se describe la IC como la causa de hospitalización más habitual en los pacientes de más de 65 años (101). En España, se estima una prevalencia de IC en torno a un $7-8 \%$ en la población general de 45 o más años (con una media de edad de 64 años), y el 1\% del total de las tasas de hospitalización corresponden a episodios de IC descompensada (con una media de edad más elevada) (102). Entre los mecanismos etiopatogénicos involucrados en la aparición de la IC en pacientes ancianos se pueden mencionar, por una parte, los cambios asociados al proceso de envejecimiento (incremento progresivo de la masa de ventrículo izquierdo, pérdida de la elasticidad aórtica, incremento en el contenido de colágeno en el corazón normal) $(103,104)$, y por otra parte, la asociación con patologías como la HTA, la $\mathrm{Cl}$ y la patología valvular cardiaca (102).

En nuestro estudio, también la IC fue el principal evento cardiovascular en el curso del seguimiento, por encima de la $\mathrm{Cl}$ y el ACV. Un $20 \%$ de ellos presentaron algún episodio de IC que se podría explicar por ser una población muy envejecida, y porque, además, la HTA fue una patología con alta prevalencia (superior al $80 \%$ ). Al analizar la presencia de IC por grupos, aunque las diferencias no alcanzaron significación estadística (bien por el número limitado de pacientes analizados o por el 
periodo de tiempo estudiado), los pacientes del grupo 2 sufrieron más episodios de IC. Ya se ha comentado previamente como los pacientes con antecedentes de IC en el periodo basal también tenían una peor función renal.

La aparición de novo de cardiopatía isquémica en la población estudiada fue menos frecuente que la IC, y ocurrió en un porcentaje similar en los dos grupos de estudio (un $5,3 \%$ en el grupo 1 , y $7,3 \%$ en el grupo 2 ).

Los accidentes cerebro-vasculares son una causa relevante de incapacidad en el mundo, y más del $80 \%$ de los ictus cerebrales ocurren en personas de >= 65 años (105). La elevada vulnerabilidad al ACV en ancianos se asocia a cambios en el cerebro ligados al envejecimiento y a otros factores de riesgo bien documentados como la HTA, fibrilación auricular, estenosis carotídea entre los más importantes (106). En nuestro estudio, en el periodo basal los pacientes del grupo 1 tenían registrados más episodios de ACV previos así como más antecedentes de fibrilación auricular comparados con los pacientes del grupo 2, si bien la diferencia no alcanzó significación estadística. Durante el periodo de seguimiento, sólo el $11,5 \%$ de pacientes del grupo 1 presentó algún episodio de ACV mientras que no se constató ninguno en el grupo 2, la diferencia tampoco fue significativa. Una explicación posible para este hallazgo sería que en el grupo 2 se antepuso el fallecimiento a la aparición del ACV.

\subsection{0. ¿Se deben aplicar de forma sistemática las fórmulas de estimación del filtrado glomerular en los ancianos?.}

El cálculo del FG también ha sido un punto de debate en la especialidad de Nefrología $(54,107)$. Desde la introducción en algunos países de la estimación rutinaria del FG ( $\mathrm{FGe}$ ) para toda la población que es vista por sus médicos de cabecera, se ha producido un incremento considerable de derivaciones de pacientes a las consultas de Nefrología. En estos pacientes la única manifestación de ERC sería tener un nivel de FGe inferior a $60 \mathrm{ml} / \mathrm{min}$. Muchos de ellos serían mujeres de más de 65 años sin otras 
manifestaciones de ERC. Este aspecto no sólo genera preocupación en los pacientes, sino un importante impacto en los costes de la asistencia sanitaria (108).

En nuestro estudio la Crs presenta mejor correlación con otros parámetros analíticos asociados a la enfermedad renal (calcio, potasio) que con las fórmulas matemáticas derivadas de la Crs. Además, las cifras de FGe son diferentes según los métodos de estimación utilizados; por lo tanto, el empleo sistemático de fórmulas matemáticas de FG podría conducir a errores a la hora de incluir a los pacientes en un estadio u otro de ERC. Según estos datos, podríamos considerar que la generalización del uso de esas fórmulas, sobre todo para pacientes con Crs en rango normal, no estaría justificada para establecer el diagnóstico de ERC. A la vista de nuestros hallazgos, la estimación del FG podría justificarse para hacer el seguimiento de ancianos que, además de la Crs elevada, presentaran otras manifestaciones características de la ERC (anemia, alteraciones del calcio-fósforo, acidosis metabólica, alteraciones urinarias, proteinuria...), es decir, en pacientes con verdadera patología renal.

La estimación de FG mediante fórmulas matemáticas podría aplicarse en toda la población para realizar un correcto ajuste de fármacos, dado el grado de concordancia del CCr con las fórmulas CG y CKD-EPI que hemos encontrado en este estudio.

\subsection{1.¿Se debe extender la Clasificación KDOQI de ERC a toda la población?.}

Las Guías KDOQI defienden que la clasificación de la ERC debe generalizarse a toda la población (3). Según venimos comentando a lo largo de la exposición, con los datos de nuestro estudio, vemos que muchos ancianos con $\mathrm{Crs}$ en rango normal, de acuerdo a la clasificación KDOQI, deberían de ser etiquetados de enfermos renales por el hecho de tener un FGe disminuido (inferior a $60 \mathrm{ml} / \mathrm{min}$ ), pero sin presentar otras manifestaciones de enfermedad renal (anemia, acidosis metabólica, proteinuria etc...). Por otra parte, también vemos que muchos ancianos tienen un FGe inferior a $60 \mathrm{ml} / \mathrm{min}$ al inicio del estudio y que, con el paso del tiempo, el nivel de FGe

permanece estable ó se deteriora muy lentamente. Es más, en ocasiones el 
fallecimiento del paciente sucede antes de que el FGe se deteriore a un ritmo como para necesitar TSR.

Otro argumento que habría que considerar sería que los donantes de riñón vivo, que representarían el paradigma de personas sanas, tienen generalmente unos niveles de FG inferior a $60 \mathrm{ml} / \mathrm{min} / 1.73 \mathrm{~m} 2$ y es raro que estas personas recuperen el grado de FG a niveles pre-nefrectomía $(22,109)$. En estos casos no se ha demostrado un mayor riesgo de progresión a la nefropatía terminal ni de muerte con el transcurso del tiempo $(22,110)$.

Por todo ello, creemos que la clasificación KDOQI de ERC no debería de aplicarse de forma sistemática a la población anciana. De igual modo, un número significativo de nefrólogos ingleses apoya la propuesta de Glassock y Winearls de ser más cuidadosos y evitar la estimación rutinaria del FG hasta que la clasificación propuesta por las Guías KDOQI sea científicamente más defendible $(32,53)$. Ello evitaría miedos innecesarios en los pacientes así como contribuiría a reducir la creciente preocupación entre los nefrólogos por derivaciones innecesarias a sus consultas y los altos costes derivados de dicha situación.

\subsection{El manejo de la ERC en el anciano.}

Diferentes estudios que utilizan la clasificación KDOQI demuestran que la mayor parte de la población que se diagnostica de ERC es anciana $(27,111)$. Al tiempo, en el estudio realizado por Wetzels et al, en ancianos sanos, se concluye que en la mayoría de ellos la única manifestación de ERC es el hallazgo de un FGe disminuido que no se acompaña de otras alteraciones de daño renal, salvo una pequeña proporción de casos que presenta proteinuria (112).

Por lo tanto, creemos que, en la clínica rutinaria, la detección y el manejo de la ERC en el anciano podrían realizarse como venía haciéndose antes de aparecer la definición de ERC según las Guías KDOQI. Sería una forma más sencilla, con una simple determinación de Crs y un sistemático de orina (Multistix) despistaríamos la 
presencia de patología renal que precise atención especializada. Estas medidas permitirían aclarar la confusión que muchos facultativos, no acostumbrados al manejo de la ERC, sienten a la hora de abordar este tipo de pacientes (54). Por otra parte, esta actitud permitiría evitar o reducir las interconsultas innecesarias y la sobrecarga de los equipos de Nefrología (113). Por ello, proponemos que cuando se identifiquen ancianos con Crs mayor de $1,1 \mathrm{mg} / \mathrm{dl}$, que no presentan alteraciones secundarias a la ERC (anemia, acidosis metabólica etc.) ni proteinuria, no es necesaria la derivación sistemática a Atención Especializada. De hecho, las recomendaciones publicadas en el Documento de Consenso sobre la ERC de la SEN y la Sociedad Española de Medicina Familiar y Comunitaria establecen que los pacientes mayores de 70 años con FG estable $>30 \mathrm{ml} / \mathrm{min}$ y albuminuria $<0,5 \mathrm{~g} / 24$ pueden seguirse en Atención Primaria sin necesidad de derivación, siempre que se mantenga un adecuado control de la tensión arterial y del resto de factores de riesgo cardiovascular (recomendación 11) (66).

\subsection{Repercusión de los agentes antihipertensivos sobre la función renal.}

El envejecimiento conlleva un aumento de la presión arterial, sobre todo de la sistólica, por lo que la HTA es una patología con elevada prevalencia en los ancianos $(33,114)$. En los últimos años, la HTA se ha considerado como un síndrome cardiovascular progresivo, en el que se produce daño en diversos órganos diana, entre ellos el riñón (115). Es por ello que la HTA, junto con la DM, son las principales causas de ERC que precisa TSR (34). Además, la enfermedad cardiovascular es la principal responsable de muerte de los pacientes con ERC (116).

Distintos ensayos clínicos demuestran los beneficios de los agentes antihipertensivos en la reducción de la morbimortalidad cardiovascular y en el enlentecimiento en la progresión del daño renal $(35,80,117)$. La mayoría de los estudios que analizan el uso de agentes antihipertensivos concluyen que los diuréticos son los agentes más frecuentemente utilizados $(33,118)$. Estos fármacos, además de estar indicados en el 
tratamiento de la HTA, a dosis bajas presentan la ventaja de prevenir la aparición de ataques cardíacos y la IC (119). En el conjunto de nuestros pacientes, también los diuréticos fueron los fármacos mas utilizados (68\%) sobre todo en aquellos pacientes con antecedentes de IC. La aparición de nuevos episodios de IC, en pacientes con esta patología, justificaría la necesidad de utilizar estos medicamentos.

El tratamiento con betabloqueantes, considerado hasta hace poco como primera línea de tratamiento en pacientes con HTA esencial, ha pasado a ser de segunda línea según un metaanálisis (120). La única indicación para mantener la terapia con betabloqueante como primera línea, sería pacientes con $\mathrm{Cl}$ e IC. En nuestro trabajo, los betabloqueantes eran los agentes antihipertensivos menos usados (7\%); su indicación quedaría limitada a pacientes con antecedentes de $\mathrm{Cl}$.

La mayoría de los estudios evidencian que se necesita la combinación de varios agentes antihipertensivos para el correcto control de la presión arterial $(80,121)$. Nosotros comprobamos igualmente que la mayoría de nuestros pacientes recibían dos ó más fármacos antihipertensivos, independientemente de los níveles de Crs basal. También analizamos la evolución de la función renal según los agentes antihipertensivos prescritos. Comprobamos que sólo los diuréticos producían variaciones en la función renal, y confirmamos en el análisis univariante y multivariante que el empleo de diuréticos actúa como factor predictor independiente para el aumento de la Crs. Cuando introducimos en el modelo los antecedentes de IC, se pierde la significación estadística, posiblemente por la fuerte asociación entre el empleo de diuréticos e IC (el 100\% de pacientes con IC tenían prescrito diurético).

Los diuréticos impiden la reabsorción de $\mathrm{CINa}$ en diferentes tramos de la nefrona que induce pérdida de sal y agua (122). En ocasiones, la excesiva depleción de volumen extracelular provoca situaciones de azotemía prerrenal (123), más aún en ancianos en los que la ingesta hídrica puede estar disminuida.

En nuestro estudio, encontramos que los pacientes en tratamiento con diuréticos, al cabo de un año, presentaban una elevación de Crs respecto a los que no utilizaban 
estos fármacos, y por ende un descenso en el nivel de FG. Sin embargo, en aquellos pacientes no se observó un incremento significativo de la proteinuria, por lo que es posible que el deterioro de función renal asociado a los diuréticos pudiera ser funcional, y por tanto, potencialmente reversible al suspenderlos. Este fenómeno habría que tenerlo en cuenta a la hora de estimar el FG y de catalogar al paciente en un determinado estadio de ERC.

\subsection{Concordancia entre el aclaramiento de creatinina (gold standard) y las} fórmulas derivadas de ella en el diagnóstico de enfermedad renal.

En la práctica clínica rutinaria no se determina el FG de forma exacta, sino que se recurre a estimaciones para su conocimiento (14). El CCr, determinado mediante una recogida de orina de 24 horas, ha sido el método tradicional empleado en la clínica para valorar el FG. Sin embargo, el CCr sobreestima ligeramente el FG debido a la secreción tubular de creatinina. Por otra parte, en algunos pacientes, puede ser complicada la recogida exacta de la orina. Para facilitar y simplificar la estimación del FG se desarrollaron otras fórmulas derivadas de la Crs: La fórmula de CG ha sido validada frente al CCr como gold standard y ha sido el método tradicional de conocer el FGe para el ajuste de fármacos (13). La clasificación KDOQI ha pretendido simplificar aún más este cálculo a través de la fórmula MDRD (utiliza la Crs, la edad, el sexo, la raza, pero no el peso), cuyo resultado es proporcionado muchas veces por el propio laboratorio (13). Recientemente ha aparecido una nueva ecuación (CKDEPI) que se considera más exacta (23). Sin embargo, ninguna de estas fórmulas han sido validadas en la población anciana y, por tanto, los resultados obtenidos pueden variar, con implicaciones pronosticas diferentes $(1,6)$.

En este apartado, de nuestro estudio podríamos llegar a dos conclusiones: en primer lugar, confirmamos que los niveles de FG determinados por MDRD son significativamente superiores respecto a otras fórmulas derivadas de la Crs y del 
CCr. En segundo lugar, la concordancia alcanzada en el diagnóstico de daño renal fue mejor con el uso de las fórmulas CG y CKD-EPI que con la fórmula MDRD.

Nuestros resultados, a pesar de haber hecho este estudio en sólo treinta y dos pacientes, son superponibles a un estudio más amplio de Pequignot et al, que estudiaron a ciento veintiún ancianos hospitalizados (124). Los autores compararon la exactitud en la predicción del CCr con las fórmulas CG y MDRD, y encontraron una concordancia entre el CCr y CG de 0,50 mientras que entre el CCr y MDRD fue de 0,33. Los autores concluyeron que el CG da una mejor predicción de medida que la fórmula MDRD. Sin embargo, tanto los hallazgos del estudio anterior como los nuestros se deberían de tomar con cautela, ya que en ambos estudios el grado de concordancia alcanzado ha sido sólo moderado. Tampoco hay que olvidar que ninguna de las fórmulas matemáticas derivadas de la Crs recomendadas para estimar el FG se han validado en la población anciana. Un reto de futuro sería realizar estudios específicos en ancianos que permitan clarificar el método de estimación de FG más apropiado. 
6. CONCLUSIONES 


\section{CONCLUSIONES.}

El análisis de los datos de nuestro estudio demuestra que los ancianos presentan un FGe inferior al rango considerado normal ( $<90 \mathrm{ml} / \mathrm{min})$. Estos resultados se confirman por tres métodos de estimación de FG (MDRD, CKD-EPI y Cockcroft-Gault). El seguimiento de la función renal en el tiempo de los pacientes que sobreviven a los cinco años demuestra una disminución de $\mathrm{FGe}$ en un promedio de 0,52 $\mathrm{ml} / \mathrm{min} / \mathrm{año}$.

1) Los ancianos con Crs en rango normal y sin proteinuria (grupo 1) tienen un FGe

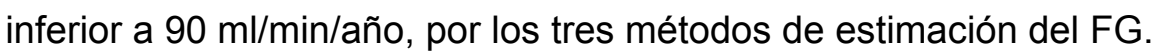

2) Los niveles medios de FGe por MDRD son significativamente superiores a los obtenidos en los mismos pacientes al emplear otras fórmulas (Cockcroft-Gault y CKDEPI). Los niveles de FGe por CKD-EPI, por término medio, son $4 \mathrm{ml} / \mathrm{min}$ inferiores al uso de la fórmula MDRD en ambos grupos, por lo que el empleo de la nueva fórmula CKD-EPI, mantendría o aumentaría la prevalencia de ERC en los ancianos.

3) Las mujeres con Crs en rango normal tienen un FGe significativamente inferior a los varones (por MDRD, CKD-EPI y Cockcroft-Gault); Estas diferencias en el género no son significativas en el grupo de pacientes con peor función renal basal (grupo 2). La "enfermedad renal oculta" es un problema exclusivo de mujeres.

4) Los ancianos con antecedentes de patología cardiaca previa (insuficiencia cardiaca, cardiopatía isquémica) presentan de forma significativa mayor deterioro de función renal. 
5) Sólo los pacientes con FGe (MDRD) inferior a $30 \mathrm{ml} / \mathrm{min}$ presentan manifestaciones asociadas a la ERC que precisen tratamiento con AEE o captores del fósforo. No se detectó acidosis metabólica en el grupo de pacientes con peor función renal basal (grupo 2).

6) En ambos grupos de pacientes se comprueba un lento deterioro de la función renal asociado a la edad: por término medio, el descenso fue de $0,52 \mathrm{ml} / \mathrm{min}$ año en los pacientes que sobrevivieron cinco años: en el grupo 1 este descenso es de 0,67

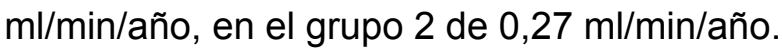

7) Los ancianos con proteinuria en el periodo basal son los que presentan mayor deterioro de función renal a los tres años. Además, la proteinuria junto con la edad son predictores de mortalidad en esta cohorte de personas añosas.

8) La mortalidad es el pronóstico más frecuente. Sólo el 2,5\% del total de ancianos estudiados progresó a nefropatía terminal (ningún paciente del grupo 1).

9) La mortalidad fue de forma significativa más elevada en el grupo de ancianos con peor función renal basal (grupo 2). La principal causa de muerte fue el deterioro progresivo del estado general. La enfermedad cardiovascular fue menos frecuente.

10) El ácido úrico se mostró como un factor de riesgo independiente de muerte en nuestros pacientes.

11) La insuficiencia cardiaca es el principal evento cardiovascular durante los cinco años de seguimiento. Fue más frecuente en el grupo 2 (no significativo). 
12) Los diuréticos son las drogas antihipertensivas más prescritas y los betabloqueantes las menos utilizadas. Los pacientes en tratamiento con diuréticos incrementaron los niveles de Crs en el corte realizado al año.

13) Las fórmulas Cockcroft-Gault y CKD-EPI presentan mejor grado de concordancia con el CCr que la fórmula MDRD. No obstante, el grado de concordancia es moderado.

14) Finalmente, creemos que en ancianos con Crs en rango normal, sin proteinuria ni otras alteraciones de ERC, que presenten como única manifestación de alteración renal un FG disminuido ( $<60 \mathrm{ml} / \mathrm{min}$ ), se debe evitar seguir las recomendaciones de las Guías KDOQI para la ERC. En nuestra opinión, esta consideración permitiría evitar preocupaciones y costes innecesarios generados de derivaciones inapropiadas de personas sanas a las consultas de Nefrología. 
7. BIBLIOGRAFÍA. 


\section{BIBLIOGRAFIA.}

1. Zhou XJ, Rakheja D, Yu X, Saxena R, Varizi ND, Silva FG. The aging kidney. Kidney Int 2008; 74: 710-20.

2. Levey AS, Atkins R, Coresh J, Cohen EP, Collins AJ, Eckardt K-U, Nahas ME, Jaber BL, Jadoul M, Levin A, Powe NR, Rossert J, Wheeler DC, Lameire N, Eknoyan G. Chronic kidney disease as a global public health problem: Approaches and iniciatives-a position statement from Kidney Disease Improving Global Outcomes. Kidney Int 2007; 72, 247-259.

3. National Kidney Foundation: K/DOQI Clinical practice guidelines for chronic kidney disease: evaluation, classification, and stratification. Am J Kidney Dis 2002; 39: S1-S266.

4. Stevens LA, Levey AS. Current status and future perspectives for CKD testing. Am J Kidney Dis 2009; 53, Suppl 3: S17-S26.

5. Levey AS, Stevens LA, Coresh J. Conceptual Model of CKD: Applications and implications. Am J Kidney Dis 2009; 53 (Suppl 3): S4-S16.

6. O'Hare AM, Choi Al, Bertenthal D, Bacchetti P, Garg AX, Kaufman JS et al. Age affects outcomes in Chronic Kidney Disease. J Am Soc Nephrol 2007; 18 : $2758-2765$.

7. Silva FG: The aging kidney: A review-part I. Int Urol Nephrol 2005; 37: 185-205.

8. Silva FG: The aging kidney: A review-part II. Int Urol Nephrol 2005; 37: 419432.

9. Lindeman RD, Tobin J, Shock NW. Longitudinal studies on the rate of decline in renal function with age. J Am Geriatr Soc 1985; 33: 278-85.

10. Epstein M, Hollenberg NK. Age as a determinant of renal sodium conservation in normal man. J Lab Clin Med 1976; 87: 411-417.

11. Rowe JW, Shock NW, De Fronzo RA. The influence of age on the renal response to water deprivation in man. Nephron 1976; 17: 270-278. 
12. Zhou XJ, Saxena R, Liu Z, Vaziri ND, Silva FG. Renal senescence in 2008: progress and challenges. Int Urol Nephrol 2008; 40: 823-39.

13. Gill J, Malyuk R, Djurdjev O, Levin A. Use of GFR equations to adjust drug doses in an elderly multi-ethnic group-a cautionary tale. Nephrol Dial Transplant 2007; 22: 2894-2899.

14. De Jong PE, Halbesma N and Gansevoort RT. Screening for early chronic kidney disease- what method fits best?. Nephrol Dial Transplant 2006; 21: 2358-2361.

15. Madero M, Sarnak MJ, Stevens LA. Serum cystatin C as a marker of glomerular filtration rate. Curr Opin Nephrol Hypert 2006; 15: 610-16.

16. Shlipak MG, Sarnak MJ, Katz R, Fried LF, Seliger SL, Newman AB et al: Cystatin $\mathrm{C}$ and the risk of death and cardiovascular events among elderly persons. N Engl J Med 2005;352(20):2049-60.

17. Rose BD, Post TW: Circulación renal y tasa de filtración glomerular. En: Rose BD, Post TW, editores. Trastornos de los electrólitos y del equilibrio ácido-base. Ed Marbán, 2005:21-70.

18. Doolan PD, Alpen EL,Theil GB. A clinical appraisal of the plasma concentration and endogenous clearance of creatinine. Am J Med 1962;32:65-79.

19. Douville P, Martel A.R, Talbot J, Desmeules S, Langlois S, Agarráis M. Impact of age on glomerular filtration estimates. Nephrol Dial Transplant 2009; 24: 97103.

20. Poggio ED, Wang X, Greene T, Van Lente F, Hall PM. Performance of the Modification of Diet in Renal Disease and Cockcroft-Gault Equations in the estimation of GFR in health and chronic kidney disease. J Am Soc Nephrol 2005; 16: 459-466.

21. Roderick PJ, Atkins RJ, Smeeth L, Nitsch DM, Hubbard RB, Flectcher AE et al. Detecting chronic kidney disease in older people; what are the implications? Age and Aging 2008; 37: 179-186. 
22. Poggio ED, Rule AD. A critical evaluation of chronic kidney disease-should isolated reduced estimated glomerular filtration rate be considered a "disease"?. Nephrol Dial Transplant 2009; 24: 698-700.

23. Levey AS, Stevens LA, Schmid CH, Zhang Y, Castro AF, Feldman HI et al. A new equation to estimate glomerular filtration rate. Ann Intern Med 2009; 150: $604-612$.

24. Balakumar P, Rohilla A, Thangathirupathi A. Gentamicin-induced nephrotoxicity: do we have a promising therapeutic approach to blunt it? Pharmacol Res 2010;62 (3): 179-86.

25. Ishani A, Xue JL, Himmelfarb J, Eggers PW, Kimmel PL, Molitoris BA et al. Acute kidney injury increases risk of ESRD among elderly. J Am Soc Nephrol 2009; 20: 223-228.

26. Pascual J, Zamora J, Pirsch JD. A systematic review of kidney transplantation from expanded criteria donors. Am J Kidney Dis 2008; 52 (3):553-86.

27. Zhang QL, Rothenbacher D. Prevalence of chronic kidney disease in population-based studies: systematic review. BMC Public Health 2008; 8:117.

28. Manjunath G, Tifhiouart H, Coresh J, Macleod B, Salem DN, Griffith JL et al. Level of kidney function as a risk factor for cardiovascular outcomes in the elderly. Kidney Int 2003; 63: 1121-9.

29. Hemmelgarn BR, Zhang J, Manns BJ, Tonelli M, Larsen E, Ghali WA et al.. Progresion of kidney dysfunction in the community-dwelling elderly. Kidney Int 2006; 69: 2155-2161.

30. Otero A, de Francisco A, Gayoso P, García F; EPIRCE Study Group. Prevalence of chronic renal disease in Spain: results of the EPIRCE study. Nefrología 2010;30 (1):78-86.

31. Glassock RJ, Winearls C. An epidemic of chronic kidney disease: fact or fiction? Nephrol Dial Trasplant 2008; 23 (4): 1117-21. 
32. Campbell $\mathrm{KH}$, O'Hare AM. Kidney disease in the elderly: update on recent literature. Curr Opin Nephrol Hypertens 2008; 17: 298-303.

33. Martín-Baranera M, Sánchez Ferrin P, Armario P; Geriatric HTA Study Group: Prevalence of hypertension in elderly long-term care residents in Spain. The Geriatric HTA Study. Med Clin (Barc), 2006; 127 (18): 681-687.

34. Atkins RC: The epidemiology of chronic kidney disease. Kidney Int 2005, Suppl (94): S14-8.

35. Leonetti G, Cuspidi C, Facchini M: Antihypertensive therapy in the elderly: results of large trials. Ital Heart J 2001; Suppl 2 (11): 1161-1169.

36. Samiy AH. Renal disease in the elderly. Med Clin North Am 1983; 67 (2): 46380.

37. Heras M, Saiz A, Sánchez R, Fernández-Reyes MJ, Molina A, Rodríguez MA, Álvarez-Ude. La biopsia renal en pacientes de 65 ó más años: ¿existen diferencias en la indicación y en la histopatología respecto al resto de pacientes? Rev Esp Geriatr Gerontol 2010; 45 (6):316-19.

38. Rivera F, López Gómez JM, Pérez-García R. Frequency of renal pathology in Spain 1994-1999. Nephrol Dial Transplant 2002; 17 (9): 1594-602.

39. National Kidney Foundation. NKF-KDOQI Clinical Practice Guidelines for Anemia of Chronic Kidney Disease: update 2000. Am J Kidney Disease 2001; 37 (suppl 1): 182-238.

40. Nurko S. Anemia in Chronic Kidney Disease: causes, diagnosis, treatment. Cleve Clin J Med 2006; 73 (3): 289-97.

41. Agarwal AK. Practical approach to the diagnosis and treatment of anemia associated with CKD in elderly. J. Am Med Dir Assoc 2006; 7 (9 Suppl): S7S12.

42. Wish JB, Coiné DW. Use of erythropoiesis-stimulating agents in patients with anemia of chronic kidney disease:overcoming the pharmacological and 
pharmacoeconomic limitations of existing therapies. Mayo Clin Proc 2007; 82 (11):1371-80.

43. Kurtz I, Maher T, Hulter HN. Effect of diet on plasma acid-base composition in normal humans. Kidney Int 1983;24 (5): 670-80).

44. Rose BD, Post TW: Regulación del equilibrio ácido-base. En: Rose BD, Post TW, editores. Trastornos de los electrólitos y del equilibrio ácido-base. Ed Marbán, 2005:326-371.

45. Kraut JA, Kurtz I. Metabolic acidosis of CKD: Diagnosis, Clinical Characteristics, and Treatment. Am J Kidney Dis 2005; (45):6:978-993.

46. Kraut JA, Madias NE. Consequences and therapy of the metabolic acidosis of chronic kidney disease. Pediatr Nephrol 2011; 26: 19-28.

47. Brito-Ashurst I, Varagunam M, Raftery MJ, Yaqoob MM. Bicarbonate supplementation slows progression of CKD and improves nutritional status. $J$ Am Soc Nephrol 2009; 20 (9): 2075-2084.

48. Block GA, Cunningham J. Morbidity and mortality associated with abnormalities in bone and mineral metabolism in CKD. En Olgaard K (ed). Clinical Guide to the Basics of Bone and Mineral Metabolism in CKD. National Kidney Foun dation: New York, 2006:77-92.

49. Moe SM, Drüeke T, Lameire N, Eknoyan G. Chronic Kidney Disease-mineral bone disorder: a new paradigm. Adv Chronic Kidney Dis 2007;14 (1): 3-12.

50. Martín KJ, González EA. Prevention and control of phosphate retention/hyperphosphatemia in CKD-MBD: What is normal, when to star, and how to treat?. Clin J Am Soc Nephrol 2011;6 (2):440-446.

51. Hallan SI, Dahl K, Oien CM, Grootendorst DC, Aasberg A, Holmen J et al. Screening strategies for chronic kidney disease in the general population : follow-up of cross sectional health survey. BMJ 2006; 333: 1047-50. 
52. Agarwal R, Bunaye Z, Bekele D, Light RP. Competing risk factor analysis of End-Stage-Renal-Disease and mortality in chronic kidney disease. Am J Nephrol 2008;28:569-75.

53. Glassock R J, Winearls CG. Routine reporting of estimated glomerular filtration rate: not ready for prime time. Nature Clinical Practice Nephrology 2008; 4: $422-423$.

54. Robles NR. Cálculo del filtrado glomerular: una visión escéptica. Nefrología $2007 ; 27: 405-407$.

55. O' Hare A M, Bertenthal D, Covinsky K E, Landefeld C.S, Sen S, Mehta K et al.: Mortality risk stratification in chronic kidney disease: One size for all ages?. J Am Soc Nephrol 2006; 17: 846-853.

56. Keith D, Nichols GA, Gullion C, Brown JB, Smith DH. Longitudinal follow-up and outcome among a population with chronic kidney disease in a large managed care organization. Arch Intern Med 2004; 164: 659-663.

57. Manns B, Tonelli M, Yilmaz S, Lee H, Laupland K, Klarenbach S, et al. Establishment and maintenance of vascular access in incident hemodialysis patients: a prospective cost analysis. J Am Soc Nephrol 2005; 16:201-209.

58. Owen WF, Lowrie EG. C-reactive protein as an outcome predictor for maintenance hemodialysis patients. Kidney Int 1998; 54:627-36.

59. Goldstein RS, Tarloff JB, Hook JB. Age-related nephropathy in laboratory rats. FABEB J 1988; 2 (7): 2241-51.

60. Anderson S, Brenner BM. Effects of aging on the renal glomerulus. Am J Med 1986;80:435-442.

61. Kaysen GA, Myers BD. The aging kidney. Clin Geriatr Med 1985;1: 207-222.

62. Fliser D, Zeier M, Nowack R, Ritz E. Renal functional reserve in healthy elderly subjects. J Am Soc Nephrol 1993;3:1371-77. 
63. Fliser D, Franek E, Joest M, Block S, Mutschler E, Ritz E: Renal function in the elderly:impact of hypertension and cardiac function. Kidney Int 1997;51:11961204.

64. Fliser D, Franek E, Ritz E. Renal function in the elderly-is the dogma of an inexorable decline of renal function correct?. Nephrol Dial Transplant $1997 ; 12: 1553-55$.

65. Levey AS, Greene T, Kusek JW, Beck GJ. Simplified equation to predict glomerular filtration rate from serum creatinine. J Am Soc Nephrol 2000; 11: $828(\mathrm{~A})$.

66. Documento de consenso sobre la Enfermedad Renal Crónica. SEN-semFYC. Nefrología 2008; 28 (3): 273-82. (Disponible www.senefro.org).

67. Cockcroft DW, Gault MH. Prediction of creatinine clearance from serum creatinine. Nephron 1976; 16: 31-41.

68. Charlson ME, Pompei P, Ales K, MacKenzie CR. A new method of classifying prognostic comorbidity in longitudinal studies:development and validation. $\mathrm{J}$ Chron Dis 1987; 40 (5):373-83.

69. Stevens LA, Coresh J, Levey AS. CKD in the elderly-Old questions and new challenges: World Kidney Day 2008. Am J Kidney Dis 2008;51(3):353-57.

70. Glassock RJ, Winearls C. CKD in the elderly. Am J Kidney Dis 2008;52:803.

71. Coresh J, Stevens LA, Levey AS. Chronic Kidney Disease is common : what do we do next? Nephrol Dial Transplant 2008; 23:1122-25.

72. Praga M. Progresión de la insuficiencia renal crónica en el paciente geriátrico. Nefrología 1997; 17; S3:68-72.

73. Chadban SJ, Briganti EM, Kerr PG, Dunstan DW, Welborn TA, Zimmet PZ, Atkins RC. Prevalence of kidney damage in Australian adults: The AusDiab kidney study. J Am Soc Nephrol 2003; 14, S131-38. 
74. Labrador PJ, Mengotti T, Jiménez M, Macías M, Vicente F, Labrador J, Martín Orcina J. Insuficiencia renal oculta en Atención Primaria. ¿Un problema exclusivo de mujeres? Nefrología 2007; 27: 716-720.

75. Heras M, Fernández-Reyes MJ, Guerrero MT. Sobre la estimación de la función renal en el anciano: implicaciones del uso sistemático de la fórmula Modification of Diet in Renal Disease para el ajuste farmacológico. Rev Esp Ger Gerontol 2010; 45 (1):50-1.

76. Montañés R, Bover J, Oliver A, Ballarín JA, Gracia S. Valoración de la nueva ecuación CKD-EPI para la estimación del filtrado glomerular. Nefrología 2010; 30 (2): 185-94.

77. Stevens LA, Schmid CH, Greene T, Zhang YL, Beck GJ, Froissart M et al. Comparative performance of the CKD- Epidemiology Collaboration (CKD-EPI) and the Modification of Diet in Renal Disease (MDRD) study equations for estimating GFR levels above $60 \mathrm{ml} / \mathrm{min} / 1.73 \mathrm{~m} 2$. Am J Kid Disease 2010; 56 (3): 486-95.

78. Kasiske BL. Relationship between vascular disease and age-associated changes in the human kidney. Kidney Int 1987; 31: 1153-1159.

79. Lindeman RD, Tobin J, Shock NW. Association between blood pressure and the rate of decline in renal function with age. Kidney Int 1984;26:861-868.

80. Wenzel RR: Renal protection in hypertensive patients: selection of antihypertensive therapy. Drugs 2005; 65: S 2: 29-39.

81. Obrador GT, Pereira BJ. Systemic complications of chronic kidney disease. Pinpointing clinical manifestations and best management. Postgrad Med $2002 ; 111(2): 115-22$.

82. Thomas R, Kanso A, Sedor JR. Chronic kidney disease and its complications. Prim Care 2008; 35 (2):329-44.

83. Cibulka R, Racek J. Metabolic disorders in patients with chronic kidney failure. Physiol Res 2007; 56:697-705. 
84. Pendse S, Singh AK. Complications of chronic kidney disease: Anemia, mineral metabolism and cardiovascular disease. Med Clin N Am 2005; 89:549-61.

85. Román-García P, Carrillo-López N, Cannata-Andia JB. Pathogenesis of bone and mineral related disorders in chronic kidney disease: key role of hyperphosphatemia. J Ren Care 2009;35 S1:34-38.

86. Garella S, Chang BS, Khan SI. Dilution acidosis and contraction alkalosis: review of a concept. Kidney Int 1975;8:279-83.

87. García de Vinuesa S. Factores de progresión de la enfermedad renal crónica. Prevención secundaria. Nefrología 2008; S3:17-21.

88. Peterson JC, Adler S, Burkart JM, Greene T, Hebert LA, Hunsicker LG et al. Blood pressure control, proteinuria, and the progression of renal disease: the Modification of Diet In Renal Disease Study. Ann Intern Med 1995;123:75462.

89. Gerstein HC, Mann JF, Yi Q, Zinman B, Dinneen SF, Hoogwerf B et al. Albuminuria and risk of cardiovascular events, death, and heart failure in diabetic and nondiabetic individuals. JAMA 2001;286:421-26.

90. Gansevoort RT, Matsushita K, van der Velde M, Astor BC, Woodward M, Levey AS et al. Lower estimated GFR and higher albuminuria are associated with adverse kidney outcomes. A collaborative meta-analysis of general and highrisk population cohorts. Kidney Int 2011; 80:93-104.

91. Hemmelgarn BR, Manns BJ, Lloyd A, James MT, Klarenbach S, Jindal KK et al. Relation between kidney function, proteinuria and adverse outcomes. JAMA 2010; 303: 423-9.

92. Schieppati A, Remuzzi G. The future of renoprotection :frustration and promises. Kidney Int 2003;64: 1947-55.

93. Eriksen BO, Ingebretsen OC. The progression of chronic kidney disease: a 10year population-based study of the effects of gender and age. Kidney Int 2006; 69:375-82. 
94. Conway B, Webster A, Ramsay G, Morgan N, Neary J, Whitworth C, Harty J. Predicting mortality and uptake of renal replacement therapy in patients with stage 4 chronic kidney disease. Nephrol Dial Transplant 2009; 24:1930-37.

95. McCullough PA, Li S, Jurkovitz CT, Stevens L, Collins AJ, Chen SC et al. Chronic Kidney Disease, prevalence of premature cardiovascular disease, and relationship to short-term mortality. Am J Heart 2008; 156 (2): 277-83.

96. McCullough PA, Steigerwalt S, Tolia K, Chen SC, Li S, Norris KC et al. Cardiovascular disease in chronic kidney disease: data from the Kidney Early Evaluation Program (KEEP). Curr Diab Rep 2011; 11 (1):47-55.

97. Roderick PJ, Atkins RJ, Smeeth L, Mylne A, Nitsch DM, Hubbard RB, et al. CKD and mortality risk in older people: a community-based population study in the United Kingdom. Am J Kidney Dis 2009; 53: 950-60.

98. Minguela JI, Hernando A, Gallardo I, Martínez I, García P, Muñoz RI et al. La hiperuricemia como factor de riesgo cardiovascular y renal. Dial Trasp 2011;32 (2):57-61.

99. Waring WS, Webb DJ, Maxwell SRJ. Effect of local hyperuricemia on endothelial function in the human forearm vascular bed. $\mathrm{Br} \mathrm{J}$ Clin Pharmacol 2000; 49: 511.

100. Madero M, Sarnak MJ, Wang X, Greene T, Beck GJ, Kusek JW et al. Uric acid and long term outcomes in CKD. Am J Kidney Dis 2009:53:796-803.

101. Biernacka A, Frangogiannis NG. Aging and cardiac fibrosis. Aging Dis 2011; 2(2):158-73.

102. Chivite D, Formiga F, Pujol R. La insuficiencia cardiaca en el paciente anciano. Rev Clin Esp 2011;211 (1):26-35.

103. Olivetti G, Melissari M, Capasso JM, Anversa P. Cardiomyopathy of the aging human Heart. Myocite loss and reactive cellular hypertrophy. Circ Res 1991; 68:1560-68. 
104. Gazoti Debessa CR, Mesiano Maifrino LB, Rodrigues de Souza R. Age related changes of the collagen network of the human heart. Mech Ageing Dev $2001 ; 122: 1049-58$.

105. Di Carlo A. Human and economic burden of stroke. Age and Ageing 2009;38 $(1): 4-5$.

106. Sierra C, López-Soto A, Coca A. Connecting cerebral white matter lesions and hypertensive target organ damage. J Aging Res 2011, Epub 2011.

107. Álvarez-Ude F. Sobre el cálculo de filtrado glomerular. Nefrología 2007; 27 (6): 781 .

108. Locatelli F, Pozzoni P: Chronic kidney disease in the elderly: is it really a premise for overwhelming renal failure?. Kidney Int 2006; 69 (12): 2155-66.

109. Garg AX, Muirhead N, Knoll G, Yang RC, Prasad GV, Thiessen-Philbrook H et al. Proteinuria and reduced kidney function in living kidney donors: a systematic review, meta-analysis and meta-regression. Kidney Int 2006; 70 (10): 1801-10.

110. Fehrman-Ekholm I, Norden G, Lennerling A, Rizell M, Mjörnstedt L, Warmner L, Olausson M. Incidence of end-stage-renal -disease among live kidney donors. Transplantation 2006;82 (12): 1646-48.

111. Simal F, Martín Escudero JC, Bellido J, Arzua D, Mena FJ, González Melgosa I et al. Prevalencia de la enfermedad renal crónica leve y moderada en la población general. Estudio Hortega. Nefrología 2004; 24 (4) 329-33.

112. Wetzels JF, Willems HL, den Heijer M. Age and gender-specific reference values of estimated glomerular filtration rate in a Caucasian population: Results of the Nijmegen Biomedical Study. Kidney Int 2008; 73 (5): 657-58.

113. Torregrosa I, Solis M, Pascual B, Ramos B, González M, Ramos C et al. Resultados preliminares de la implantación de un protocolo conjunto de manejo de la enfermedad renal crónica entre Atención Primaria y Nefrología. Nefrología 2007; 27 (2): 162-67. 
114. Plouin PF, Rossignol P, Bobrie G: Hypertension in elderly. Bull Acad Natl Med 2006;190 (4-5): 793-806.

115. Giles TD, Berk BC, Black HR, Cohn JN, Kostis JB, Izzo JL et al: Expanding the definition and classification of hypertension. J Clin Hypertens (Greenwich) $2005 ; 7: 505-12$.

116. Eknoyan G: On epidemic cardiovascular disease in patients with chronic renal disease and progresive renal failure: a first step to improve the outcomes. Am J Kidney Dis 1998; 32: S1-S4.

117. Nash DT: Systolic Hypertension. Geriatrics 2006; 61 (12): 22-28.

118. Cinza Sanjurjo S, Cabarcos Ortiz de Barron A, Nieto Pol E, Lorenzo Zuniga V: Control of hypertension in elderly patients admitted in internal medicine. An Med Interna 2006; 23 (8): 369- 373.

119. Kaplan NM: Tratamiento de la hipertensión: farmacoterapia. En: Kaplan NM. Hipertensión Clínica. Ed Waverly hispánica S.A, 2003: 237-338.

120. Lindholm LH, Carlberg B, Samuelsson O: Should $\beta$ blockers remain first choice in the treatment of primary hypertension? A metaanalysis . Lancet 2005; 366: 1545- 1553.

121. Stokes GS: Treatment of isolated systolic hypertension. Curr Hypertens Rep 2006; 8 (5): 377-383.

122. Rose BD: Diuretics. Kidney Int 1991; 39 (2): 336-352.

123. Lottermoser $\mathrm{K}$, Hertfelder $\mathrm{HJ}$, Vetter $\mathrm{H}$, Düsing $\mathrm{R}$ : Fibrinolytic function in diuretic -induced volume depletion. Am J Hypertens 2000; 13: 359-363.

124. Pequignot R, Belmin J, Chauvelier S, Gaubert JY, Konrat C, Duron E, Hanon O. Renal function in older hospital patients is more accurately estimated using the Cockcroft-Gault than the Modification Diet in Renal Disease formula. J Am Geriatr Soc 2009;57 (9):1638-43. 
